\title{
WestVirginiaUniversity
}

THE RESEARCH REPOSITORY @ WVU

Graduate Theses, Dissertations, and Problem Reports

2010

\section{Boys' and girls' strategies for managing peer conflict in adolescence}

\author{
Emily Keener \\ West Virginia University
}

Follow this and additional works at: https://researchrepository.wvu.edu/etd

\section{Recommended Citation}

Keener, Emily, "Boys' and girls' strategies for managing peer conflict in adolescence" (2010). Graduate Theses, Dissertations, and Problem Reports. 4615.

https://researchrepository.wvu.edu/etd/4615

This Dissertation is protected by copyright and/or related rights. It has been brought to you by the The Research Repository @ WVU with permission from the rights-holder(s). You are free to use this Dissertation in any way that is permitted by the copyright and related rights legislation that applies to your use. For other uses you must obtain permission from the rights-holder(s) directly, unless additional rights are indicated by a Creative Commons license in the record and/ or on the work itself. This Dissertation has been accepted for inclusion in WVU Graduate Theses, Dissertations, and Problem Reports collection by an authorized administrator of The Research Repository @ WVU.

For more information, please contact researchrepository@mail.wvu.edu. 
Boys' and Girls' Strategies for Managing Peer Conflict in Adolescence Emily Keener, M.A.

Dissertation Submitted to the Eberly College of Arts and Sciences at West Virginia University in Partial Fulfillment of the Requirements for the Degree of

Doctor of Philosophy

in Psychology

JoNell Strough, Ph.D., Chair

Katherine Karraker, Ph.D.

Amy Gentzler, Ph.D.

Elisa Krackow, Ph.D.

Ann Oberhauser, Ph.D.

Department of Psychology

Morgantown, WV 


\section{Abstract \\ Boys' and Girls' Strategies for Managing Peer Conflict in Adolescence}

\section{Emily Keener}

The purpose of the present study was to examine boys' and girls' endorsement of communal and agentic conflict-management strategies in three types of relationships: same-sex friends, other-sex friends, and romantic relationships. Relationship type was examined as a moderator of gender differences and similarities in strategies. Also, the role of gender-typed personality traits (expressive, instrumental) was examined as a covariate to investigate whether gender differences in conflict-management strategies reflect personality traits.

Participants ( $N=108 ; 49$ boys; 59 girls) were adolescents aged 14-17 years ( $M$ age $=$ 15.79 years, $S D=1.07)$. Participants were asked to complete the Peer Conflict Questionnaire to rate the degree to which they endorsed communal and agentic strategies for managing conflict. As the current study used a within-subject design, all participants responded to the following three components of the strategy assessment: strategy endorsement with a same-sex friend, strategy endorsement with an other-sex friend, and strategy endorsement with a romantic partner. After completing the strategy assessment, participants completed the gender-typed personality traits assessment. Gender-typed personality traits were assessed via the 24-item Personal Attributes Questionnaire (PAQ; Spence \& Helmreich, 1978; see Appendix A section 3). Participants rated eight instrumental traits (e.g., 1, not at all aggressive vs. 5, very aggressive) and eight expressive or feminine traits (e.g., 1, not at all emotional vs. 5, very emotional) on a 1 to 5-point numerical scale. Participants also reported demographic information.

Results showed that gender, relationship type, and gender-typed personality traits were associated with adolescents' strategies for managing peer conflict. Specifically, compared to boys, girls were more likely to endorse both communal and agentic strategies. Also, both communal and agentic strategies were endorsed less in romantic relationships than in friendships. Further, for agentic strategies, when instrumental traits were covaried, the main effect of relationship type was no longer significant.

Results are discussed in relation to contextual approaches to interpersonal problem solving (see Berg \& Strough, in press) and the gender similarity hypothesis suggesting boys and girls are more similar than they are different (see Hyde, 2005). 
To Dan

I'm gonna love you everyday and every night

I'm gonna love you in sunshine and in rain

I'm gonna love you forever and ever, forever and ever amen. 


\section{Acknowledgements}

I would like to thank my committee, JoNell Strough, Ph.D., Katherine Karraker, Ph.D., Amy

Gentzler, Ph.D., Elisa Krackow, Ph.D., and Ann Oberhauser, Ph.D. for their thoughtful feedback, guidance, and support with this project. I would like to especially thank all of my advisors and teachers for what they have taught me about learning, teaching, research, and life. Your lessons are the knowledge in my head and the words in my mouth that I will be passing on to my own students. Thank you! I would like to thank my parents, sisters, family and friends for all the love and support. In addition to my teachers, family, and friends, I would also like to thank my colleagues and research assistants who made finishing this project possible: Susan Wiese, Tracy Thomas, Jessica Stoltzfus, The Strough Life-span Developmental Lab, Andrea Strope, Emily Craun, Michelle Harris, Brittany Hubbard, Matt Basil, Hong Zhi Zou, Kristie Young, \& Whitney DeBolt. 
Table of Contents

Abstract

Dedication

iii

Acknowledgments

iv

Table of Contents

V

LIST OF TABLES

vi

Introduction

1

Methods

16

Results

26

Discussion

45

References

60

Appendix A: Measures

79 


\section{List of Tables}

Table 1: Demographic Characteristics of Participants

Table 2: Relationship History Characteristics of Participants

Table 3: Procedure: Order of each Assessments

Table 4: Means, Standard Deviations and Range for Expressivity, Instrumentality, Communal

Strategies, and Agentic Strategies

Table 5: Order of strategy item presentation throughout the Peer Conflict Questionnaire

Table 6: Intercorrelations among Variables of Interest for Total Sample

Table 7: Intercorrelations among Variables of Interest

Table 8: Mean Communal and Agentic Strategies for Managing Conflict

Table 9: Mean Agentic Strategies for Managing Conflict after Controlling for Traits

Table 10: Mean Communal and Agentic Strategies for Managing Conflict by Relationship Type 


\section{Boys' and Girls' Strategies for Managing Peer Conflict in Adolescence}

Interpersonal conflict is commonly defined as a mutual opposition that requires action to end the disagreement (Collins \& Laursen, 1992; Jensen-Campbell, Graziano, \& Hair, 1996). People are likely to encounter conflict across the lifespan (Shantz \& Hartup, 1992). During adolescence and young adulthood, failure to successfully manage peer conflict has a negative impact on mental health as well as general emotional functioning (Buhrmester, 1990; Feldman \& Gowen, 1998; Jensen-Campbell et al.; Reese-Weber \& Marchland, 2000). Consequently, for adolescents, learning to manage conflict is a particularly important developmental task (Laursen, 1994; Shantz \& Hartup, 1992; Shantz \& Hobart, 1989). The purpose of the present study was to examine boys' and girls' endorsement of communal/expressive strategies and agentic/instrumental strategies to manage conflicts. More specifically, the current study drew from work in the adolescent conflict- management literature, suggesting that relationship type is a key factor to consider when investigating conflict-management strategies (Creasey, Kershaw, \& Boston, 1999; Jensen-Campbell et al.). Thus, the present study examined relationship type (i.e., same- and other-sex friendships and other-sex romantic relationships) as a moderator of gender differences and similarities in strategies. Also, the role of gender-typed personality traits (i.e., expressive, instrumental) was examined to investigate whether gender differences in conflict-management strategies are better understood as reflecting personality traits that vary within as well as between groups of boys and girls.

It is important to examine conflict-management strategies in same-sex friendships, othersex friendships, and other-sex romantic relationships because these relationships are vital for adolescents' social development. As parental control decreases, friendships become increasingly important (Burhmeister, 1990; Opotow, 1991). As adolescents begin to date, the number of 
other-sex friends increases, working to encourage heterosexual romantic relationships (Connoly, Craig, Goldberg, \& Peppler, 2004; Darling, Dowdy, Van Horn, \& Caldwell, 1999; Kuttler, La Greca, \& Prinstein, 1999). The onset of romantic relationships is one of the most salient social changes from childhood to adolescence (Collins, 2003; Leaper \& Anderson, 1997; Maccoby, 1990). Furthermore, conflicts with romantic partners and friends have been linked to mental health concerns for both adolescents and college students (Creasey et al., 1999; Reese-Weber \& Marchland, 2000). Importantly, research has yet to systematically compare these three relationship types to understand gender differences and similarities in the strategies used for conflict management.

Communion and Agency, Gender-Typed Personality, and Gender

Communion and agency are of long-standing interest to researchers studying gender development. Communion refers to an orientation toward meeting others' needs, whereas agency refers to an orientation toward meeting self needs (see Bakan, 1966). At a conceptual level, communal orientations are concordant with gender-stereotypical "feminine" (Bem, 1974) and "expressive" (Spence \& Helmrich, 1978) personality traits, such as being compassionate or sensitive to the needs of others. Communal orientations are reflected in relationship-maintenance goals and accommodation and compromise strategies (Rose \& Asher, 1999). In the current study, the term "communal strategies" was used to refer to efforts or tactics that involve working with or talking to the person involved in the conflict to reach a solution collaboratively.

Conceptually, agentic orientations are concordant with gender-stereotypical "masculine" (Bem, 1974) and "instrumental” personality traits (Spence \& Helmrich, 1978), such as being competitive and assertive. Agentic orientations are reflected in instrumental and control goals as well as self-interest or assertion strategies (Rose \& Asher, 1999). In the current study, the term 
"agentic strategies" was used to refer to efforts or tactics that involve convincing the other person to do what one wants instead of what the other person wants.

Stereotypical gender roles emphasize that girls and women are relatively more likely than boys and men to approach interpersonal interactions with a communal orientation; whereas, boys and men are relatively more likely than girls and women to approach interpersonal interactions with an agentic orientation (Bem, 1974; Broverman, Broverman, Clarkson, Rosenkrantz, \& Vogel, 1970). Prior research examining communal and agentic conflict-management strategies has focused on how these strategies differ as a function of a person's self-reported sex (boy or girl) rather than on a person's gender-typed personality. Based on the degree to which a person endorses traits stereotypically ascribed to men or women, a person's gender-typed personality is more or less instrumental (masculine) or expressive (feminine), regardless of biological sex. Research shows that, compared to boys, girls are more likely to endorse expressive traits and are less likely to endorse instrumental traits (Eagly, 1987; Feingold, 1994; Leszczynski \& Strough, 2008; Spence, 1993). However, both boys and men and girls and women endorse instrumental and expressive traits (Bem, 1974; Constantinople, 1973; Spence \& Helmreich, 1978; Suh, Moskowitz, Fournier, \& Zuroff, 2004; Twenge, 1997). Thus, it could be that differences in conflict-management strategies attributed to a person's sex may be better understood as personality differences. The current study expanded on prior research by investigating whether gender-typed personality traits account for the variation in strategies that is typically attributed to a person's sex. More importantly, the current study examined variation in communal and agentic conflict-management strategies, not only as a function of person sex (and gender-typed personality traits), but also as a function of the sex of the partner with whom the conflict occurs and the type of relationship (i.e., friendship versus romantic relationship). 


\section{Conceptual Background}

The present study drew from a social-constructionist perspective. From this perspective gender-typed behaviors are thought to develop via the transaction of individual and contextual factors (Deaux \& Major, 1987; Maccoby, 2000). Conflict-management strategies, a gender-typed behavior, were viewed as emerging not only from an individual's gender, but also from the situational demands of the immediate context -- the presence of a same-sex friend, other-sex friend, or other-sex romantic partner. Gender differences in communal and agentic strategies for managing peer conflict may arise from socialization in sex-segregated groups by same-sex peers (Leaper, 1994; Maccoby, 1990; Rose \& Rudolph, 2006). According to Rose and Rudolph (p. 117), "exposure to same-sex peers elicits and strengthens sex-linked relationship processes" such as strategies. Thus, sex segregation may be one causal mechanism for the gender difference in the endorsement of communal and agentic conflict management strategies.

Along with considering individual factors, such as gender, empirical work guided by a developmental social-constructionist perspective demonstrates the importance of considering contextual factors such as the sex of others with whom a person interacts when investigating gender-typed behaviors (Leszczynski \& Strough, 2008; Pickard \& Strough, 2003; Strough, Berg, \& Sansone, 1996). For example, gender differences and similarities in preadolescents' conversation strategies for peer collaboration (Strough \& Berg, 2000), young adults' goals for interaction with peers during a collaborative task (Pickard \& Strough, 2003), and college students' decision making with peers (Leaper, 1998; Lips \& Keener, 2007) vary according to whether peers are same-sex (i.e., boy-boy; girl-girl) vs. other-sex (i.e., boy-girl). These studies underline the importance of considering how the sex of the person with whom boys and girls interact might give rise to gender differences or similarities. The current study drew from a 
social-constructionist perspective to examine whether the strategies boys and girls endorse for managing conflict with peers depends on the sex of the peer (same- or other-sex peers).

\section{Limitations of the Existing Literature}

In addition to considering how the sex of the peer with whom a conflict occurs may influence gender differences in strategies, it also is important to consider the type of relationship. Within the existing literature, a peer's sex is often confounded with relationship type.

Differences and similarities in gender-typed behaviors with same- and other-sex peers might depend on whether peers are strangers, acquaintances, friends, or romantic partners (e.g., Leaper, 1998; Leaper \& Smith, 2004; Maccoby, 2000). When gender differences in strategies have been examined it is usually within a single type of relationship without consideration of sex composition (e.g., Lindeman, Harakka, \& Keltikanga-Jarvinen, 1997; Rose \& Asher, 1999). In the current study, the confound between relationship type and the sex of peers was disentangled by investigating conflict strategies across sex composition and relationship type (i.e., same-sex friends, other-sex friends, and other-sex romantic partners). By doing so, it was possible to evaluate whether strategies differed as a function of sex composition or by relationship type. If the gender difference in strategies is due to sex composition rather than relationship type, results regarding conflict involving an other-sex friend and a romantic partner would be similar (for heterosexual persons) and these two groups would differ compared to conflict involving a samesex friend. In contrast, if the gender difference is due to relationship type rather than sex composition, results for endorsing communal strategies would be the same for conflict involving a same- and other-sex friend.

Research examining gender differences and similarities in conflict-management has been primarily conducted with children. Therefore, our understanding of the role of gender in conflict- 
management for adolescents is limited. In the current study, this limitation was addressed by investigating gender differences and similarities in the strategies endorsed by adolescents to manage peer conflict.

In short, by investigating same- and other-sex contexts in combination with the type of relationship, the present study adds to the understanding of gender differences and similarities in the strategies chosen by adolescents for managing conflicts with peers.

Communal and Agentic Conflict-Management Strategies:

Do Strategies vary by Sex Composition and Type of Relationship?

\section{Overview}

To better understand gender differences and similarities in the use of communal and agentic strategies for managing peer conflict, the literature on gender and strategies is reviewed below with particular attention to the sex composition of the group or dyad, the type of relationship, and the age group, as well as the methods used (i.e., observation, actual problems, and hypothetical situations). First, the research examining boys' and girls' use of communal strategies in conflicts with same- and other-sex peers is reviewed. Second, the findings examining boys' and girls' use of agentic strategies in conflicts with same- and other-sex peers are discussed.

\section{Communal Strategies}

Same-sex peer interactions. Existing research on adolescents suggests that when managing conflict with same-sex peers, girls are more likely to endorse or use communal strategies as compared to boys. For example, Black (2000) observed participants discussing an unresolved conflict with a same-sex best friend; girls were more likely to use communal strategies (e.g., expressing reassurance) than were boys. Studies based on Australian adolescents 
(Owens, Daly, \& Slee, 2005) and Dutch adolescents (de Wied, Branje, \& Meeus, 2007) yielded the same pattern of gender differences: girls used communal strategies (e.g., obliging strategies) for managing peer conflicts more than did boys. Research using hypothetical vignettes rather than actual conflict also indicates that young girls use communal strategies such as discussing the conflict with peers or finding a compromise for managing peer conflict with classmates (Chung \& Asher, 1996; Lindeman et al., 1997; Pakaslahti, Karjalainen, \& Keltikangas-Jarvinen, 2002) and with friends (Rose \& Asher, 1999) more than do boys. Similar results are found when observational methods are used across a variety of specific situations involving friends or classmates (e.g., a cooperative task, Strough \& Berg, 2000; a sharing task involving limited resources, McElwain \&Volling, 2002).

In summary, results from studies investigating conflict between same-sex peers are consistent across methodology, age group, and type of relationship (i.e., classmates and friends). When managing conflict with same-sex peers, girls are more likely to use or endorse communalconflict management strategies than are boys. Thus, in the current study, it was predicted that, when managing conflicts with a same-sex friend, girls would endorse communal strategies more than would boys.

Other-sex peers: friends and classmates. Conflict-management studies directly examining girls' and boys' use or endorsement of communal strategies for managing conflict with an other-sex peer have yet to be published. Thus, the current study drew from research examining peer interactions with other-sex peers. For example, Leszczynski and Strough (2008) examined the endorsement of communal or expressive self-descriptive traits by adolescents during a block building game. Their results showed that boys endorsed expressive or communal self-descriptive traits more when working with an other-sex classmate than when working with a 
same-sex classmate. Girls' endorsement of such traits did not differ as a function of whether they were interacting with a same- or other- sex peer. Taken together, the findings that boys increased the degree to which they used communal strategies when working with an other-sex friend compared to working with a same-sex friend and that girls' use of strategies did not change, suggests that boys and girls would be equally likely to endorse communal strategies when the conflict involves an other-sex friend. Similar to Leszczynski and Strough (2008), Strough and Berg's (2000) research on pre-adolescents who collaborated on a writing task with an other-sex classmate and McElwain and Volling's (2002) research on children who interacted with an other-sex friend during a sharing task involving a limited resource did not find a gender difference in the use of communal strategies.

In the current study, based on the research with adolescents (Leszczynski \& Strough, 2008), it was predicted that there would not be a gender difference in the endorsement of communal strategies when the conflict involved an other-sex peer. However, the research used to support this hypothesis only examined two types of relationships: classmates and friends. Therefore, it was possible that this finding would be moderated by relationship type. In the current study, this issue was addressed by examining three types of relationships: same- and other-sex friends and other-sex romantic partners.

Other-sex peers: romantic partners. Feldman and Gowen (1998) asked adolescents to indicate how often they use various strategies during disagreements with romantic partners. Results showed that girls rated communal strategies (e.g., compromising) for managing conflict with romantic partners higher than did boys. Further, research on adults and marital conflict has shown that, rather than using communal conflict management strategies, men use affect regulation strategies (e.g., avoid thinking about the conflict) when engaged in conflict with 
romantic partners (Gottman, Coan, Carrere \& Swanson, 1998; Heavey, Layne, \& Christensen, 1993; Kurdek, 1995). Thus, the adult research on marital conflict suggests that girls are more likely than boys to endorse communal strategies. Other evidence to support this prediction comes from research suggesting that adolescent boys have fewer communal perceptions or expectations about their romantic relationships than do girls. Specifically, research has shown that, compared to girls, boys perceived their relationships to be less supportive (Connolly \& Johnson, 1996). Also, boys had less respect for their romantic partners (Shulman, Levy-Shiff, Kedem, \& Alon, 1997), were less attentive to their partners, reported less affective intensity, were less likely to report valuing the care and attachment within the relationship, and were more likely to perceive their relationships as a game (Shulman \& Schart, 2000) compared to girls.

In summary, the results from studies investigating adolescents (Feldman \& Gowen, 1998) and adults (e.g., Gottman et al., 1998) conflict within romantic relationships and adolescents' perceptions of romantic relationships (Shulman \& Schart, 2000) are fairly consistent in suggesting that girls are more likely than boys to endorse communal strategies. Thus, in the current study it was predicted that, when managing conflicts with a romantic partner, girls would endorse communal strategies more than would boys.

Sex Composition vs. Relationship Type Differences

Based on the research just reviewed, for both same-sex friendships and other-sex romantic partners, it was predicted that girls would be more likely than boys to endorse communal strategies, but that boys and girls would endorse communal strategies to the same degree when the conflict involved an other-sex friend. Because it was predicted that the pattern of results for conflict involving an other-sex friend would be different than the pattern of results for conflict involving either a same-sex friend or an other-sex romantic partner, it was predicted 
that endorsement of communal strategies would vary by relationship type rather than by sex composition.

\section{Agentic Strategies}

Same-sex peers. Existing research on adolescents suggests that when managing conflict with same-sex peers, girls are less likely to endorse agentic strategies as compared to boys. For example, Lindeman et al. (1997) found that, in response to hypothetical conflicts involving a same-sex friend, adolescent girls were less likely to endorse agentic or aggressive strategies than were boys. Research on children using hypothetical vignettes also indicates that girls use agentic strategies (e.g., self-assertion) for managing peer conflict with classmates (Chung \& Asher, 1996) and with friends (Rose \& Asher, 1999) less than do boys. Similar results have been found in research with children when observational methods are used during a sharing task involving a limited resource (McElwain \& Volling, 2002).

In summary, the results from studies investigating conflict between same-sex peers are consistent across methodology, age group, and type of relationship (i.e., classmates and friends). When managing conflict with a same-sex peer, girls are less likely to use or endorse agentic strategies than are boys. Therefore, it was predicted that, when managing conflict with a samesex friend, girls would endorse agentic strategies less than boys.

Other-sex peers: friends and classmates. Research suggests that girls are less likely to endorse agentic strategies than are boys. Specifically, one study on adolescents (Leszczynski \& Strough, 2008) showed that for both boys and girls, instrumental or agentic self-descriptive traits did not vary as a function of whether participants interacted with a same-or other-sex classmate during a block-building game. If boys and girls do not change their endorsement of agentic traits based on the sex of their peer and evidence suggests that boys are more agentic than girls in 
same-sex contexts, then Leszczynski and Strough's (2008) finding suggests that boys would be more likely to endorse agentic strategies than would girls when the conflict involves an other-sex friend. Results consistent with Leszczynski and Strough (2008) have been found with research on children when observational methods were used during a sharing task involving a limited resource (McElwain \& Volling, 2002).

In summary, in line with the research on adolescents (Leszczynski \& Strough, 2008), it was predicted that, when managing conflict with an other-sex peer, girls would be less likely to endorse agentic strategies than would boys. The research used to support this hypothesis examined classmates and friends. Therefore, it was possible that this finding would be moderated by relationship type. The present study extended the existing research by also examining othersex romantic relationships.

Other-sex peers: Romantic partners. Research suggests that girls are more likely than are boys to endorse or use agentic strategies when managing a conflict with a romantic partner. Specifically, Feldman and Gowen's (1998) research showed that girls rated agentic strategies (e.g., yelling) higher than did boys when managing conflict with a romantic partner. Further, research on marital conflict has shown that, rather than using agentic conflict management strategies, men use affect regulation strategies when engaged in conflict with romantic partners (Gottman et al., 1998; Heavey et al., 1993; Kurdek, 1995) suggesting that girls are more likely than boys to endorse agentic strategies.

In summary, the results from studies investigating adolescent (Feldman \& Gowen, 1998) and adult (e.g., Gottman et al., 1998) conflict within romantic relationships are consistent in suggesting that girls are more likely than boys to endorse communal strategies. Thus, in the 
current study it was predicted that, when managing conflicts with a romantic partner, girls would endorse communal strategies more than would boys.

\section{Sex Composition vs. Relationship Type Differences}

Based on the research just reviewed, for both same-sex friendships and other-sex friends, it was predicted that girls would be less likely than boys to endorse agentic strategies, but girls would endorse communal strategies more than would boys when the conflict involved an othersex romantic partner. Because it was predicted that the pattern of results for conflict involving an other-sex romantic partner would be different than the pattern of results for conflict involving an other-sex romantic partner, it was predicted that endorsement of agentic strategies would vary by relationship type rather than by sex composition.

Gender-Typed Personality: Expressive and Instrumental Traits

Conceptually, instrumentality and expressivity are concordant with communal and agentic strategies, respectively. Both boys and girls endorse both types of traits (expressive and instrumental; e.g., Bem, 1974) and researchers have shown an association between gender-typed traits and some types of strategies (Renk \& Creasy, 2003; Suh et al., 2004; Washburn-Ormachea, Hillman, \& Sawilowsky, 2004). For example, adolescent boys' and girls' greater endorsement of expressive traits was related to greater endorsement of emotion-focused coping strategies (Renk \& Creasy; Washburn-Ormachea et al.). Also, Suh et al. found that women's greater endorsement of expressive traits was related to greater use of communal behaviors in situations with friends (same- and other-sex), but not with romantic partners. Men's greater endorsement of expressive traits was associated with greater use of communal behaviors with romantic partners, but not with friends. Consequently, the gender difference between boys' and girls' endorsement of conflict- management strategies may be better explained as a personality difference. Both boys 
and girls who endorse expressive traits might also endorse communal conflict-management strategies and both boys and girls who endorse instrumental traits might also endorse agentic conflict-management strategies. Therefore, it was predicted that when gender-typed personality traits were accounted for, there would not be a significant difference between boys' and girls' endorsement of strategies. To investigate this prediction, when gender differences in strategies were found, traits were examined as a covariate and were explored as a mediator of the association between gender and strategies.

As traits are thought to be stable characteristics (McCrae \& Costa, 2003), traits might relate to strategies similarly across relationship type. In contrast, the association between traits and strategies might vary as function of relationship type. Specifically, research has shown that contextual factors can override personal inclinations. For example, studies on leadership and traits have shown that women who endorsed dominant/instrumental traits often avoid agenticleadership roles in the presence of men who did not endorse dominant traits (Megargee 1969; Nyquist \& Spence 1986; Lips \& Keener 2007). Further, Suh et al. (2004) found the association between traits and communal and agentic responses to interpersonal situations varied by gender and relationship contexts. Based on this research, traits were also explored as a moderator of the association between gender and strategies.

\section{Statement of the Problem}

When adolescent girls' and boys' same-sex peer interactions are compared, gender differences and similarities in strategies for managing conflict often are apparent. To better understand gender differences and similarities in the endorsement of strategies for managing peer conflict, research is needed that examines conflict with same- and other-sex peers while taking the type of relationship into consideration. Thus, the current study compared the strategies boys 
and girls endorse for managing conflict across three relationship types: same-sex friends, othersex friends, and other-sex romantic partners. The purpose of the present study was to investigate conflicts with same- and other-sex peers in combination with the various relationship types to better understand the gender differences and similarities in the strategies chosen for managing conflicts with peers. The role of gender-typed personality traits was examined to determine whether gender differences in strategy endorsement were accounted for by boys' and girls' identification with gender-typed personality traits.

\section{Research Questions}

The proposed study investigated the role of gender in the conflict-management process by examining the moderating factor of relationship type on the strategies used to manage peer conflict.

The specific research questions were:

RQ 1: Do differences between boys' and girls' endorsement of communal and agentic strategies depend on relationship type (i.e., same-sex friend, other-sex friend, other-sex romantic partner)?

H 1) Communal strategies. A significant interaction between gender and type of relationship was expected. Specifically, based on research with adolescents examining gender and conflict management strategies (e.g., Owens et al., 2005), it was predicted that gender differences would be apparent when the conflict involved a same-sex friend with girls rating communal strategies significantly higher than boys. However, when the conflict involved an other-sex friend, based on research with adolescents examining selfdescriptive traits (e.g., Leszczynski \& Strough, 2008), it was predicted that there would not be a significant difference between girls and boys on the ratings of communal strategies. In terms of gender differences in communal strategies with romantic partners, 
based on research with adolescents examining conflict management strategies with romantic partners (Feldman \& Gowen, 1998), it was predicted that girls would rate communal strategies higher than would boys.

H 2) Agentic strategies. A significant interaction between gender and type of relationship was expected. Specifically, based on research with adolescents examining conflict management strategies (e.g., de Wied et al., 2007), it was predicted that gender differences would be apparent when the conflict involved a same-sex friend with girls rating agentic strategies significantly lower than would boys. Similarly, when the conflict involved an other-sex friend, based on research with adolescents examining selfdescriptive traits (e.g., Leszczynski \& Strough, 2008), it was predicted that girls would rate agentic strategies lower than would boys. In terms of gender differences in agentic strategies when managing conflict with romantic partners, it was predicted that girls would rate agentic strategies higher than boys (e.g., Feldman \& Gowen, 1998).

RQ 2: Do gender-typed personality traits better explain variation in the endorsement of strategies used for managing peer conflict than does gender?

H 2) Communal strategies. Because research suggests that both boys and girls endorse expressive traits (e.g., Bem, 1974) and because gender differences may be better explained by personality traits (Renk \& Creasy, 2003; Suh et al., 2004; WashburnOrmachea et al., 2004), when the gender-typed personality trait expressivity was accounted for, it was predicted that there would not be a significant difference between boys' and girls' endorsement of communal strategies. 
H 2) Agentic strategies. Because research suggests that both boys and girls endorse instrumental traits (e.g., Bem, 1974) and because gender differences may be better explained by personality traits (Renk \& Creasy, 2003; Suh et al., 2004; WashburnOrmachea et al., 2004), when the gender-typed personality trait instrumentality is accounted for, it was predicted that there would not be a significant difference between boy' and girls' endorsement of agentic strategies.

\section{Method}

\section{Sample Size Considerations}

Communal strategies: Mixed-model ANOVA. G-Power was used to determine the sample size needed to detect the gender by relationship interaction with communal strategies as the dependent variable. The following information was entered into G-Power: effect size $(f=.1$; a small effect size based on pilot data), number of groups (gender; 2), number of repeated factors (type of relationship; 3), correlation between repeated factors (.71; based on pilot data), and power (.80). The suggested sample size was 96 .

Agentic strategies: Mixed-model ANOVA. G-Power was used to determine the sample size needed to detect the gender by relationship interaction with agentic strategies as the dependent variable. The following information was entered into G-Power: effect size $(f=.25$; a small effect size based on pilot data), number of groups (gender; 2), number of repeated factors (types of relationships; 3 ), correlation between repeated factors (.48; based on pilot data), and power (.80). The suggested sample size was 30 .

Communal strategies: Mixed-model ANCOVA. Sample Power was used to determine the sample size needed to detect the gender by relationship interaction with communal strategies as the dependent variable and expressive personality traits as the covariate. The following 
information was entered into Sample Power: effect size (based on pilot data) for the main effect of gender $(f=.16)$, the main effect of relationship $(f=.21$; a small effect size $)$, and the interaction $(f=.07)$, power $(.80)$ with the covariate (expressive personality traits) having a small effect. The suggested sample size was 1,890 .

Agentic strategies: Mixed-model ANCOVA. Sample Power was used to determine the sample size needed to detect the gender by relationship interaction with agentic strategies as the dependent variable and instrumental personality traits as the covariate. The following information was entered into Sample Power: effect size (based on pilot data) for the main effect of gender $(f=.09)$, the main effect of relationship $(f=.36)$, and the interaction $(f=.25$; a small effect size), power (.80) with the covariate (instrumental personality traits) having a small effect. The suggested sample size was 150 .

Conclusions: sample size. Based on the analyses described above, it was determined the sample size for the proposed study would be approximately 100. Although the power analyses for the analyses using ANCOVA suggested a larger sample size, it should be noted that those analyses were conducted with the assumption that the proposed study is using a between-subjects design because neither G-power nor Sample Power have an option for repeated measures ANCOVA. Because the proposed study uses a within-subjects design, those analyses provide an overestimation of the sample size needed (see Tabachnick \& Fidell, 2007). Therefore, the goal was to recruit at least 100 adolescents to participate in the current study.

\section{Participant Recruitment}

Participants were recruited in a variety of ways. First, psychology students, university employees, and community members were contacted via e-mail and asked to provide contact information for adolescents who were eligible for the study. Second, adolescent organizations 
(e.g., The Mountaineer Boys and Girls' Club, Upward Bound, high school bands) referred teens to participate in the study. One organization (a high school marching band) asked their members to participate in the online study as a fundraiser. Third, personal referrals, flyers, and social networking sites were used to make contact with adolescents and their parents. Fourth, teens were recruited from community events (e.g., health fairs) at local malls. All participants were told that the first 60 males and females to complete the study would earn $\$ 10$. When the participants participated in the study as part of a fundraiser, they were told they would have the option to donate the $\$ 10$ to their organization.

\section{Total Sample: Exclusion Criteria}

First, of the 140 participants from whom we obtained parental consent and assent, five elected not to participate in the study (i.e., they never accessed the questionnaires). Thus, there are no data from these five participants. Second, 11 participants started the study and finished Part 1, but elected not to complete Parts 2 and 3. Third, six participants started the study and finished parts one and two, but elected not to complete part three. These 22 participants who did not complete all parts of the study were excluded from analyses. Fourth, seven participants were excluded from the study because they failed a manipulation check. These participants' answers to the true/false or yes/no questions pertaining to the instructions indicated that they did not understand the instructions or were not paying attention to the instructions when answering questions. Fifth, one participant, who passed all of the manipulation checks, elected not to answer the vast majority of the questions assessing strategies (i.e., only four of the 36 items assessing communal and agentic strategies were answered) and his or her responses to openended questions indicated that he or she did not understand the instructions (i.e., "why am I answering the same thing you just asked me 5 minutes ago?! This doesn't make any sense!!"). 
Thus, this participant was excluded from analyses. Sixth, one participant reported his or her age as 18 and the inclusion requirement for the study was such that participants had to be between the ages of 14 and 17 . Therefore, a total of 32 participants (27 of whom at least started the study) were excluded from analyses. Analyses to determine whether the 27 excluded participants with data differed from the 108 participants that completed the study are presented in the Preliminary Analyses section.

Participants: Final Sample

Participants $(N=108 ; 49$ boys; 59 girls $)$ were adolescents aged 14-17 years $(M$ age $=$ 15.79 years, $S D=1.07)$ in grades $9(20.4 \%), 10(27.8 \%), 11(23.1 \%)$, and $12(22.2 \%) ; 6.5 \%$ did not report their grade. The age range of 14-17 years was chosen based on the literature showing that by age 13 or 14 years most adolescents have had experience with both friendships and romantic relationships (Carver, Joyner, \& Udry, 2003; Connolly, Furman, \& Konarski, 2000; Laursen, 1996; Laursen \& Koplas, 1995). Participants identified their race as Caucasian (84.3\%), Asian American (.9\%), African American (2.8\%), Hispanic (.9\%), other (9.3\%), and 1.9\% did not report their race. The racial distribution of the current study approximates the racial distribution of Washington County in PA, Monongalia, and surrounding counties in WV (Census, 2000). The vast majority of participants were from these counties. (See Tables 1 and 2 for additional demographic information.)

Procedure

Parental consent and adolescent assent. Parental consent and adolescent assent forms were either mailed to the parent and teen, were distributed by teen organization leaders, or were given out to teens at community events. Approximately 330 consent forms were mailed home to potential participants and approximately 380 were otherwise distributed (e.g., given out at 
community events). Of the approximately 710 forms distributed, 140 participants returned signed parental consent and adolescent ascent forms (100\% of adolescents with parental consent assented to participate in the study). Only adolescents with signed and returned parental consent forms and who gave their assent were eligible for participation in the study.

Data collection. The measures were given to participants in one of two formats: via a paper and pencil measure or online via the Experiment Management System developed by Sona Systems, Ltd (65 participants completed the study via Sona and 43 participants completed the study via paper and pencil measures). Tests of method (online vs. paper and pencil) differences are presented in the preliminary analyses section. Unless otherwise specified, the presentation of the measures was the same in both formats.

The measures were administered in three parts. All participants were instructed to complete the three parts and to take a short break after each part if needed. Participants were randomly assigned to complete one of three "orders" of the measures. Participants were randomly assigned to an order by drawing a card labeled either A, B, or C. Based on the card drawn, participants were assigned to complete order A, B, or C (see Table 3 for the presentation of all measures for each order). For the paper and pencil format, participants were given a copy of the measures corresponding to the order to which they were randomly assigned. For the online format, participants received a post card in the mail and an e-mail including an invitation code allowing them access to the survey corresponding to the order to which they were randomly assigned. Tests of order effects are presented in the preliminary analyses section.

All participants were first asked to complete the Peer Conflict Questionnaire to rate the degree to which they endorsed communal and agentic strategies for managing conflict. As the current study used a within-subject design, all participants responded to the following three 
components of the strategy assessment: strategy endorsement with a same-sex friend, strategy endorsement with an other-sex friend, and strategy endorsement with a romantic partner. However, the order of relationship type was counterbalanced. Therefore, participants rated strategies for managing conflict involving a same-sex friend, other-sex friend, or romantic partner first (in Part 1) depending on random assignment to order A, B, or C (see Table 3).

As part of the Peer Conflict Questionnaire, for use in future research, participants rated the degree to which they endorsed affect regulation strategies and reported conflict-management strategies in an open-ended and forced-choice format (see Appendix A, Section 1). After completing the strategy assessment, participants completed the gender-typed personality traits assessment (Appendix A, Section 3), provided demographic information (e.g., sex, age), reported information pertaining to relationship history (e.g., length of relationships, current relationship status) with same-sex friends, other-sex friends, and romantic partners (Appendix A, Section 2), or completed other measures for use in future research (i.e., relationship quality, sex segregation, social desirability, relationship quality, and conflict-management goals; see Appendix A, Section 7). The measures completed by participants for use in future research (i.e., those from Appendix A, sections 2, 3, \&7), were also used as distraction tasks between each of the three strategy assessments, but these assessments were not central to the present study and will not be discussed further.

Part 1. First, participants completed the Peer Conflict Questionnaire to rate the degree to which they endorsed communal and agentic strategies for managing conflict. Second, participants completed a self-report measure of gender-typed personality. Also, participants were asked to report demographic information and information pertaining to their relationship history 
with same-sex friendships, other-sex friendships, and romantic relationships. Third, for use in future research, participants rated the degree to which they endorsed conflict-management goals. Part 2. All participants were first asked to complete the Peer Conflict Questionnaire to rate the degree to which they endorsed communal and agentic strategies for managing conflict. Second, for use in future research, sex-segregation and social desirability were assessed. Third, (for use in future research) participants rated conflict-management goals.

Part 3. First, participants were asked to complete the Peer Conflict Questionnaire to rate the degree to which they endorsed communal and agentic strategies for managing conflict. Second, for use in future research, relationship quality with participants' same-sex best friend, other-sex best friend, and boyfriend/girlfriend was assessed. Third, (for use in future research) participants rated conflict-management goals.

Receiving payment. For the online format, after completing the three-part study online via Sona, participants entered a "payment" link where they were thanked for their time. This link was only accessible to participants after the three-part questionnaire was completed. Participants were instructed to provide the mailing address where they would like their honorarium $(\$ 10.00)$ to be sent. As the contact information was not linked with the data, using this procedure to collect contact information aided in the maintenance of anonymity.

For the paper and pencil format, participants were asked to complete a reimbursement form where they provided their mailing address and signature. This form was kept separate from the data. After completing this form, participants were given $\$ 10$ cash.

When adolescents participated as part of a fundraiser, Sona was used, and rather than entering their own mailing address after following the payment link, they entered the name of the organization where they wanted their $\$ 10$ to be sent. 
Measures

Gender-typed personality traits. Gender-typed personality traits were assessed via the 24item Personal Attributes Questionnaire (PAQ; Spence \& Helmreich, 1978; see Appendix A section 3). Participants rated eight instrumental traits (e.g., 1, not at all aggressive vs. 5, very aggressive) and eight expressive or feminine traits (e.g., 1, not at all emotional vs. 5, very emotional) on a 1 to 5-point numerical scale. Responses for each of the two scales were summed and averaged such that higher scores indicated greater endorsement of the trait. Therefore, there were two scores for each participant: an average instrumental and average expressive score. Participants also rated eight additional items that could be used to assess androgyny; however these items were not used in the present study. In the present study, the PAQ instrumental and expressive scales have coefficient alphas of .63 and .71, respectively. See Table 4 for means and standard deviations.

Construction of the Peer Conflict Questionnaire. The Peer Conflict Questionnaire was developed for the purposes of this study. To develop the hypothetical vignettes Owens's (2001, 2003) research on friendships was consulted. Also, a focus group and two pilot studies with undergraduate participants were used. First, an early version of the vignettes was given to undergraduate students $(N=88)$ and they were asked to rate the degree to which each situation was easy to understand on a 1 (very untrue) to 5 (very true) numerical scale. All of the situations were found to be easy to understand (mean scores ranged from 4.21 to $4.84 ; S D=.64$ to .93 ). Also, participants rated the degree to which each person involved in the hypothetical situation had a convincing case to get his or her own way on a 1 (very untrue) to 5 (very true) numerical scale. Based on the results, several situations were edited and the lowest scoring situation was replaced (mean scores ranged from 3.21 to $4.23 ; S D=1.02$ to 1.32 ). 
Next, a small focus group $(n=3)$ of undergraduates was consulted. The results of the focus group were helpful in terms of creating a new vignette and for increasing the degree to which each person described in the vignettes had a convincing case to get his or her own way.

Finally, undergraduate participants $(N=334)$ completed the Peer Conflict Questionnaire with five vignettes. In this version of the questionnaire, conflict-management strategies were assessed with same-sex friends and romantic partners, but did not include the other-sex friends. This relationship type was added to the measure after the pilot research was completed. Based on reliability analyses of strategies one of the five vignettes was dropped. Also one of the five vignettes was dropped due to the lack of relevance to adolescents (i.e., deciding where to go on spring break). Thus, adolescent participants in the present study responded to three vignettes that were repeated three times; once for each of the three types of relationships under investigation (same-sex friends, other-sex friends, and romantic partners).

To develop the strategy items, existing measures of conflict-management strategies developed for use with younger (Rose \& Asher, 1999) and older (Sorkin \& Rook, 2006) age groups were consulted. Also, data from Strough, McFall, Flinn, and Schuller (2008) examining strategies for everyday problem solving in both younger and older adults were used to further develop the items. Items from these measures were adapted for use in the Peer Conflict Questionnaire. Data from the undergraduate pilot study $(N=334)$ suggested that the strategy items formed reliable measures of communal and agentic conflict-management strategies. Coefficient alphas from the undergraduate pilot study for each of the strategies scores were as follows: communal same-sex friend $=.86$; communal romantic partner $=.88$; agentic same-sex friend $=.64$; agentic romantic partner $=.72$. As the other-sex friend strategy assessment was 
added to the measure after this pilot study was completed, there are no pilot data available from which reliability could be calculated.

Peer Conflict Questionnaire. Adolescents's strategies (i.e., communal and agentic) for managing conflict were assessed via responses to written vignettes that portrayed hypothetical interpersonal conflicts involving either a same-sex friend, an other-sex friend, or a romantic partner (see Appendix A, section 1). Before the presentation of the vignettes, participants were instructed to think about how they would respond to the described situations with their current best friend or romantic partner (if possible). For each of the three types of relationships, three hypothetical conflict vignettes were presented. One vignette described a conflict involving a concert. Both people involved wanted to attend a different concert and only one person could get their own way. Another vignette described a conflict involving a term paper. Each person had a paper due the next day and the peer needed help with their paper due to a problem with their computer. The participant only had time to complete one of the papers, their own paper or their peer's paper. A third vignette described a conflict involving a scheduling conflict for each person's party. The parties could not be combined, thus, only one of the people involved would be able to get their own way. The nature of each of the conflicts was the same for each relationship type and the only difference between the vignettes for each of the three types of relationships was the description or label for the type of relationship (i.e., same-sex best friend, other-sex best friend, and boyfriend/girlfriend).

After reading each vignette, participants rated the following communal strategies on a 1 (strongly disagree) to 4 (strongly agree) numerical scale (see Appendix A, section 1: Strategy Endorsement Ratings): "I would talk with my best friend to decide which concert to attend" and "I would work with my best friend to find a way to decide which concert to attend." Participants 
also rated two agentic strategies on a 1 (strongly disagree) to 4 (strongly agree) numerical scale: "I would stand my ground and explain why I should get to decide which concert we attend" and "I would step aside and let my best friend decide which concert we attend" (reverse scored). The order in which the strategy items were presented was consistent throughout the entire Peer Conflict Questionnaire (see Table 5). A participant's score for each type of strategy was the mean of his or her ratings of that strategy (communal and agentic), respectively across the three hypothetical situations. Items were scored such that higher scores indicated greater endorsement of the strategy. Subsequently, there were six average strategy scores: (1) communal same-sex friend ( $\alpha=.81)$; (2) agentic same-sex friend ( $\alpha=.74)$; (3) communal other-sex friend $(\alpha=.80)$; (4) agentic other-sex friend $(\alpha=.71)$; (5) communal romantic partner $(\alpha=.74)$; (6) agentic romantic partner $(\alpha=.76)$. See Table 4 for means and standard deviations.

Results

\section{Preliminary Analyses}

\section{Exclusion vs. Inclusion}

Criteria for excluding 32 participants based on large amounts of missing data were outlined above in the Total Sample: Exclusion Criteria section. Some data were available for 27 of the excluded participants to examine whether the excluded participants differed from included participants in terms of demographic characteristics or other variables of interest using logistic regression. To do so, a dummy variable for inclusion (1) and exclusion (0) was created and used as the criterion variable in the regressions. Due to the large number of predictors, six separate analyses using different sets of predictors were used. The sets of predictors for each regression are as follows: (1) all six of the strategy variables; (2) expressivity and instrumentality scores; (3) gender and age; (4) demographic characteristics relating to academic performance; (5) 
demographic characteristics relating to parents education and income; and (6) demographic characteristics relating to relationship history. The results of each of the six logistic regressions suggested that the 27 participants who were excluded did not differ from the 108 who were included in terms of demographic characteristics or by any other variables of interest. Missing Data

Prior to conducting the primary analyses, data were screened for missing data. There was a small amount of missing data in the final sample of 108 participants. For these participants, missing data came from participants electing not to answer a question by simply skipping the question (paper/pencil) or by clicking a box that read "check this box if you do not wish to provide an answer for this question" (Sona). For the variables of interest (expressivity, instrumentality, communal strategies, and agentic strategies), there were five items with missing data: other-sex friend communal strategy scale, one item; other-sex friend agentic strategy scale, one item; romantic partner agentic strategy scale, one item. The missing items were not from the same participants. Thus, no one participant elected not to answer more than one item assessing strategies. For instrumental traits, two different participants were missing data on one item.

For all scales, missing data were estimated based on the individual participant's responses to other items on the scale (i.e., the serial mean; George \& Mallery, 2008). Specifically, the arithmetic "MEAN" function in SPSS [MEAN (var1, var2, var3, ...)] was used. Because no single participant was missing data on more than one item for a given scale, there was no need to specify a minimum number of items required to calculate the mean.

\section{Assumption of Mixed-Model ANOVA}

Outliers. Prior to primary data analysis, data were explored for outliers. Using the method recommended by Branstetter and Furman (2005), outliers were identified as values falling 
outside a box and whisker plot. The following variables contained at least one outlier: (1) othersex friend communal strategy scores (4 outliers); (2) romantic partner communal strategy scores (15 outliers); (3) same-sex friend agentic strategy scores (4 outliers); (3) other-sex friend agentic scores (8 outliers); (4) romantic partner agentic strategy scores (1 outlier); and (5) expressivity scores (3 outliers).

As outlined below in the section on normality, several variables violated the assumption of normality. Normality is an assumption of the ANOVA and ANCOVA tests used to examine the two research questions in the primary results sections. For all but two variables (i.e., romantic partner communal strategy scores and expressivity scores), using the square-root transformation corrected for non-normality and an outlier correction was not needed. To correct for violations of normality for romantic partner communal strategy scores and expressivity scores, several attempts were made to deal with the outliers. Specifically, recoding the outliers to fall on the whisker (to a value equal to the 75 th percentile plus 1.5 times the interquartile range), using the $\log$ transformations with original data and with the outliers recoded to whiskers, and using the square-root transformation with original data and with the outliers recoded to whiskers were attempted. These attempts failed to correct normality. As recommended by Branstetter and Furman (2005), outliers were recoded by adding (for extreme low scores) or subtracting (for extreme high scores) 2.36 times the standard deviation from the mean. For romantic partner communal strategies, the outliers were extreme high scores and for expressivity the outliers were extreme low scores. After using this correction, the data were no longer skewed. Five outliers for romantic partner communal strategies scores and 3 for expressivity scores were recoded. 
All analyses were conducted using communal strategies or expressivity with both the trimmed data and original data. Results did not differ based on which variables were used. Thus, all analyses are reported using the original data (i.e., the non transformed, untrimmed data).

Normality. Using the original data for all variables, which included outliers, the distribution of the scale scores was examined for normality by converting skewness $\left(Z_{\text {Skewneess }}=\right.$ Skewneess/S.E. $)$ and kurtosis $\left(Z_{\text {Kurtosis }}=\right.$ Kurtosis $/ S . E$. $)$ values into Z-scores. $Z$ values greater than 2.58 were considered a significant violation of normality (Field, 2009). The same-sex communal strategy scores and the other-sex friend communal strategy scores were negatively skewed. Expressivity was negatively skewed and platykurtic. The romantic partner communal strategy scores were leptokurtic. To correct for these violations of normality, the square root transformation was used. In all but two cases, violations of normality were corrected using this transformation. For romantic partner communal strategy scores and expressivity scores, the square root transformation did not correct for violations of normality. As detailed in the section on outliers, for romantic partner communal strategy scores and expressivity scores, it was necessary to recode outliers. After recoding the outliers, the assumption of normality was met.

All analyses using communal strategies or expressivity were conducted with both the transformed and untransformed data. The results did not differ based on which variables were used. Thus, all analyses are reported using the untransformed data.

Independence and interval data. There was no reason to expect non-independence in the present study (i.e., behaviors between participants were independent). Also, the dependent variables in the present study were measured on an interval scale. Thus, there was no reason to explore these assumptions further. 
Homogeneity of variance. The assumption of homogeneity of variance was tested prior to analyses by using the explore function in SPSS. Results showed that for all communal and agentic strategy variables and instrumentality scores, this assumption was met. However, for expressivity scores, this assumption was not met $(p=.03)$. For all variables, when the transformed data (square root transformation described in the section on normality) was used to test the assumption of homogeneity of variance, this assumption was met.

All analyses using expressivity were conducted with both the transformed and untransformed data. Because the results did not differ based on which variable was used, all analyses were reported using the untransformed data.

Sphericity. Sphericity is an assumption of repeated-measures ANOVA. To test this assumption (i.e., to test whether variances across the within-subjects conditions were equal) Mauchly's test was examined. Mauchly's test was included when the repeated-measures ANOVA was conducted. The assumption of sphericity was violated in all mixed models. As recommended by Field (2009), the Greenhouse-Geisser correction was used to correct for violating this assumption. This correction is provided in the output for all mixed models and is reported in the primary results section. Assumption of Mixed-model ANCOVA

The assumptions of the mixed-model ANCOVA are the same as for mixed model ANOVA with two additional assumptions described below. Mixed-model ANCOVA was used to test the hypotheses for RQ 2 (i.e., do gender-typed personality traits better explain variation in the endorsement of communal strategies used for managing peer conflict than does gender?).

Homogeneity of regression slopes. Homogeneity of regression slopes is an assumption of analyses of covariance. When a covariate is included in analysis of variance, the means are 
adjusted for the inclusion of the covariate (see Tabachnick \& Fidell, 2007). Because adjustment of scores is made using the within-cell regression coefficient with the assumption that all cells are equal, it is important that there is not a between-cell difference in the regression slopes. Heterogeneity of regression, or when there is a between cell difference, implies that the adjustment needed for various cells (i.e., the cells for boys vs. girls) is different. Thus, if this assumption is violated, then the adjustment made as a result of including a covariate is not valid. According to Field (2009), to test this assumption an interaction term between the between-subjects factor and the covariate should be specified in the model (using the custom model option in SPSS for mixed models). For the mixed models with communal strategies as the dependent variable, the interaction between gender and expressivity was significant, $F$ (2, $104)=12.91, p<.0001, \eta_{p}^{2}=.20$. For the mixed model with agentic strategies as the dependent variable, the interaction between gender and instrumentality was not significant, $F(2,104)=$ 1.09, n.s., $\eta_{p}^{2}=.02$.

The violation of homogeneity of regression slopes when the strategies are communal and the covariate is expressivity suggests that conclusions based on these analyses should be tentative at best (Tabachick \& Fidell, 2007).

Independence of covariate and treatment effect. Testing whether a covariate and treatment effects (i.e., the groups or independent variables) are independent, which is analogous to assessing multicollinearity in regression, can be done by via ANOVA with the covariate as the dependent variable (Field, 2009).

For expressivity (covariate), results showed that girls $(M=4.05, S D .43)$ endorsed expressive traits significantly more than did boys $(M=3.73, S D .61), F(1,106)=9.69, p<.01$, $\eta_{p}^{2}=.08$. According to this analysis, the covariate (i.e., expressivity) was not independent of the 
treatment effect (i.e., gender). However, the effect size was small and the bivariate correlation was small, $r=-29, p<.01$. Multicollinearity would only be of concern if the bivariate correlation exceeded .80, which was not the case in the present study (Field, 2009).

To determine whether the covariate was independent from relationship type (i.e., a treatment effect), correlations between expressivity (the covariate) and communal strategy scores within each type of relationship were examined. As can be seen in Table 6 expressivity was correlated with communal strategies in the same-sex friend condition $(r=.37, p<.001)$ and in the other-sex condition $(r=.44, p<.001)$. However, these correlations were small (less than .80 , which Field, 2009, suggests as cut off for multicollinearity). Thus, the covariate (i.e., expressivity) was independent of the treatment group (i.e., relationship type).

In sum, because the effect size and correlation between gender and expressivity and relationship and expressivity were small, the violation of independence was not large enough to be of concern in the present study.

For instrumentality (covariate), results showed that girls $(M=3.62, S D .53)$ and boys $(M=3.68, S D .63)$ equally endorsed instrumental traits, $F(1,106)=.28$, n.s., $\eta_{\mathrm{p}}^{2}=.003$. Thus, the covariate (i.e., instrumentality) was independent of the treatment group (i.e., gender).

To determine whether the covariate was independent from relationship type (i.e., a treatment effect), correlations between instrumentality (the covariate) and agentic strategy scores within each type of relationship were examined. As can be seen in Table 7, instrumentality was significantly correlated with other-sex friend agentic strategy scores $(r=.22, p<.001)$. However, the correlation was small (less than .80, which Field, 2009, suggests as cut off for multicollinearity). In sum, the covariate (i.e., instrumentality) was independent of the treatment group (i.e., relationship type). 


\section{Method: Online vs. Paper and Pencil}

Communal strategies. A mixed-model ANOVA was conducted to examine whether method (format of the questionnaire) was associated with communal strategies (65 participants completed the measures via Sona and 43 participants completed the measures via paper and pencil measures) or gender. The within-subjects factor was relationship type (same-sex friendship, other-sex friendship, romantic relationship) and the between-subjects factors were gender (male, female) and method (paper and pencil, Sona). Results showed that the interaction between gender and method was significant, $F(1,104)=9.91, p<.05, \eta_{p}^{2}=.09$. Examinations of the simple effects using the Sidak post-hoc test, showed that for girls there was not a significant difference between the online method $(M=2.91 ; S E=.08)$ and the paper and pencil method $(M=3.07 ; S E=.08), F(1,104)=2.58$, n.s., $.01, \eta_{\mathrm{p}}^{2}=.02$. Boys rated communal strategies significantly higher when using the online method $(M=3.07 ; S E=.08)$ than when using the paper and pencil method $(M=2.71, S E=.10), F(1,104)=7.80, p<.05, .01, \eta_{\mathrm{p}}^{2}=.07$.

Because the interaction between method and gender was significant, using method as a covariate for all analyses with communal strategies and gender was justified. Whether to include method as a covariate in the primary analyses examining communal strategies was explored by testing Research Question (RQ) 1, Hypothesis (H) 1 and RQ 2, H 2 of the present study with and without method as a covariate (analyses for RQ 1, H 1 and RQ2, H 2 involved communal strategies and gender). However, as outlined below, the results of the primary analyses were the same with and without the covariate. Thus, for ease of interpretation, method was not included as a covariate in the analyses presented in the primary results section.

For RQ 1 (i.e., do differences between boys' and girls' endorsement of communal strategies depend on relationship type), method was included as a covariate, gender was the 
between-subjects factor and relationship type was the within-subjects factor. Results showed that method was not a significant covariate, $F(1,104)=.99$, n.s., $\eta_{p}^{2}=.01$. Analyses including method as a covariate yielded the same results as the analyses not including this covariate. Thus, in the primary analysis sections, results are presented based on analyses without the covariate.

For RQ 2 (i.e., do gender-typed personality traits better explain variation in the endorsement of communal strategies used for managing peer conflict than does gender?), a mixed-model ANCOVA was used with relationship type as the within-subjects factor, gender as the between-subjects factor, and expressive traits and method as the covariates to determine whether results would be different depending on whether method was included as a covariate. Results showed that method was not a significant covariate, $F(1,104)=.00$, n.s., $\eta_{\mathrm{p}}^{2}=.00$. Analyses including method as a covariate yielded the same results as the analyses not including this covariate. Thus, in the primary analysis sections, results are presented based on analyses without the covariate.

Agentic strategies. First, a mixed-model ANOVA was conducted to test whether method was associated with agentic strategies or gender. The within-subjects factor was relationship type and the between-subjects factors were gender and method. Results showed that the main effect of method was significant, $F(1,104)=6.39, p<.05, \eta_{\mathrm{p}}^{2}=.06$. Participants who completed the measures online $(M=2.50 ; S E=.06)$ rated agentic strategies significantly higher than did participants who completed the measures via the paper and pencil method $(M=2.25 ; S E=.08)$. The interaction between gender and method was not significant.

Because the main effect of method on agentic strategies was significant, using method as a covariate for all analyses with agentic strategies was justified. Whether to include method as a covariate in the primary analyses examining agentic strategies was explored by testing RQ 1, H 2 
and RQ 2, H 2 of the present study with and without method as a covariate (analyses for RQ1 and RQ2 involved agentic strategies). However, as outlined below, the results of the primary analyses were the same with and without the covariate. Thus, for ease of interpretation, method was not included as a covariate in the analyses presented in the primary results.

For RQ 1 (do differences between boys' and girls' endorsement of agentic strategies depend on relationship type?), a mixed-model ANCOVA was conducted with relationship type as the within-subjects factor, gender as the between-subjects factor, and method as the covariate. Results showed that method was a significant covariate, $\mathrm{F}(1,105)=6.45, p<.05, \eta_{\mathrm{p}}^{2}=.06$. Analyses including method as a covariate yielded the same results as the analyses not including this covariate. Thus, in the primary analysis sections, results are presented based on analyses without the covariate.

For RQ 2 (do gender-typed personality traits better explain variation in the endorsement of strategies used for managing peer conflict than does gender?), a mixed-model ANCOVA was used with relationship type as the within-subjects factor, gender as the between-subjects factor, and instrumental traits and method as the covariates. Results showed that method was a significant covariate, $\mathrm{F}(1,105)=5.53, p<.05, \eta_{\mathrm{p}}^{2}=.05$. Analyses including method as a covariate yielded the same results as the analyses not including this covariate. Thus, in the primary analysis sections, results are presented based on analyses without the covariate. Order

Because the order in which participants completed the strategy assessment for each relationship type was counterbalanced, participants were randomly assigned to complete the measures in one of three orders (see Table 3). To assess for order effects, mixed-model ANOVAs were conducted. Two separate mixed-model ANOVAs were conducted: one with 
communal strategies as the dependent variable and one with agentic strategies as the dependent variable. In both analyses, the within-subjects factor was relationship type (same-sex friendship, other-sex friendship, and romantic relationship) and the between-subjects factors were gender (male, female) and order (A, B, or C). The main effect of order was not significant nor were the interactions. Thus, results suggested that order was not associated with strategies or gender and order effects will not be discussed further.

Age

Communal strategies. A mixed-model ANOVA was conducted to test whether the age of participants was associated with communal strategies. The within-subjects factor was relationship type and the categorical between-subjects factor was gender. Age was a continuous between-subjects variable. A model was specified that included the main effects of relationship type, gender, and age, and the two-way interactions. Results showed that the main effect of age was not significant. Also, the interactions between age and relationship type and age and gender were not significant. Thus, for communal strategies, age effects will not be discussed further.

Agentic strategies. A Mixed-model ANOVA was conducted to test whether the age of the participants was associated with agentic strategies. The within-subjects factor was relationship type and the categorical between-subjects factor was gender. Age was a continuous betweensubjects variable. A model was specified that included the main effects of relationship type, gender, and age, and the two-way interactions. Results showed that the main effect of age was not significant and was not associated with gender. However, the interaction between relationship type and age was significant, $F(11,187)=3.92, p=.02, \eta_{p}^{2}=.04$. Examination of parameter estimates suggested that for same-sex friend agentic strategy scores, younger 
participants were more likely to endorse agentic strategies than were older participants, $t(106)=$ $-2.97, p<.01, \eta_{p}^{2}=.08(\beta=-15, S E ß=.05)$.

Because the interaction between age and relationship type was significant, using age as a covariate for all analyses with agentic strategies and relationship type was justified. Whether to include age as a covariate in the primary analyses examining agentic strategies was explored by testing RQ 1, H 2 and RQ 2, H 2 of the present study with and without age as a covariate (analyses for RQ1 and RQ2 involved agentic strategies and relationship). However, as outlined below, the results of the primary analyses were the same with and without the covariate. Thus, for ease of interpretation, age was not included as a covariate in the analyses presented in the primary results.

For RQ 1 (do differences between boys' and girls' endorsement of agentic strategies depend on relationship type?), the interaction between relationship type and age was significant, $\mathrm{F}(11,187)=3.92, p<.05, \eta_{\mathrm{p}}^{2}=.03$. Examination of parameter estimates suggested that for same-sex friend agentic strategy scores, younger participants were more likely to endorse agentic strategies than were older participants, $t(106)=-2.97, p<.01, \eta_{p}^{2}=.08(\beta=-.15, S E \beta=.05)$. However, the analyses including age as a covariate yielded the same results as the analyses not including this covariate. Thus, in the primary analysis sections, results are presented based on analyses without the covariate.

For RQ 2 (do gender-typed personality traits better explain variation in the endorsement of strategies used for managing peer conflict than does gender?), the interaction between relationship type and age was significant, $F(2,184)=3.92, p<.05, \eta_{p}^{2}=.04$. Examination of parameter estimates suggested that for same-sex friend agentic strategy scores, younger participants were more likely to endorse agentic strategies than were older participants, $t(106)=$ 
$-2.97, p<.01, \eta_{\mathrm{p}}^{2}=.08(\beta=-.15, S E \beta=.05)$. However, the analyses including age as a covariate yielded the same results as the analyses not including this covariate. Thus, in the primary analysis sections, results are presented based on analyses without the covariate. Inter-Correlations among Measures.

Before data were analyzed, bivariate correlations were calculated in order to examine the inter-relationships among the study variables (see Tables 6 and 7). Associations varied by strategy type, relationship type, and gender.

Traits. Specifically, for boys expressive traits were related to communal strategies, but not agentic strategies, for managing conflicts with same- and other-sex friends, but not with romantic partners. For girls, expressivity was not related to either communal or agentic strategies. In contrast, instrumental traits were related to agentic strategies for managing conflict with friends (same and other sex) and romantic partner for girls, but not for boys. This pattern of results suggests that traits may be more predictive of strategies when the trait is inconsistent with gender roles (i.e., expressivity for boys and instrumentality for girls).

Relationship Type. For both boys and girls, the pattern of associations for communal strategies showed that strategies for managing conflict with same-sex friends were associated with strategies for managing conflict with other-sex friends. For communal strategies, romantic partner strategies were not related to strategies for managing conflicts with same-sex friends, but were related to strategies for managing conflict with other-sex friends. However, the association between communal strategies for managing conflict with same and other-sex friends (.72) was significantly stronger than the association between strategies for managing conflict with othersex friends and other-sex romantic partners $(.25), p<.001$. For agentic strategies, strategies for managing conflict with same- and other-sex friends were associated. Romantic strategies were 
also related to same- $(.57)$ and other-sex (.56) friend strategies. However, the association between same- and other-sex friends (.74) was significantly stronger than the association between romantic strategies and same-sex friend strategies, $p<.05$ and other-sex friend strategies, $p<.05$. This pattern of results suggests that relationship type was more predictive of strategy use than was the sex (same vs. other) of the peer, especially for communal strategies.

\section{Primary Analyses}

RQ 1: Do differences between boys' and girls' endorsement of communal and agentic strategies depend on relationship type (i.e., same-sex friend, other-sex friend, other-sex romantic partner)?

Communal strategies. A mixed-model ANOVA was used to test the hypothesis that there would be an interaction between gender and relationship type for the endorsement of communal strategies. Specifically, when the conflict involved a same-friend and romantic relationship, it was hypothesized that girls would endorse communal strategies more than boys. When the conflict involved an other-sex friend, it was hypothesized that girls and boys would equally endorse communal strategies. To test moderation, the within-subjects factor was relationship type (same-sex friend, other-sex friend, and romantic relationship) and the between-subjects factor was gender (boys, girls). The main effect of relationship was significant, $F(2,176)=$ 76.29, $\mathrm{p}<.001, \eta_{\mathrm{p}}^{2}=.42$. Based on Sidak post-hoc tests, the endorsement of communal strategies was significantly lower in romantic relationships $(M=2.50, S E=.04)$ than in samesex friendships, $(M=3.18, S E=.07)$ and in other-sex friendships $(M=3.20, S E=.06), F(2$, $105)=54.53, p<.001, \eta_{p}^{2}=.51$. Also, the main effect of gender was not significant, $F(1,106)$ $=.41$, n.s. Girls $(M=2.99, S E=.06)$ and boys $(M=2.93, S E=.07)$ were equally likely to endorse communal strategies. In contrast to the hypothesis, the main effect of relationship type was not modified by gender, $F(2,176)=.32$, n.s. $($ see Table 8$)$. 
Agentic strategies. A mixed-model ANOVA was used to test the hypothesis regarding moderation that there would be an interaction between gender and relationship type for the endorsement of agentic strategies. Specifically, it was predicted that in same- and other-sex friendships, girls would be less likely than boys to endorse agentic strategies. In the romantic partner condition, it was hypothesized that girls would be more likely than boys to endorse agentic strategies. To test moderation, the within-subjects factor was relationship type (same-sex friend, other-sex friend, and romantic relationship) and the between-subjects factor was gender (boys, girls). The main effect of relationship type was significant, $F(2,189)=9.40, p<.001, \eta_{p}^{2}$ $=.08$. Based on Sidak post-hoc tests, endorsement of agentic strategies was lower in romantic relationships $(M=2.28, S E=.06)$ than in same-sex friendships, $(M=2.49, S E=.06)$ and in other-sex friendships $(M=2.45, S E=.06), F(2,150)=7.30, p<.01, \eta_{p}^{2}=.12$. The main effect of gender was also significant, $F(1,106)=10.71, \mathrm{p}<.01, \eta_{\mathrm{p}}^{2}=.09$. Specifically, endorsement of agentic strategies was greater for girls, $(M=2.56, S E=.07)$ than it was for boys $(M=2.24, S E$ $=.07)$. In contrast to the hypothesis, main effects were not modified by an interaction between gender and relationship type, $F(12,189)=.91$, n.s. (see Table 8$)$.

RQ 2: Do gender-typed personality traits better explain variation in the endorsement of strategies used for managing peer conflict than does gender?

Communal strategies. Based on findings from RQ 1, boys and girls endorsed communal strategies to the same degree, thus, the hypothesis that after accounting for expressivity, there would not be a significant difference between girls' and boys' endorsement of communal strategies, was not tested.

Agentic strategies. Although the hypothesis (see RQ 1) that the association between gender and agentic strategies would be modified by agentic strategies was not supported, because 
the main effect of gender on agentic strategies was significant, instrumentality was examined as a covariate. Specifically, the hypothesis that after accounting for instrumentality, there would not be a significant difference between girls' and boys' endorsement of agentic strategies was tested via a mixed-model ANCOVA. The within-subjects factor was relationship type (same-sex friend, other-sex friend, and romantic relationship), the between-subjects factor was gender (boys, girls), and the covariate was instrumentality. Instrumentality was a significant covariate, $F(1,105)=6.12, p<.05, \eta_{p}^{2}=.06$. Higher instrumental scores were associated with higher agentic strategy scores, $t(106)=2.18, p<.05,(\beta=.19 ; S E \beta=.09)$. In contrast to the analysis without instrumentality as a covariate, results showed that, the main effect of relationship type was not significant, $F(2,187)=.17$, n.s. The main effect of gender was the same as in the analysis without instrumental traits included as a covariate: girls $(M=2.57, S E=.07)$ rated agentic strategies significantly higher than did boys $(M=2.24, S E=.07), F(1,105)=12.06, p<$ $.01, \eta_{p}^{2}=.10$. As in the analysis without instrumental traits as a covariate, the interaction between gender and relationship type remained nonsignificant, $F(2,188)=.86$, n.s., $\eta_{\mathrm{p}}^{2}=.001$ (see Table 9). In sum, the hypothesis that when instrumental traits were included as a covariate, gender differences in ratings of agentic strategies would not be significant was not supported.

\section{Exploratory Analyses}

\section{Gender-Typed Traits Moderation}

Expressivity. For exploratory purposes, expressivity was examined as a moderator. Specifically, a mixed-model ANOVA was used to test the three-way interaction between expressivity, gender, and relationship type. The within-subjects factor was relationship type (same-sex friend, other-sex friend, and romantic relationship) and the categorical betweensubjects factor was gender (boys, girls). The continuous between-subjects factor was 
expressivity. A model was specified to test the main effects of relationship type, gender, and the higher-order interactions.

The main effects of relationship type $\left(F(2,181)=4.62, \mathrm{p}<.05, \eta_{\mathrm{p}}^{2}=.04\right)$ and expressivity $\left(F(1,104)=13.78, \mathrm{p}<.001, \eta_{\mathrm{p}}^{2}=.12\right)$ were significant. Also, the main effect of gender was marginally significant $F(1,104)=5.42, p=05, \eta_{p}^{2}=.05$. Main effects were modified by an interaction between gender and relationship type, $F(2,181)=3.67, p<.05, \eta_{p}^{2}=$ .03 , and by an interaction between gender and expressivity, $F(1,104)=5.91, p<.001, \eta_{\mathrm{p}}^{2}=.12$. However the interaction between expressivity and relationship type was not significant, F $(1,57)$ $=.73$, n.s., $\eta_{\mathrm{p}}^{2}=.01$.

The two-way interactions were modified by a three-way interaction between gender, relationship type, and expressivity, $F(2,181)=4.02, p<.05, \eta_{\mathrm{p}}^{2}=.04$. Regression analyses were conducted to follow up this finding and indicated that, for girls, the interaction between relationship type and expressivity was not significant, $F(2,96)=1.91$, n.s., $\eta_{p}^{2}=.03$. For boys, the interaction between relationship type and expressivity was significant, $F(2,96)=20.16, p<$ $.001, \eta_{\mathrm{p}}^{2}=.30$. For boys, when conflict involved a same-sex friend, greater endorsement of expressive traits was significantly associated with greater endorsement of communal strategies $(\beta$ $=.74, S E \beta=.14), t(106)=5.33, p<.001, \eta_{\mathrm{p}}^{2}=.38$. Similarly, for boys, when conflict involved an other-sex friend, greater endorsement of expressive traits was significantly associated with greater endorsement of communal strategies $(\beta=.75, S E ß=.15), t(106)=5.12, p<.001, \eta_{\mathrm{p}}^{2}=$ .36. However, for boys, when conflict involved a romantic partner, greater endorsement of expressive traits was not significantly associated with endorsement of communal strategies $(\beta=$ $.01, S E \beta=.10), t(\mathrm{df})=.06$, n.s., $\eta_{\mathrm{p}}^{2}=.00$. Thus, expressivity moderated the association between gender and relationship type on communal strategies. However, when additional analyses were 
conducted to further understand this result, results suggested that expressivity did not moderate the association between gender and relationship type. More specifically, when this analysis was conducted after excluding participants (three boys) who indicated that they had never had a same-sex best friend, the findings were no longer significant.

Instrumentality. For exploratory purposes, instrumentality was examined as a moderator. Specifically, a mixed-model ANOVA was conducted to test the three-way interaction between instrumentality, gender, and relationship type. The within-subjects factor was relationship type (same-sex friend, other-sex friend, and romantic relationship) and the categorical betweensubjects factor was gender (boys, girls). The continuous between-subjects factor was instrumentality. A model was specified to test the main effects of relationship type, gender, and the higher-order interactions. The main effect of instrumental traits was significant, $F(1,104)=$ $6.37, p<.05, \eta_{\mathrm{p}}^{2}=.06$. Greater endorsement of instrumental traits was associated with greater endorsement of agentic strategies, $(\beta=.19, S E \beta=.09), t(106)=2.18, p<.05$. None of the other main effects or interactions were significant. Thus, instrumental traits did not moderate the associations between relationship type, gender, and agentic strategies.

Gender-Typed Traits: Mediation Analyses

Because, for communal strategies, gender was not related to communal strategies and for agentic strategies, gender was not related to instrumental traits, mediation analysis was not appropriate.

Strategy Type

A mixed-model MANOVA was conducted to explore the association between strategy type, gender, and relationship type. The within-subjects factors were strategy type (communal 
vs. agentic) and relationship type (same-sex friend, other-sex friend, and romantic relationship. The between-subjects factor was gender (boys, girls).

The main effect of strategy type was significant, $F(1,106)=58.94, p<.001, \eta_{\mathrm{p}}^{2}=.36$. Communal strategies $(M=2.96, S E=.05)$ were rated significantly higher than were agentic strategies $(M=2.40, \mathrm{SE}=.05)$. The main effect of relationship type was significant, $F(2,105)=$ $61.04, p<.001, \eta_{\mathrm{p}}^{2}=.54$. Based on Sidak post-hoc tests, romantic strategy scores $(M=2.39, S E$ $=.03)$ were significantly lower than same- $(M=2.83, S E=.04)$ and other-sex friend $(M=2.82$, $S E=.04)$ strategy scores. Same-sex friend strategy scores were not significantly different than other-sex friend strategy scores. There was also a main effect of gender, $F(1,106)=9.86, p<$ $.001, \eta_{\mathrm{p}}^{2}=.09$. Girls $(M=2.78, S E=.04)$ rated all strategies significantly higher than did boys $(M=2.59, \mathrm{SE}=.05)$.

The main effects were modified by a two-way interaction. Specifically, the interaction between relationship type and strategy type was significant, $F(1,105)=16.03, p<.001, \eta_{\mathrm{p}}^{2}=$ .23. To further investigate this interaction, simple effects were examined using the Sidak posthoc test. Results showed that communal strategies were rated significantly lower when the conflict involved a romantic partner $(M=2.50, S E=.04)$ than when the conflict involved a same-sex friend $(M=3.18, S E=.07)$ or other-sex friend $(M=3.20, S E=.06), F(2,105)=$ 54.53, $p<.001, \eta_{\mathrm{p}}^{2}=.51$. Agentic strategies were also rated significantly lower when the conflict involved a romantic partner $(M=2.28, S E=.06)$ than when the conflict involved a same-sex friend $(M=2.49, S E=.06)$, or an other-sex friend $(M=2.45, S E=.06), F(1,106)=$ 7.30, $p<.01, \eta_{\mathrm{p}}^{2}=.12$. In sum, the simple effect of relationship was significant for communal and agentic strategies. The direction of the differences was the same such that communal and agentic strategies were both rated significantly higher when the conflict involved a same- or 
other-sex friend than when the conflict involved a romantic partner. The size of the difference appears to be larger for communal strategies than for agentic strategies. None of the other interactions were significant (see Table 10).

\section{Discussion}

The purpose of the present study was to examine boys' and girls' endorsement of communal and agentic conflict-management strategies in three types of relationships: same-sex friends, other-sex friends, and romantic relationships. Specifically, relationship type was examined as a moderator of gender differences and similarities in strategies. Also, the role of gender-typed personality traits (expressive, instrumental) was examined as a covariate to investigate whether gender differences in conflict-management strategies are better understood as reflecting personality traits. For exploratory purposes, gender-typed traits were also examined as a moderator of the association between gender and strategies. In addition, for exploratory purposes, differences in strategy type (i.e., communal vs. agentic), gender, and relationship type were examined.

Gender, relationship type, strategy type, and gender-typed personality traits were associated with adolescents' strategies for managing peer conflict. Specifically, girls were more likely to endorse both agentic and communal strategies than were boys. The main effects of relationship type showed that both communal and agentic strategies were endorsed less in romantic relationships than in friendships; however, this relationship type difference was greater for communal strategies than for agentic strategies. Further, for agentic strategies, when instrumental traits were included in the model as a covariate, the main effect of relationship type was no longer significant. 


\section{Gender by Relationship Type Interaction}

In the present study, it was predicted that there would be a gender by relationship type interaction for both communal and agentic strategies. Specifically, for communal strategies [RQ1 (H1)], it was predicted that girls would be more likely than boys to endorse communal strategies when the conflict involved a same-sex friend and a romantic partner, but that boys and girls would equally endorse communal strategies when the conflict involved an other-sex friend. For agentic strategies, it was predicted that girls would be less likely than boys to endorse agentic strategies when the conflict involved a same- or other-sex friend, but would be more likely than boys to endorse agentic strategies when the conflict involved a romantic partner [RQ 1 (H2)]. In contrast to the prediction, for both communal and agentic strategies, the gender by relationship type interaction was not significant. It could be that the interaction between gender and relationship type was not significant as predicted due to the relatively small sample used in the present study. Because the effect sizes for gender differences are often small (see Hyde, 2005), a larger sample may be needed to detect gender differences within relationship type. In contrast to the research cited in support of the predictions in the present study, this is the first study examining adolescents to consider both relationship type and sex composition. It may be that gender differences within same-sex and other-sex contexts are exaggerated in the literature as a result of not considering whether the same- and other-sex peers are friends, romantic partners, classmates, acquaintances, or strangers. To better understand this finding, replication is needed using a larger sample. Although power analyses were conducted to determine an appropriate sample size needed detect small effects, the correlation between repeated measures that was entered into the power analysis was overestimated (based on pilot data). As a result of overestimating the correlation between repeated measures, the suggested sample size was lower 
than needed to detect the small effects found in the present study. Without replication, it is unclear whether findings represent a Type II error due to the small sample or are valid in suggesting that gender differences are not modified by relationship type. Although the interaction between gender and relationship type was not significant, some of the main effects were and are discussed below.

\section{Gender Differences and Similarities}

Girls and boys were equally likely to endorse communal strategies, but girls were more likely than boys to endorse agentic strategies. Although these findings are inconsistent with traditional gender roles suggesting that women are more communal and less agentic than are men (e.g., Eagly, 1987), exploratory analyses suggested that girls were more likely to endorse all strategies (communal and agentic strategies) more than were boys. Thus, this finding may reflect a methodological weakness of the present study. Specifically, the strategy items created for the Peer Conflict Questionnaire might be more representative of strategies girls were willing to endorse compared to those boys were willing to endorse. The wording of the agentic items might not have been agentic enough, which could explain why boys were less likely to endorse these strategies compared to girls. In an attempt to avoid social desirability effects, the items were not intended to be extreme (either overly aggressive or overly submissive). Consequently, we may have inadvertently created items that boys were less willing than girls to endorse regardless of the strategy type.

Another possible explanation for the finding that girls rated all strategies higher than boys is consistent with Sheldon's (1992) research with children: girls' goals reflect the self and the other person, suggesting that girls use agentic strategies to get their own way, but also use communal strategies to maintain the relationship. On the other hand, boys are relatively more 
likely than girls to use agentic strategies with peers; strategies focusing more exclusively on the self rather than on the relationship. If the agentic items in the Peer Conflict Questionnaire did not represent the types of strategies boys use to manage conflict (i.e., if the wording was not agentic enough) and if, consistent with Sheldon's research, girls were willing to endorse both types of strategies, then this pattern of strategy endorsement would explain the main effect of gender. Future research with this data set that examines the qualitative, open-ended responses where participants described the strategies they would use to manage conflict might be useful in understanding why girls were more likely to endorse both types of strategies than were boys.

\section{Relationship Type}

A hypothesis for the main effects of relationship type was not specified because studies comparing conflict management strategies across same-sex friendships, other-sex friendships, and romantic relationships with adolescents have yet to be published. Also, specific predictions for the main effect of relationship type were not made because it was hypothesized that if there were a main effect, it would be qualified by the gender by relationship type interaction. Results of the analyses conducted separately for communal and agentic strategies as well as the result of the exploratory analysis including strategy type were consistent. The main effect of relationship type in the three analyses showed that both boys and girls were less likely to endorse both types of strategies when the conflict involved a romantic partner rather than a same- or other-sex friend. This finding is consistent with contextual approaches to interpersonal problem solving emphasizing the importance of the social context (see Berg \& Strough, in press). Also, this finding adds to the research of others suggesting that strategies for managing conflict vary 
according to relationship type (Creasey et al., 1999; Jensen-Campbell et al., 1996 ; Laursen et al., 2001).

In terms of disentangling the confound between relationship type and sex composition, the pattern of strategy endorsement was similar for the two types of friendships, and the two friendships were different from romantic relationships. Further, the pattern of intercorrelations suggests that relationship type was more predictive of strategy use than was the sex (same vs. other) of the peer, especially for communal strategies. Together these results suggest that the effect of relationship type may be due to the relationship to the person rather than the sex of the person.

Perhaps limited experience with romantic partners or the relatively short-term nature typical of early romantic relationships (Carver et al., 2002) explains why strategy endorsement varied by relationship type (i.e., friendships vs. romantic relationships). Friendships and romantic relationships are similar in several ways (Furman, Simon, Shaffer, \& Bouchey, 2002). For example, friendships and romantic relationships are both voluntary and relatively egalitarian relationships. These qualities make friendships and romantic relationships unique compared to other relationships held by adolescents (e.g., with parents or siblings). However, friendships and romantic relationships are also different (Furman et al.). First, adolescent friendships are more likely to be longer in duration compared to romantic relationships (see Carver et al.). In the present study, the length of friendships, especially same-sex friendships, was longer than the length of romantic relationships (see Table 2). Regardless of the length of a particular relationship, by adolescence, most have spent the vast majority of their lives interacting with friends. In contrast, the introduction of romantic relationships only just begins at adolescence

\footnotetext{
${ }^{1}$ Jensen-Campbell et al. (1996) compared adolescent conflict management with friends, parents, and siblings and found a relationship difference, but did not compare friendships to romantic relationships.
} 
(Carver et al.). With this introduction to romantic relationships, also comes the beginning of mature sexuality. Typically, first sexual experiences occur in adolescence (Carver et al.; Furman et al.). Given these differences, it is not surprising that adolescents manage conflict differently with romantic partners than friends. However, given that experience with other-sex friends is also limited in comparison to experience with same-sex friends (see Carver et al.; Mehta \& Strough, 2009), it is interesting that there was not a difference in how conflict was managed within these two types of friendships. Research on other-sex friendships is fairly scarce, which makes interpreting this finding difficult. Perhaps because the differences in experience were not as large between same- and other-sex friends as the differences between friends and romantic partners, the difference was not significant. Experience with same-sex friends might generalize to other-sex friends more easily than to romantic partners.

There are several possible explanations for why participants were less likely to endorse both types of strategies when the conflict involved a romantic partner compared to when the conflict involved a friend. The strategies that participants were asked to rate in the present study may not be strategies adolescents would actually use to manage conflict with a romantic partner (e.g., talking to each other to find a mutually beneficial solution or standing one's ground to get one's own way). In future research with this data set, other types of strategies (e.g., avoidant/withdrawing strategies) will be examined. In addition, examining responses to openended questions asking participants to describe strategies for managing conflict might be helpful in terms of understanding what types of strategies adolescence use to manage peer conflict.

Similar to the possibility that the strategies are not representative of those used to manage conflict with romantic partners, it also could be that the types of conflicts used in the present study are not representative of the types of conflict adolescents experience within romantic 
relationships. If these situations do arise, the conflict might not be important enough to cause disagreement. Minor or everyday conflicts might not matter to adolescents who may also be experiencing a new and exciting romantic relationship. Research by Washburn et al. (2004) on adolescents' coping responses to stressful peer situations, found that the degree to which the situation or stressor mattered was an important factor relating to coping responses.

It is difficult to compare the findings relating to relationship differences to prior research on relationship differences because either adolescents were not included in the study (e.g., Laursen et al., 2001; Creasy et al., 1999), the relationship types compared were different (JensenCampbell et al., 1996) or the type of strategies examined were different. Although consistent with research suggesting conflict management strategies vary by relationship type, the direction of the present study's finding is inconsistent with previous research with adults comparing conflict-management strategies within friendships and romantic relationships. Specifically, Laursen et al.'s meta-analysis and Creasy et al.'s research suggested that conflict management for romantic partners was more likely to be characterized by negotiation or constructive strategies (i.e., communal strategies) than were friendships and that the use of coercion (i.e., agentic strategies) did not differ by relationship type. Possibly due to the different ages studied, our because the agentic strategies used in the present study were not coercive, but rather assertive, their findings are inconsistent with the present study's finding that communal and agentic strategies were less likely to be endorsed within romantic relationships than within friendships. That is, adolescents' romantic relationships are new (Carver et al., 2002), and thus adolescents have limited experience managing conflicts with romantic partners. Young adults are more likely than adolescents to have had long-term romantic relationships (Carver et al.) where opportunities to manage conflict are likely to have occurred. As a result of the difference in 
experience with romantic partners, it is not surprising that the present study's findings were inconsistent with previous research on adults. Future studies should empirically compare adolescents' and young adults' use or endorsement of conflict management strategies.

Further, the difference between previous findings (i.e., Creasy et al., 1999) and the present study's findings related to the main effect of relationship type could be due to methodology differences. In the present study, participants rated strategies in response to the same conflicts for all relationship types; however, in Creasy et al.'s study, participants rated conflict-management strategies that were not linked to a specific conflict (i.e., participants rated the degree to which they have used each listed strategy). Consequently, participants were likely thinking of specific conflicts and these conflicts were likely different for friends vs. romantic partners. Hence, the relationship difference found by Creasy and colleagues might reflect a difference in the types of conflicts experienced within friendships vs. romantic relationships rather than the effects of relationship type per se.

In addition, the inconsistency in the findings of the present study and previous research might reflect a difference in the type of conflicts used. For example, the conflicts used in the current study are minor conflicts or conflicts one is likely to encounter with some frequency across the duration of a relationship in everyday interactions. In contrast, when participants were asked to rate the frequency of strategy use in previous research (e.g., Creasey et al., 1990), participants might have been thinking about major conflicts such as violations of trust. This explanation for the inconsistent findings highlights the need for conflict situations to be held constant across relationship type to determine whether differences are due to relationship type rather than to the types of conflicts reported for each relationship. In sum, research on adolescents using hypothetical situation methodology directly comparing strategies used for 
managing conflict with friends vs. romantic partners is needed to better understand the finding in the present study that strategies were least likely to be used when the conflict involved a romantic partner vs. a friend.

\section{Traits}

For communal strategies, the three-way interaction between expressivity, gender, and relationship type was examined for exploratory purposes. The main effect of expressivity was significant such that greater expressivity scores were associated with greater endorsement of communal strategies. This main effect was modified by a three-way interaction with expressivity, gender, and relationship type. Expressivity was associated with greater endorsement of communal strategies for boys, but not girls. Although exploratory, these results are consistent with the pattern of the intercorrelations suggesting that traits may be more predictive of strategies when the trait is inconsistent with gender roles (i.e., expressivity for boys and instrumentality for girls). Also, for boys, the association between strategies and expressivity was moderated by relationship type and the findings for the two friendships were similar to each other and different from the findings for romantic relationships, supporting the proposition that relationship type, rather than sex composition, was driving the association between gender and communal strategies. Because these analyses were exploratory and because the finding was contingent upon including the three boys who reported never having had a same-sex best friend, this finding is in need of replication.

For agentic strategies, the analyses with instrumentality as the covariate [RQ 2 (H 2)], showed that when instrumentality was covaried, the endorsement of agentic strategies no longer varied by relationship type. Thus, for agentic strategies, the relationship type difference may be better understood as reflecting personality traits. Specifically, the main effect of instrumentality 
suggests that greater endorsement of instrumental traits was associated with greater endorsement of agentic strategies. This effect did not vary by gender or by relationship type. Therefore, adolescents who endorse instrumental traits were likely to use agentic conflict management strategies regardless of gender and relationship type.

As traits are defined as characteristics that are often stable across various contexts (McCrae \& Costa, 2003), as girls and boys are equally likely to endorse instrumental traits (Twenge, 1999), and as previous research has shown an association between traits and strategies (Jensen-Campbell et al., 1996; Renk \& Creasy, 2003; Suh et al., 2004; Washburn-Ormachea et al., 2004), it is not surprising that instrumental traits are related to the endorsement of agentic strategies independent of gender or relationship type. With one exception, previous research examining gender-typed traits have either only examined one context (Renk \& Creasy; Washburn-Ormachea et al.) or have shown that the association between traits and strategies depended on both the context and gender (Suh et al.). Jensen-Campbell et al.'s findings are most similar to the present study's findings in that in their study on adolescent conflict management, boys and girls scoring low on the trait of agreeableness were more likely to endorse destructive strategies and the association between traits and strategies did not vary by relationship type (i.e., parent, sibling, or friend). Thus, for some types of traits and some types of strategies, traits may be more predictive of strategies compared to gender or relationship type. Perhaps boys who endorse instrumental traits are likely to endorse the less socially desirable agentic strategies regardless of the context because of their inclination toward control and assertiveness. Those who have this inclination might show more stability across contexts, because they do not let the context influence their behavior (e.g., they might not want to give into a conflict "just" because they are with their significant other). As this finding (that when traits were included, the effect 
of relationship was no longer significant) was not predicted, future research should replicate this finding before conclusions can be made.

\section{Summary}

Although results did not support the hypothesis that gender differences and similarities in the endorsement of conflict-management strategies would be moderated by relationship type, results are consistent with Hyde's (2005) gender similarity hypothesis (i.e., that boys and girls are more similar than they are different). Consistent with a contextual approach to problem solving, results showed that particularly for communal strategies, girls and boys were less likely to endorse conflict-management strategies when the conflict involved a romantic partner compared to when the conflict involved a same- or other-sex friend.

In terms of disentangling the confound between sex composition (same- vs. other-sex peer) and relationship type, findings in the present study suggested that the pattern of strategy endorsement for managing conflict was associated with relationship type rather than sex composition--suggesting that relationship type rather than sex composition is a key factor to investigate when studying conflict management strategies. For agentic strategies, instrumental traits may be a better predictor of strategies than relationship type or gender perhaps due to inclination to assert their opinion and control the situation. Taken together the present study suggests that conflict management is associated with gender, relationship type, strategy type, and gender-typed traits.

\section{Limitations and Future Directions}

Results should be interpreted within the context of the limitations of the current study. First, although using hypothetical situation methodology allowed for greater experimenter control (i.e., all of the conflict situations were exactly the same across relationship type), using 
this methodology may decrease ecological validity. That is, findings in response to hypothetical situations might not generalize to real world situations. According to Laursen et al.'s (2001) meta-analysis, negotiation, prosocial, or communal strategies are more likely to be reported in response to hypothetical situations than observed in response to actual conflicts. Therefore, it is likely that endorsement of communal strategies is overestimated in the present study due to the use of hypothetical situation methodology.

Second, adolescents may have been influenced by the social desirability of communal vs. agentic strategies. It may be that adolescents were more likely to endorse communal strategies compared to agentic strategies in the present study because it is more socially acceptable to be polite and use communal strategies than it is to use agentic strategies. Although attempts were made to measure and control for social desirability effects, the short form of the measure used was unreliable $(\alpha=.42)$ and could not be used. As suggested by Laursen et al.'s (2001) metaanalysis, future research should utilize observational techniques to measure conflict management strategies to determine whether these findings would be replicated with actual problems or with observational methods.

Third, because all of the measures used in the present study were self-report, the common method used may have biased the results. Consequently, conclusions based on exploratory analyses should be tentative and are in need of replication. Common method bias may have resulted in significant effects or Type I errors.

Fourth, the finding that girls were more likely than boys to endorse strategies (regardless of strategy type) may be indicative of a lack of structural validity for the communal and agentic strategy items. In the future, a study with a large sample of adolescent boys and girls should be conducted to examine whether the structure of the strategy scale varies by gender. 
Fifth, the findings of the present study have limited generalizability. It is unclear whether findings generalize to other relationship types, to adolescents with varying experiences with same- and other-sex peers or family members, to other types of conflicts, or to other social and historical contexts. However, future research should examine whether the findings from the present study would generalize to homosexual romantic relationships. Future researchers should also consider investigating additional types of relationships. For example, the present study could be replicated and extended by examining conflict management with family members (e.g., parent-child or sibling-sibling conflict). In addition to examining other types of relationships, it is also important for future researchers to examine whether the findings of the present study generalize to adolescence with varying degrees of experience in managing conflict. For example, adolescents with other-sex siblings may have more experience managing conflict with the other sex compared to those with only same-sex siblings or no siblings. It might be that those with increased experience with other-sex peers or family members manage conflict with other-sex friends and other-sex romantic partners differently than those with less experience (e.g., those without siblings or those with only same-sex siblings). Similarly, varying experiences with relationships in general (e.g., attachment style) might influence how adolescents manage conflict (e.g., Creasey \& Ladd, 2004). Also, related to generalizability, the present study only examined one type of conflict. Namely, everyday interpersonal conflicts were exclusively examined. It is unclear whether the findings from the present study would generalize to other types of problems (e.g., more severe conflicts such as violations of trust). Further, results should be interpreted within the socio-historical context and culture from which the data was obtained. It unclear whether finding would generalize to other historical and culture contexts such as times in history or cultures with more or less stringent or oppressive gender roles. In sum additional research is 
needed to investigate whether the present study's findings generalize to other relationship types, to adolescents with varying experiences with same- and other-sex peers or family members, to other types of conflicts, cultures and historical contexts.

\section{Implications}

Results of the present study are important as they add to the work of others studying the consequences of gender-typed relationship processes (see Rose and Rudolph, 2006). During adolescence and young adulthood, failure to successfully manage peer conflict has a negative impact on mental health as well as general emotional functioning (Buhrmester, 1990; Feldman \& Gowen, 1998; Reese-Weber \& Marchland, 2000). Consequently, it is essential that we fully understand relationship processes for managing peer conflict.

Cross sectional research such as the present study contribute to a more nuanced understanding of the developmental trajectory of conflict management within romantic relationships. As suggested by many (e.g., Rose and Rudolph) understanding the associations between the socialization occurring in same-sex contexts and relationship processes (e.g., conflict management) with same- and other-sex peers early in the life span, may contribute to our understanding of the same processes within romantic relationships in adulthood.

As divorce is a problem in the U.S., research aimed at understanding the developmental trajectory of conflict management with other-sex peers (friends and romantic partners) may help improve other-sex interactions. For example, researchers are currently investigating whether requiring children to work with other-sex peers at school starting in preschool, could improve interactions between men and women and boys and girls across the life span. The ultimate goal of this incentive is to decrease divorce rates by $50 \%$ in 50 years (see the Sanford Harmony Project at http://sanford.clas.asu.edu/index.html). Millions of dollars from the private sector have 
been donated to fund the research needed to solve this social problem. The present study informs this line of research by showing that the pattern of conflict management with romantic partners appears to be different from that of friends. Cross sectional, longitudinal, or ideally cross sequential research using the methodology from the present study comparing preadolescents, adolescents, and young adults, will help to better understand whether there is continuity in how conflict is management within romantic relationships. This knowledge is needed to inform inventions aimed at improving other-sex interactions.

\section{Conclusions}

The findings of the current study suggest that research aimed at understanding gender differences and similarities in adolescent peer conflict should consider relationship type, strategy type, and gender-typed personality in their investigations. In addition, the present study contributes to a greater understanding of contextual approaches to problem solving. Specifically, these findings suggest that future researchers interested in adolescent peer conflict should not only consider relationship type, but also strategy type and gender-typed personality traits. 


\section{References}

Bakan, D. (1966). The duality of human existence: An essay on psychology and religion Oxford, England: Rand McNally.

Bem, S. L. (1974). The measurement of psychological androgyny. Journal of Consulting and Clinical Psychology, 42, 155-162.

Berg, C., \& Strough, J. (in press). Problem Solving Across the Life Span. Berg, C. A., \& Strough, J. (in press). Problem solving across the lifespan. In K. Fingerman, C.A. Berg, T. Antonnuci, \& J. Smith, (Eds), Handbook of lifespan psychology. New York: Springer.

Black, K. (2000). Gender differences in adolescents' behavior during a conflict resolution tasks with best friends. Adolescence, 35, 499-512.

Buhrmester, D. (1990). Intimacy of friendship, interpersonal competence, and adjustment during preadolescence and adolescence. Child Development, 61, 1101-1111.

Broverman, I. K., Broverman, D. M., Clarkson, F. E., Rosenkrantz, P. S., \& Vogel, S. R. (1970). Sex-role stereotypes and clinical judgments of mental health. Journal of Consulting and Clinical Psychology, 34, 1-7

Carver, K., Joyner, K., \& Udry, J. R. (2003). National estimates of adolescent romantic relationships. In P. Florsheim (Ed.), Adolescent romantic relations and sexual behavior (pp. 23-56). New Jersey: Lawrence Erlbaum Associates.

Census (2000). State \& County Quick Facts. Retrieved April 10, 2010, from http://www.census.gov/

Chung, T., \& Asher, S. R. (1996). Children's goals and strategies in peer conflict situations. Merrill-Palmer Quarterly, 42, 125-147.

Collins, A. W. (2003). More than myth: The developmental significance of romantic 
relationships during adolescence. Journal of Research on Adolescence, 13, 1-24.

Collins, W. A., \& Laursen, B. (1992). Conflicts and relationships during adolescence. In C.Shantz, W. Hartup (Eds.), Conflict in child and adolescent development (pp. 216241). New York: Cambridge University Press.

Connolly, J., Furman, W., \& Konarski, R. (2000). The role of peers in the emergence of heterosexual romantic relationships on adolescence. Child Development, 71, 1395-1408.

Connolly, J. A., \& Johnson, A. M. (1996). Adolescents' romantic relationships and the structure and quality of their close interpersonal ties. Personal Relationships, 3, 185-195.

Creasey, G., Kershaw, K., \& Boston, A. (1999). Conflict management with friends and romantic partners: The roles of attachment and negative mood regulation expectancies. Journal of Youth and Adolescence, 28, 523-543.

Creasey, G., \& Ladd, A. (2004). Negative mood regulation expectancies and conflict behaviors in late adolescent college student romantic relationships: The moderating role of generalized attachment representations. Journal of Research on Adolescence, 14, 235255.

Darling, N., Dowdy, B. B., Van Horn, M. L., \& Caldwell, L. L. (1999). Mixed-sex settings and the perception of competence. Journal of Youth and Adolescence, 28, 461-480.

Deaux, K., \& Major, B. (1987). Putting gender into context: An interactive model of gender related behavior. Psychological Review, 94, 369-389.

De Wied, M., Branje, S. T., \& Meeus, W. H. J. (2007). Empathy and conflict resolution in friendship relations among adolescents. Aggressive Behavior, 33, 48-55.

Field, A. (2009). Discovering statistics using SPSS, $3^{\text {rd }}$ edition. London: Sage Publications. Feingold, A. (1994). Gender differences in personality: A meta-analysis. Psychological Bulletin, 
116, 429-456.

Feldman, S. S., \& Gowen, L. K. (1998). Conflict negotiation tactics in romantic relationships in high school students. Journal of Youth and Adolescence, 27, 691-717.

Furman, W., Simon,V. A., Shaffer, L., \& Bouchey, H. A. (2002). Adolescents' working models and styles for relationships with parents, friends, and romantic partners. Child Development, 73, 241- 255. ,

George, D., \& Mallery, P. (2008). SPSS for windows step by step: A simple guide and reference 15.0 update ( $8^{\text {th }}$ ed.). Boston, MA: Pearson Education, Inc.

Gottman, J. M., Coan, J., Carrere, S., \& Swanson, C. (1998). Predicting marital happiness and stability from newlywed interactions. Journal of Marriage and the Family, 60, 5-22.

Heavey, C. L., Layne, C., \& Christensen, A. (1993). Gender and conflict structure in marital interaction: A replication and extension. Journal of Consulting and Clinical Psychology, 61, 16-27.

Jensen-Campell, L. A., Graziano, W. G., \& Hair, E. C. (1996). Personality and relationships as moderators of interpersonal conflict in adolescence. Merrill-Palmer Quarterly, 42, 148164.

Kurdek, L. A. (1995). Predicting change in marital satisfaction from husbands' and wives' Conflict resolution styles. Journal of Marriage \& the Family, 57, 153-164.

Kuttler, A. F., La Greca, A. M., \& Prinstein, M. J. (1999). Friendship qualities and socialmotional functioning of adolescents with close, cross-sex friendships. Journal of Research on Adolescence, 9, 339-366.

Laursen, B. (1996). Closeness and conflict in adolescent peer relationships: Interdependence with friends and romantic partners. In W.M. Bukowski, A.F., Newcomb, \& W.W. 
Hartup (Eds.), The company they keep: Friendship in childhood and

adolescence (pp. 186-210). New York: Cambridge University Press.

Laursen, B., \& Collins,W. A. (1994). Interpersonal conflict during adolescence. Psychological Bulletin, 115, 197-209.

Laursen B., Finkelstein, B. D., \& Townsend Betts, N. (2001). A developmental meta-analysis of peer conflict resolution. Developmental Review, 21, 423-449.

Laursen, B., \& Koplas, A. L. (1995). What's important about important conflicts? Adolescents' perceptions of daily disagreements. Merrill-Palmer Quarterly, 41, 536-553.

Leaper, C. (1994). Childhood gender segregation: Causes and consequences. San Francisco, CA: Jossey-Bass.

Leaper, C. (1998). Decision making processes between friends: Speaker and partner gender effects. Sex Roles, 39, 125-133.

Leaper, C., \& Anderson, K. J. (1997). Gender development and heterosexual romantic relationships during adolescence. In S. Shulman, \& W. A. Collins (Eds.), Romantic relationships in adolescence: Developmental perspectives (pp. 85-103). San Francisco: Jossey-Bass.

Leaper, C., \& Smith, T. E. (2004). A meta-analytic review of gender variations in children's language use: Talkativeness, affiliative speech, and assertive speech. Developmental Psychology, 40, 993-1027.

Leszczynski, J. P., \& Strough, J. (2008). Contextual specificity of masculinity and femininity. Social Development, 17, 719-736.

Lindeman, M., Harakka, T., \& Keltikanga-Jarvinen, L. (1997). Age and gender differences in adolescents' reactions to conflict situations: Aggression, prosociality, and withdrawal. 
Journal of Youth and Adolescence, 26, 339-351.

Lips, H., \& Keener, E. (2007). Effects of gender and dominance on leadership emergence: Incentives make a difference. Sex Roles, 56, $563-572$.

Maccoby, E. E. (1990). Gender and relationships: A developmental account. American Psychologist, 45, 513-520.

Maccoby, E. E. (2000). Perspectives on gender development. International Journal of Behavioraldevelopment, 4, 398-406.

McCrae, R. R., \& Costa, P. T. Jr., (2003). Personality in adulthood: A Five-Factor Theory perspective (2nd ed.). New York: Guilford Press.

McElwain, N. L., \& Volling, B. L. (2002). Relating individual control, social understanding, and gender to child-friend interaction: A relationships perspective. Social Development, 11, $362-385$.

Megargee, E. I. (1969). Influence of sex roles on the manifestation of leadership. Journal of Applied Psychology, 53, 377-382.

Mehta, C. M., \& Strough, J. (2009). Sex segregation in friendships and normative contexts across the life span. Developmental Review, 29, 201-220

Nyquist, L. V., \& Spence, T. (1986). Effects of dispositional dominance and sex role expectations on leadership behaviors. Journal of Personality and Social Psychology, 50, 87-93.

Opotow, S. (1991). Adolescent peer conflicts: Implications for students and for schools. Education and Urban Society, 23, 416-441.

Owens, L., Daly, A., \& Slee, P. (2005). Sex and age differences in victimisation and conflict 
resolution among adolescents in a south Australian school. Aggressive Behavior, 31, 1-12.

Owens, R. A. (2003). Friendship features associated with college students' friendship maintenance and dissolution following problems (Doctoral dissertation, West Virginia University, 2003). Dissertation Abstracts International, 64, 2961.

Owens, R. A. (2001). Friendship characteristics associated with adolescent friendship maintenance and dissolution (Masters thesis, West Virginia University, 2001). Masters Abstracts International, 40, 1625.

Pakaslahti, L., Karjalainen, A., \& Keltikangas-Järvinen, L. (2002). Relationships between adolescent prosocial problem-solving strategies, prosocial behaviour, and social acceptance. International Journal of Behavioral Development, 26, 137-144.

Pickard, J., \& Strough, J. (2003). Variability in goals as a function of same-sex and other-sex contexts. Sex Roles. 49, 643-652.

Reese-Weber, M., \& Marchland, J.F. ( 2000). Family and individual predictors of late adolescents' romantic relationships. Journal of Youth and Adolescence, 31, 197-206.

Renk, K., \& Creasey, G. (2003). The relationship of gender, gender identity and coping strategies in late adolescents. Journal of Adolescence, 26, 159-168

Rose, A. J., \& Asher, S. R. (1999). Children's goals and strategies in response to conflicts within a friendship. Developmental Psychology, 35, 69-79.

Rose, A. J., \& Rudolph, K. D. (2006). A review of sex differences in peer relationship processes: Potential trade-offs for the emotional and behavioral development of girls and boys. Psychological Bulletin, 132, 98-131.

Shantz, C. U., \& Hartup, W.W. (1992). Conflict in Child and Adolescent Development. New 
York: Cambridge University Press.

Shantz, C. U., \& Hobart, C. (1989). Social conflict and development: Peers and siblings. In T.J. Berndt, \& G.W. Ladd (Eds.), Peer Relationships in Child Development (pp. 71-94). New York: Wiley.

Sheldon, A. (1992). Conflict talk: Sociolinguistic challenges to self-assertion and how young girls meet them. Merrill-Palmer Quarterly, 38, 95-117.

Shulman, S., Levy-Shiff, R., Kedem, P., \& Alon, E. (1997). Intimate relationships among adolescent romantic partners and same-sex friends: Individual and systemic perspectives. In S. Shulman \& W. A. Collins (Eds.), Romantic Relationships in Adolescence: Developmental Perspectives (pp. 37-51). San Francisco: Jossey-Bass.

Shulman, S., \& Scharf, M. (2000). Adolescent romantic behaviors and perceptions: Age-and gender-related differences, and links with family and peer relationships. Journal of Research on Adolescence, 10, 99-118.

Sorkin, D. H \& Rook, K. S. (2006). Dealing with negative social exchanges in later life: Coping responses, goals, and effectiveness. Psychology and Aging, 21, 715-725.

Spence, J. T., \& Helmreich, R. L. (1978). Masculinity and femininity: Their psychological dimensions, correlates and antecedents. Austin: University of Texas Press.

Strough, J., \& Berg, C.A. (2000). Goals as a mediator of gender differences in high-affiliation dyadic conversations. Developmental Psychology, 36, 117-125.

Strough, J., Berg, C.A., \& Sansone, C. (1996). Goals for solving everyday problems across the lifespan: Age and gender differences in the salience of interpersonal concerns. Developmental Psychology, 32, 1106-1115.

Strough, J., McFall, J.P., Flinn, J. A., \& Schuller, K. L. (2008). Collaborative Everyday Problem 
Solving Among Same Gender Friendships in Early and Later Adulthood. Psychology and Aging, 23(3), 517-530.

Suh E. J., Moskowitz, D. S., Fournier, M. A., \& Zuroff, D.C. (2004). Gender and relationships: influences on agentic and communal behaviors. Personal Relationships, 11(1), 41-59.

Tabachnick, B. G. \& Fidell, L. S. (2007) Using Multivariate Statistics, $5^{\text {th }}$ edition. New York: Harper Collins.

Twenge, J. M. (1997). Changes in masculine and feminine traits of over time: A meta-analysis. Sex Roles, 36, 305-325.

Washburn-Ormachea, J .M., Hillman, S. B., \& Sawilowsky, S. S. (2004). Gender and genderrole orientation differences on adolescents' coping with peer stressors Journal of Youth and Adolescence, 33. 31-40. 
Table 1

Demographic Characteristics of Participants $(N=108)$

\begin{tabular}{llr}
\hline Demographic Index & Categories & $\%$ \\
\hline State of residency & West Virginia & 47.20 \\
& Pennsylvania & 35.20 \\
& OH, VA, MD, NC, KY, DE, SC, CT, FL & 22.00 \\
& Missing & 5.60 \\
Mother's education & Less than high school & 3.70 \\
& High school degree (or GED) & 22.20 \\
& Some college & 14.80 \\
& Associates Degree & 11.10 \\
& Bachelor's Degree & 24.10 \\
& Master's Degree & 15.70 \\
& Doctoral Degree & 3.70 \\
& Professional Degree (MD, JD) & .00 \\
& Missing data & 4.60
\end{tabular}

Father's education

Income

Less than high school

High school degree (or GED)

Some college

9.30

Associates Degree

10.20

Bachelor's Degree

17.60

Master's Degree

9.30

Doctoral Degree

7.40

Professional Degree (MD, JD)

3.70

Missing

4.60

Less than $\$ 30,000$

11.10

$\$ 30,001-\$ 50,000$

13.90

More than $\$ 50,001$

27.80

Don't know

43.50

Missing

3.70

Degree of Financial Difficulty

A great deal $\quad 8.30$

Some $\quad 38.90$

None $\quad 31.50$

Missing $\quad 21.30$ 
Table 2

Relationship History Characteristics of Participants $(N=108)$

Relationship History Index Categories

$\% \quad M_{\text {years }}(S D)$

Range

Have you ever had a samesex best friend?

$\begin{array}{lr}\text { Yes } & 96.30 \\ \text { No } & 2.80 \\ \text { Missing } & 0.90\end{array}$

Do you currently have a same- sex best friend?

$\begin{array}{lr}\text { Yes } & 91.70 \\ \text { No } & 7.40 \\ \text { Missing } & 0.90\end{array}$

Length (in yrs) of

relationship with current

same-sex best friend

Interact with same-sex best

$6.08(4.08) \quad .50-16.00$

friend alone vs. in a group

Mostly interact alone

23.20

Mostly interaction with others $\quad 25.00$

in a group

Equal between time alone and

45.40

time with others in a group

Missing

6.50

Have you ever had an othersex best friend?
Yes
90.70
No
8.30
Missing
0.90

Do you currently have an

other- sex best friend?

$\begin{array}{lr}\text { Yes } & 77.80 \\ \text { No } & 20.40 \\ \text { Missing } & 1.90\end{array}$

Length of relationship with current other-sex best friend 
Table 2, continued

(Table continues)

Interact with other-sex best

friend alone vs. in a group

Mostly interact alone

18.60

Mostly interaction with others

in a group

Equal between time alone and

time with others in a group

Missing

42.60

Have you ever had a

boyfriend/girlfriend?

Yes

67.60

No

31.50

Missing

Age of first romantic

relationship

Length of longest romantic relationship

$16.24(19.68) \quad 5.00-15.00$

$1.31(1.02) \quad 0.17-5.00$

Current status

Not dating not committed

29.60

Dating but not committed

12.00

Committed (new) $<1 \mathrm{yr}$

29.60

Committed (long-term) $>1 \mathrm{yr}$

8.30

N/A or missing

20.40

Age of current

romantic partner

$15.90(29.28)$

Interact with romantic

partner alone vs. in a group

Mostly interact alone

24.00

Mostly interaction with others

11.20

in a group

Equal between time alone and

16.70

time with others in a group

Missing

48.10 
Table 3

Procedure: Order of each Assessment

\begin{tabular}{|c|c|c|c|c|c|}
\hline \multicolumn{6}{|l|}{ Measure } \\
\hline \multirow[t]{2}{*}{ Part 1} & & \multicolumn{2}{|l|}{ Part 2} & \multirow[t]{2}{*}{ Part 3} & \\
\hline & \multicolumn{3}{|c|}{ Order A } & & \\
\hline \multirow[t]{4}{*}{ Strategies: same-sex friend } & & Strategies: other-sex friend & & Strategies: romantic & \\
\hline & Paper & & Concert & & Party \\
\hline & Concert & & Party & & Paper \\
\hline & Party & & Paper & & Concert \\
\hline \multicolumn{2}{|l|}{ Gender-typed personality } & Sex segregation & & Relationship quality & \\
\hline \multicolumn{2}{|l|}{ Demographics } & Social desirability & & & \\
\hline \multirow[t]{4}{*}{ Goals: other-sex friend } & & Goals: romantic & & \multicolumn{2}{|l|}{ Goals: same-sex friend } \\
\hline & Party & & Paper & & Concert \\
\hline & Paper & & Concert & & Party \\
\hline & Concert & & Party & & Paper \\
\hline & & Order B & & & \\
\hline \multirow[t]{4}{*}{ Strategies: other-sex friend } & & Strategies: romantic & & Strategies: same-sex friend & \\
\hline & Paper & & Concert & & Party \\
\hline & Concert & & Party & & Paper \\
\hline & Party & & Paper & & Concert \\
\hline \multicolumn{2}{|l|}{ Gender-typed personality } & Sex segregation & & Relationship quality & \\
\hline \multicolumn{2}{|l|}{ Demographics } & Social desirability & & & \\
\hline \multirow[t]{4}{*}{ Goals: romantic } & & Goals: same-sex friend & & \multirow[t]{4}{*}{ Goals: other-sex friend } & \\
\hline & Party & & Paper & & Paper \\
\hline & Paper & & Concert & & Concert \\
\hline & Concert & & Party & & Party \\
\hline \multicolumn{6}{|c|}{ Order C } \\
\hline \multirow{5}{*}{$\begin{array}{l}\text { Part } 1 \\
\text { Strategies: romantic }\end{array}$} & & Pant 2 & & Part 3 & \\
\hline & & Strategies: same-sex friend & & Strategies: other-sex friend & \\
\hline & Paper & & Concert & & Party \\
\hline & Concert & & Party & & Paper \\
\hline & Party & & Paper & & Concert \\
\hline \multicolumn{2}{|l|}{ Gender-typed personality } & Sex segregation & & Relationship quality & \\
\hline \multicolumn{2}{|l|}{ Demographics } & Social desirability & & & \\
\hline \multirow[t]{4}{*}{ Goals: same-sex friend } & & Goals: other-sex friend & & Goals: romantic & \\
\hline & Party & & Paper & & Paper \\
\hline & Paper & & Concert & & Party \\
\hline & Concert & & Party & & Concert \\
\hline
\end{tabular}


Table 4

Means, Standard Deviations and Range for Expressivity, Instrumentality, Communal Strategies, and Agentic Strategies

\begin{tabular}{|c|c|c|c|c|c|c|c|c|c|}
\hline & Gir & & & Boy & & & Total & & \\
\hline Variable & $M$ & $S D$ & Range & $M$ & $S D$ & Range & $M$ & $S D$ & Range \\
\hline Expressivity & 4.04 & .43 & $3.13-5.00$ & 3.73 & .61 & $1.88-4.63$ & 3.90 & .54 & $1.88-5.00$ \\
\hline Instrumentality & 3.62 & .53 & $2.25-4.50$ & 3.68 & .63 & $2.50-5.00$ & 3.65 & .57 & $2.25-5.00$ \\
\hline $\begin{array}{l}\text { Communal Strategies } \\
\text { (same-sex friend) }\end{array}$ & 3.23 & .62 & $2.00-4.00$ & 3.12 & .74 & $1.00-4.00$ & 3.18 & .68 & $1.00-4.00$ \\
\hline $\begin{array}{l}\text { Communal Strategies } \\
\text { (other-sex friend) }\end{array}$ & 3.20 & .58 & $1.67-4.00$ & 3.20 & .76 & $1.00-4.00$ & 3.20 & .66 & $1.00-4.00$ \\
\hline $\begin{array}{l}\text { Communal Strategies } \\
\text { (romantic relationship) }\end{array}$ & 2.53 & .43 & $1.50-3.83$ & 2.48 & .43 & $1.50-3.67$ & 2.51 & .43 & $1.50-3.83$ \\
\hline $\begin{array}{l}\text { Agentic Strategies } \\
\text { (same-sex friend) }\end{array}$ & 2.61 & .55 & $1.17-4.00$ & 2.36 & .63 & $1.00-4.00$ & 2.50 & .60 & $1.00-4.00$ \\
\hline $\begin{array}{l}\text { Agentic Strategies } \\
\text { (other-sex friend) }\end{array}$ & 2.61 & .59 & $1.50-4.00$ & 2.28 & .58 & $1.00-4.00$ & 2.46 & .61 & $1.00-4.00$ \\
\hline $\begin{array}{l}\text { Agentic Strategies } \\
\text { (romantic relationship) }\end{array}$ & 2.47 & .56 & $1.33-4.00$ & 2.08 & .67 & $1.00-3.83$ & 2.29 & .64 & $1.00-4.00$ \\
\hline
\end{tabular}


Table 5

Order of strategy item presentation throughout the Peer Conflict Questionnaire

Strategy Type $\quad$ Strategy Item

Affect Regulation 1 . I would avoid dealing with the decision as to [which concert to attend].

Communal I would talk with my [other-sex best friend] to decide [which concert to attend].

Agentic 3. I would to stand my ground and explain why [I should get to decide which concert to attend].

Affect Regulation 4 . I would put the problem about which [concert to attend] out of my mind and refuse to think about it.

Agentic (reversed) 5. I would [step] aside and [let my other-sex best friend decide which concert we attend].

Communal $\quad 6$. I would work with my [other-sex best friend] to find a way to decide [which concert to attend].

Note. These strategies are in response to a hypothetical conflict involving a concert. For each of the strategies, the wording of the strategy was changed slightly to match the topic of each hypothetical conflict. Segments in brackets were specific to the relationship type (same-sex best friend, other-sex best friend, or boyfriend/girlfriend) or to the conflict situation (conflict involving a concert, term paper, or party). Segments in bold were the same throughout the Peer Conflict Questionnaire. See Appendix A Section 1 for full measure. 
Table 6

Intercorrelations among Variables of Interest for Total Sample

\begin{tabular}{|c|c|c|c|c|c|c|c|c|}
\hline & 1 & 2 & 3 & 4 & 5 & 6 & 7 & 8 \\
\hline 1. Expressivity & 1 & & & & & & & \\
\hline 2. Instrumentality & .14 & 1 & & & & & & \\
\hline $\begin{array}{l}\text { 3. Communal } \\
\text { Same-Sex Friend }\end{array}$ & $.37 * *$ & -.02 & 1 & & & & & \\
\hline $\begin{array}{l}\text { 4. Communal } \\
\text { Other-Sex Friend }\end{array}$ & $.44 * *$ & -.00 & $.72 * *$ & 1 & & & & \\
\hline $\begin{array}{l}\text { 5. Communal } \\
\text { Romantic Partner }\end{array}$ & .00 & -.07 & .12 & $.25^{*}$ & 1 & & & \\
\hline $\begin{array}{l}\text { 6. Agentic } \\
\text { Same-Sex Friend }\end{array}$ & -.03 & .15 & -.08 & -.02 & -.08 & 1 & & \\
\hline $\begin{array}{l}\text { 7. Agentic } \\
\text { Other-Sex Friend }\end{array}$ & -.02 & $.22 *$ & -.18 & -.04 & -.02 & $.74 * *$ & 1 & \\
\hline $\begin{array}{l}\text { 8. Agentic } \\
\text { Romantic Partner }\end{array}$ & -.05 & .16 & $-.25^{*}$ & -.13 & -.09 & $.57 * *$ & $.56^{* *}$ & 1 \\
\hline
\end{tabular}
$* p<.01, * * p<.001$. 
Table 7

Intercorrelations among Variables of Interest

\begin{tabular}{lllllllll}
\hline & 1 & 2 & 3 & 4 & 5 & 6 & 7 & 8 \\
\hline 1. Expressivity & $\mathbf{1}$ & .14 & .02 & .24 & -.04 & -.10 & -.02 & -.16 \\
& & & & & & & & \\
2. Instrumentality & .17 & $\mathbf{1}$ & -.01 & -.01 & -.12 & $.27^{*}$ & $.30^{*}$ & $.24^{*}$ \\
$\begin{array}{l}\text { 3. Communal } \\
\quad \text { Same-Sex Friend }\end{array}$ & $.61^{* *}$ & -.01 & $\mathbf{1}$ & $.64^{* *}$ & .02 & -.24 & $-.40^{* *}$ & .00 \\
$\begin{array}{l}\text { 4. Communal } \\
\text { Other-Sex Friend }\end{array}$ & $.60^{* *}$ & .00 & $.80^{* *}$ & $\mathbf{1}$ & .11 & -.09 & $-.33^{* *}$ & .10 \\
$\begin{array}{l}\text { 5. Communal } \\
\text { Romantic Partner }\end{array}$ & .01 & -.03 & .20 & $.38^{* *}$ & $\mathbf{1}$ & $-.29^{*}$ & $-.39^{* *}$ & $-.26^{*}$ \\
$\begin{array}{l}\text { 6. Agentic } \\
\text { Same-Sex Friend }\end{array}$ & -.19 & .12 & -.22 & -.01 & .23 & $\mathbf{1}$ & $.64^{* *}$ & $.61^{* *}$ \\
$\begin{array}{l}\text { 7. Agentic } \\
\quad \text { Other-Sex Friend }\end{array}$ & -.06 & .21 & -.18 & -.03 & .24 & $.47^{* *}$ & $\mathbf{1}$ & $.39^{* *}$ \\
$\begin{array}{l}\text { 8. Agentic } \\
\text { Romantic Partner }\end{array}$ & -.19 & .07 & -.16 & -.11 & .05 & $.66^{* *}$ & $.82^{* *}$ & $\mathbf{1}$ \\
\hline
\end{tabular}

${ }^{*} p<.01,{ }^{* *} p<.001$. Boys are in the lower diagonal and girls are in the upper diagonal. 
Table 8

Mean Communal and Agentic Strategies for Managing Conflict

\begin{tabular}{|c|c|c|c|c|}
\hline & & Girls & Boys & Total \\
\hline \multicolumn{5}{|l|}{ Communal Strategies } \\
\hline & Same-sex friend & $3.23(.09)$ & $3.12(.10)$ & $3.18(.07)_{a}$ \\
\hline & Other-sex friend & $3.21(.09)$ & $3.20(.10)$ & $3.20(.06)_{\mathrm{a}}$ \\
\hline & Romantic Partner & $2.53(.06)$ & $2.48(.06)$ & $2.50(.04)_{b}$ \\
\hline Total & & $2.99(.06)$ & $2.93(.07)$ & \\
\hline
\end{tabular}

Agentic Strategies

\begin{tabular}{|c|c|c|c|c|}
\hline & Same-sex friend & $2.62(.07)$ & $2.35(.08)$ & $2.49(.06)_{\mathrm{a}}$ \\
\hline & Other-sex friend & $2.61(.08)$ & $2.28(.08)$ & $2.45(.06)_{\mathrm{a}}$ \\
\hline & Romantic Partner & $2.47(.08)$ & $2.08(.09)$ & $2.28(.06)_{b}$ \\
\hline Total & & $2.56(.07)_{\mathrm{a}}$ & $2.24(.07)_{b}$ & \\
\hline
\end{tabular}

Mean (Standard Error). Values in the same row with different subscripts are significantly different at $p<.05$. 
Table 9

Mean Agentic Strategies for Managing Conflict after Controlling for Traits Girls Boys Total

Agentic Strategies

$\begin{array}{llll}\text { Same-sex friend } & 2.62(.08) & 2.36(.08) & 2.49(.06) \\ \text { Other-sex friend } & 2.62(.08) & 2.36(.08) & 2.47(.06) \\ \text { Romantic Partner } & 2.48(.08) & 2.08(.09) & 2.28(.06) \\ & 2.57(.07)_{\mathrm{a}} & 2.24(.07)_{\mathrm{b}}\end{array}$

Mean (Standard Error). Values in the same row with different subscripts are significantly different at $p<.05$. 
Table 10

Mean Communal and Agentic Strategies for Managing Conflict by Relationship Type Communal Agentic Total

Same-sex friend$$
2.49(.06)
$$

$2.83(.04)_{\mathrm{a}}$

Other-sex friend

$3.20(.06)$

$2.45(.06)$

$2.82(.04)_{\mathrm{a}}$

Romantic Partner

$2.50(.04)$

$2.28(.06)$

$2.39(.03)_{\mathrm{b}}$

Total

$2.96(.05)_{\mathrm{a}}$

$2.40(.05)_{b}$

Mean (Standard Error). Values in the same row with different subscripts are significantly different at $p<.05$. 


\section{Appendix A}

Measures

Section 1

BEFORE ALL STRATEGIES: SECTION INSTRUCTIONS (Romantic Partner)

On the following screens, you will read several scenarios and will answer questions about your strategies in the described situations. While some scenarios are presented more than once, others may appear to be repeated but are actually different. The scenario to which the questions correspond will appear at the top of each page. Please keep in mind the specific scenario when answering questions.

\section{MANIPULATION CHECK:}

The scenario to which the questions correspond will appear at the top of each page.

True $\quad$ False

The answer to the above question is TRUE. Did you answer the question correctly?

Yes NO

If you did not answer the question correctly, did you go back and look at the instructions to be sure that you understand?

Yes No (I answered correctly) No (I did not review my incorrect answer) 


\section{ROMANTIC STRATEGY INSTRUCTIONS}

On the following screens, you will be asked what strategies you would use if you were in the described situations. Strategies refer to actions you would take to solve a problem or resolve an issue. For example, if the situation described involved buying a new cell phone, your strategy might be to talk to other people about their experiences with their cell phones. So, these are the steps you take to resolve the situation or solve the problem.

When you are imagining you and your boyfriend/girlfriend in the situations described, imagine that this boyfriend/girlfriend is very important to you. It is not important whether you have personally experienced the described situations. It is only important that you imagine yourself in the described situations.

\section{MANIPULATION CHECK:}

Strategies refer to actions I would take to solve a problem or resolve a situation.

True False

I can answer the questions even if I have never personally experienced the described situations.

True False

When imagining a boyfriend/girlfriend, I should imagine someone who is important to me.

True False

\section{All of the answers to the above questions are True.}

Did you answer all of the questions correctly?

Yes NO

If you did not answer all of the questions correctly, did you go back and look at the instructions to be sure that you understand?

Yes $\quad$ No (I answered all questions correctly) No (I did not review my incorrect answers)

\section{MORE STRATEGY INSTRUCTIONS}

On the following screens, you will read about several hypothetical situations. PLEASE READ EACH HYPOTHETICAL SITUATION EACH TIME IT IS PRESENTED EVEN IF IT SEEMS SIMILAR OR IDENTICAL TO ONE THAT YOU HAVE ALREADY READ. Even if you have never been in the situation described, imagine what you would do if that situation occurred in your own life. There are no right or wrong answers; we are just interested in your opinion. Please answer honestly. 


\section{ROMANTIC STRATEGIES}

Romantic Partner-Strategies (RP-S) 1

You are at the library working on a term paper that is due tomorrow. You have worked hard all year and you need a good grade. Your boyfriend/girlfriend sends you a message telling you that his/her computer just crashed. Despite trying everything your boyfriend/girlfriend has lost all of their work for an important project that is due tomorrow. Your boyfriend/girlfriend has worked hard all year, but still needs a good grade on this project to do well in the class and you are the only person who can help. Although you and your boyfriend/girlfriend often help each other, you will not have time to help your boyfriend/girlfriend and do your own work.

\section{STRATEGY ENDORSEMENT RATINGS:}

COMMUNAL (C)

I would talk with my boyfriend/girlfriend to decide which project I should work on.

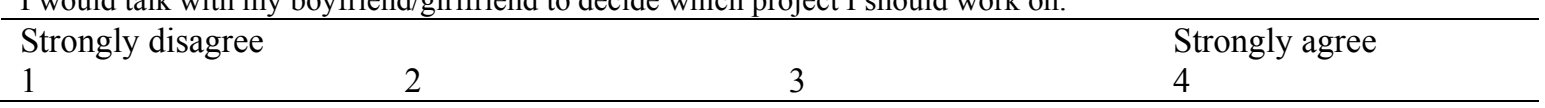

I would work with my boyfriend/girlfriend to find a way to decide which project I should work on.

\begin{tabular}{llll}
\hline Strongly disagree & & Strongly agree \\
1 & 2 & 3 & 4 \\
\hline
\end{tabular}

AFFECT REGULATION (AR)

I would avoid dealing with the decision as to which project I should work on.

\begin{tabular}{llll}
\hline Strongly disagree & & Strongly agree \\
1 & 2 & 3 & 4 \\
\hline
\end{tabular}

I would put the problem about which project I should work on out of my mind and refuse to think about it.

Strongly disagree Strongly agree

$\begin{array}{llll}1 & 2 & 3 & 4\end{array}$

AGENTIC (AG)

I would stand my ground and explain why I should only work on my own project.

\begin{tabular}{llll}
\hline Strongly disagree & & Strongly agree \\
1 & 2 & 3 & 4 \\
\hline
\end{tabular}

I would put my project aside and work on my boyfriend/girlfriend's project.

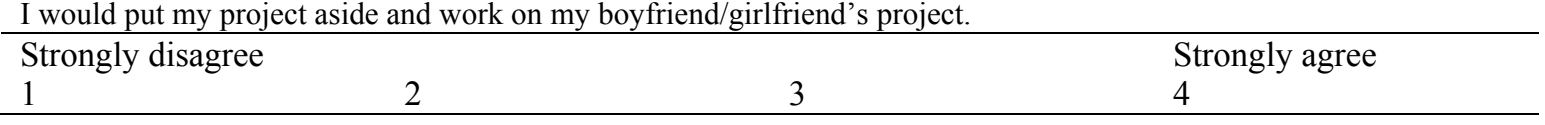

OPEN-ENDED STRATEGIES

In about a sentence, describe in your own words what strategies you would use (or what you would do) in terms of managing this conflict.

\section{FORCED CHOICE STRATEGY}

Which of the above things would you be most likely to do? (Choose one)

I would talk with my boyfriend/girlfriend to decide which project I should work on. (C)

_ I would work with my boyfriend/girlfriend to find a way to decide which project I should work on. (C)

_ I would avoid dealing with the decision as to which project I should work on. (AR)

- I would put the problem about which project I should work on out of my mind and refuse to think about it. (AR)

_ I would stand my ground and explain why I should only work on my own project. (AG)

_ _ I would put my project aside and work on my boyfriend/girlfriend's project. (AG)

\section{FORCED CHOICE DECISION:}

Ultimately, what decision would you make: (check one)

I would work on my own project and not on my boyfriend/girlfriend's. (AG)

__ I would work with my boyfriend/girlfriend on his/her project and put my project aside. (C) 
RP-S2

You and your boyfriend/girlfriend want to do something together on Saturday and you both agree that it would be fun to go to a concert. There are two different bands playing on Saturday. One is your favorite; the other is your boyfriend/girlfriend's favorite. You cannot agree on which one to attend. You cannot go to both concerts, only one of you will get to see the band that they most want.

\section{STRATEGY ENDORSEMENT RATINGS:}

COMMUNAL (C)

I would talk with my boyfriend/girlfriend to decide which concert to attend.

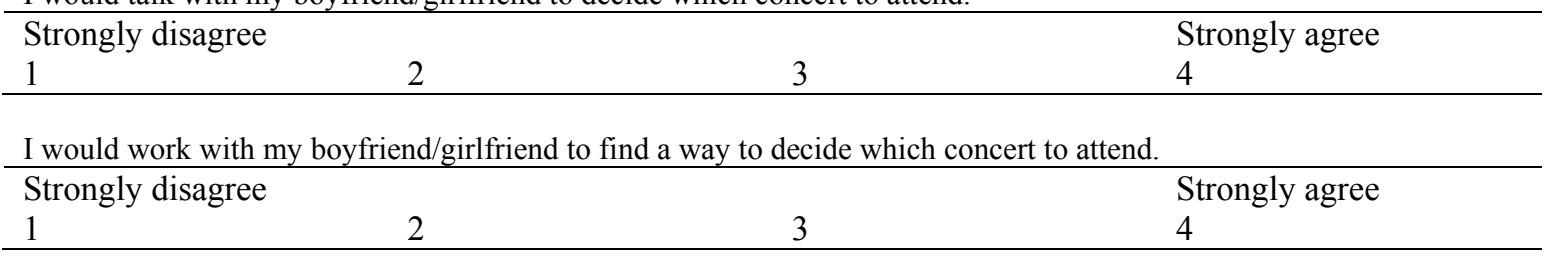

AFFECT REGULATION (AR)

I would avoid dealing with the decision as to which concert to attend.

Strongly disagree $\quad$ Strongly agree

$1 \quad 2 \quad 3 \quad 4$

I would put the problem about which concert to attend out of my mind and refuse to think about it Strongly disagree 1

23
Strongly agree

AGENTIC (AG)

I would stand my ground and explain why I should get to decide which concert we attend.

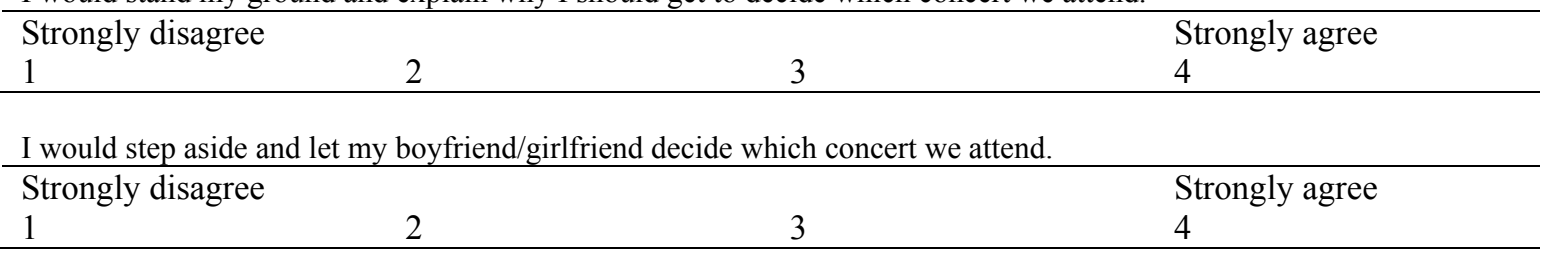

\section{OPEN-ENDED STRATEGIES}

In about a sentence, describe in your own words what strategies you would use (or what you would do) in terms of managing this conflict.

\section{FORCED CHOICE STRATEGY}

Which of the above things would you be most likely to do? (choose one)

I would talk with my boyfriend/girlfriend to decide which concert to attend. (C)

I w would work with my boyfriend/girlfriend to find a way to decide which concert to attend. (C)

I would avoid dealing with the decision as to which concert to attend. (AR)

_ I would put the problem about which concert to attend out of my mind and refuse to think about it. (AR)

_ I would stand my ground and explain why I should get to decide which concert we attend. (AG)

_ I would step aside and let my boyfriend/girlfriend decide which concert we attend. (AG)

\section{FORCED CHOICE DECISION:}

Ultimately, what decision would you make: (check one)

I would go with my boyfriend/girlfriend to see the band I most want. (AG)

_ I would go with my boyfriend/girlfriend to see the band s/he most wants. (C) 
RP-S3

You and your boyfriend/girlfriend have just completed a major accomplishment (e.g., graduation). In response to this event your family has decided to throw you a party and have set a time and date that will work for most of the important members of your family to attend. Your boyfriend/girlfriend's parents are also going to throw him/her a similar party. However, when you tell your boyfriend/girlfriend the date and time of your party, you both realize that each of your parents has picked the same day and time to hold each of the parties. You both hang out in the same group of friends. You both want all of your friends to be able to attend your party and also want to attend each other's parties. Thus, one of you will have to change the date of your party.

\section{STRATEGY ENDORSEMENT RATINGS:}

COMMUNAL (C)

I would talk with my boyfriend/girlfriend to decide who should change the date of their party.

\begin{tabular}{llll}
\hline Strongly disagree & & & Strongly agree \\
1 & 2 & 3 & 4 \\
\hline
\end{tabular}

I would work with my boyfriend/girlfriend to find a way to decide who should change the date of their party.

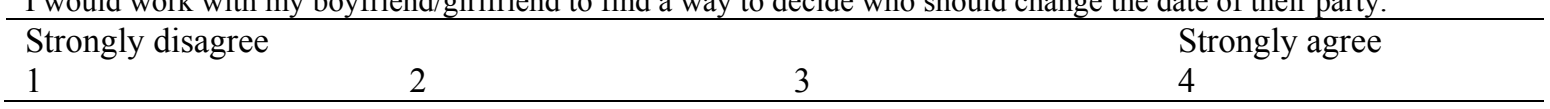

AFFECT REGULATION (AR)

I would avoid dealing with the decision as to who should change the date of their party.

\begin{tabular}{llll}
\hline Strongly disagree & & & Strongly agree \\
1 & 2 & 3 & 4 \\
\hline
\end{tabular}

I would put the problem about who should change the date of their party out of my mind and refuse to think about it.

Strongly disagree $\quad$ Strongly agree

$\begin{array}{llll}1 & 3 & 4\end{array}$

AGENTIC (AG)

I would stand my ground and explain why I should keep the date of their party.

Strongly disagree $\quad$ Strongly agree

$\begin{array}{llll}1 & 2 & 3 & 4\end{array}$

I would step aside and let my boyfriend/girlfriend keep the date of his/her party.

\begin{tabular}{llll}
\hline Strongly disagree & 2 & Strongly agree \\
1 & 2 & 3 & 4 \\
\hline
\end{tabular}

OPEN-ENDED STRATEGIES

In about a sentence, describe in your own words what strategies you would use (or what you would do) in terms of managing this conflict.

\section{FORCED CHOICE STRATEGY}

Which of the above things would you be most likely to do? (choose one)

I would talk with my boyfriend/girlfriend to decide who should change the date of their party. (C)

- I would work with my boyfriend/girlfriend to find a way to decide who should change the date of their party. (C)

_ I would avoid dealing with the decision as to who should change the date of their party. (AR)

- I would put the problem about who should change the date of their party out of my mind and refuse to think about it. (AR)

_ I would stand my ground and explain why I should keep the date of their party. (AG)

_ I would step aside and let my boyfriend/girlfriend keep the date of his/her party. (AG)

\section{FORCED CHOICE DECISION:}

Ultimately, what decision would you make: (check one) I would change the date of my party and my boyfriend/girlfriend would not. (C)

_ I would not change the date of my party and my boyfriend/girlfriend would. (AG)

(Participants will now complete a distraction task from section 2, 3, or 7) 


\section{BEFORE ALL STRATEGIES: SECTION INSTRUCTIONS (Other-Sex Friend)}

On the following screens, you will read several scenarios and will answer questions about your goals in the described situations. While some scenarios are presented more than once, others may appear to be repeated but are actually different. The scenario to which the questions correspond will appear at the top of each page. Please keep in mind the specific scenario when answering questions.

\section{MANIPULATION CHECK:}

The scenario to which the questions correspond will appear at the top of each page.

True False

The answer to the above question is TRUE. Did you answer the question correctly?

Yes NO

If you did not answer the question correctly, did you go back and look at the instructions to be sure that you understand?

Yes No (I answered correctly) No (I did not review my incorrect answer) 


\section{OTHER-SEX FRIEND INSTRUCTIONS: STRATEGIES}

On the following screens, you will be asked what strategies you would use if you were in the described situations. Strategies refer to actions you would take to solve a problem or resolve an issue. For example, if the situation described involved buying a new cell phone, your strategy might be to talk to other people about their experiences with their cell phones. So, these are the steps you take to resolve the situation or solve the problem.

When you are imagining you and your other-sex best friend in the situations described, imagine that this other-sex best friend is very important to you and is about the same age as you. It is not important whether you have personally experienced the described situations. It is only important that you imagine yourself in the described situations.

Strategies refer to actions I would take to solve a problem or resolve a situation.

True False

I can answer the questions even if I have never personally experienced the described situations.

True False

When imagining an other-sex best friend, I should imagine someone who is important to me.

True False

\section{All of the answers to the above questions are True.}

Did you answer all of the questions correctly?

Yes NO

If you did not answer all of the questions correctly, did you go back and look at the instructions to be sure that you understand?

Yes No (I answered all questions correctly) No (I did not review my incorrect answers)

\section{MORE STRATEGY INSTRUCTIONS}

On the following screens, you will read about several hypothetical situations. PLEASE READ EACH HYPOTHETICAL SITUATION EACH TIME IT IS PRESENTED EVEN IF IT SEEMS SIMILAR OR IDENTICAL TO ONE THAT YOU HAVE ALREADY READ. Even if you have never been in the situation described, imagine what you would do if that situation occurred in your own life. There are no right or wrong answers; we are just interested in your opinion. Please answer honestly. 


\section{OTHER-SEX FRIENDSHIP STRATEGIES}

Other-Sex Friend-Strategies (OSF-S) 1

You are at the library working on a term paper that is due tomorrow. You have worked hard all year and you need a good grade. Your other-sex best friend sends you a message telling you that his/her computer just crashed.

Despite trying everything your best friend has lost all of their work for an important project that is due tomorrow. Your other-sex best friend has worked hard all year, but still needs a good grade on this project to do well in the class and you are the only person who can help. Although you and your best friend often help each other, you will not have time to help your best friend and do your own work.

STRATEGY ENDORSEMENT RATINGS:

COMMUNAL (C)

I would talk with my other-sex best friend to decide which project I should work on.

\begin{tabular}{llll}
\hline Strongly disagree & & Strongly agree \\
1 & 2 & 3 & 4 \\
\hline
\end{tabular}

I would work with my other-sex best friend to find a way to decide which project I should work on.

\begin{tabular}{llll}
\hline Strongly disagree & & Strongly agree \\
1 & 2 & 3 & 4 \\
\hline
\end{tabular}

AFFECT REGULATION (AR)

I would avoid dealing with the decision as to which project I should work on.

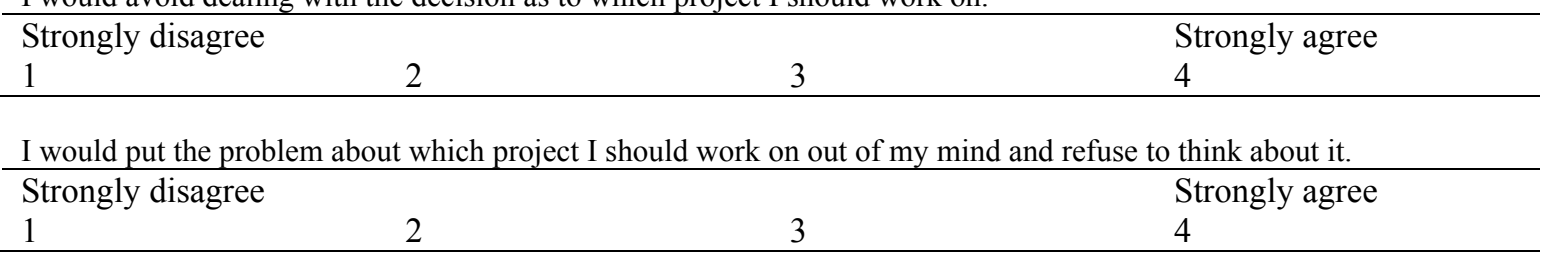

AGENTIC (AG)

I would stand my ground and explain why I should only work on my own project.

\begin{tabular}{lcl}
\hline $\begin{array}{l}\text { Strongly disagree } \\
1\end{array}$ & 2 & \multicolumn{2}{l}{ Strongly agree } \\
& 3 & 4 \\
\hline \\
I would put my project aside and work on my best friend's project. \\
\hline $\begin{array}{l}\text { Strongly disagree } \\
1\end{array}$ & 3 & Strongly agree \\
\hline
\end{tabular}

\section{OPEN-ENDED STRATEGIES}

In about a sentence, describe in your own words what strategies you would use (or what you would do) in terms of managing this conflict.

\section{FORCED CHOICE STRATEGY}

Which of the above things would you be most likely to do? (choose one)

I would talk with my other-sex best friend to decide which project I should work on. (C)

I w would work with my other-sex best friend to find a way to decide which project I should work on. (C)

I I would avoid dealing with the decision as to which project I should work on. (AR)

_ I would put the problem about which project I should work on out of my mind and refuse to think about it. (AR)

_ I would stand my ground and explain why I should only work on my own project. (AG)

_ I would put my project aside and work on my best friend's project. (AG)

\section{FORCED CHOICE DECISION:}

Ultimately, what decision would you make: (check one)

I would work on my own project and not on my other-sex best friend's. (AG)

_ I would work with my other-sex best friend on his/her project and put my project aside. (C) 
OSF-S2

You and your other-sex best friend want to do something together on Saturday and you both agree that it would be fun to go to a concert. There are two different bands playing on Saturday. One is your favorite; the other is your other-sex best friend's favorite. You cannot agree on which one to attend. You cannot go to both concerts, only one of you will get to see the band that they most want.

\section{STRATEGY ENDORSEMENT RATINGS:}

COMMUNAL (C)

I would talk with my other-sex best friend to decide which concert to attend.

Strongly disagree $\quad$ Strongly agree

$\begin{array}{llll}1 & 2 & 3 & 4\end{array}$

I would work with my other-sex best friend to find a way to decide which concert to attend.
Strongly disagree
Strongly agree

1

2

4

AFFECT REGULATION (AR)

I would avoid dealing with the decision as to which concert to attend.

\begin{tabular}{llll} 
Strongly disagree & & Strongly agree \\
1 & 2 & 3 & 4 \\
\hline
\end{tabular}

I would put the problem about which concert to attend out of my mind and refuse to think about it.
Strongly disagree
Strongly agree

1

2

4

AGENTIC (AG)

I would stand my ground and explain why I should get to decide which concert we attend.

\begin{tabular}{llll} 
Strongly disagree & & Strongly agree \\
1 & 2 & 3 & 4 \\
\hline
\end{tabular}

I would step aside and let my other-sex best friend decide which concert we attend.

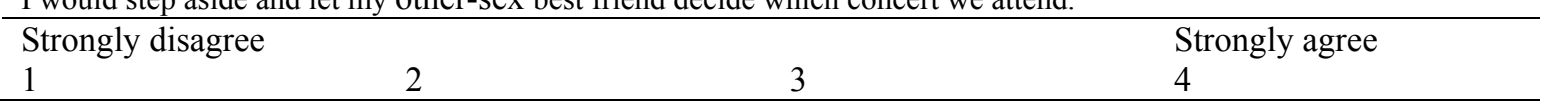

OPEN-ENDED STRATEGIES

In about a sentence, describe in your own words, what strategies you would use (or what you would do) in terms of managing this conflict.

\section{FORCED CHOICE STRATEGY}

Which of the above things would you be most likely to do? (choose one)

I would talk with my other-sex best friend to decide which concert to attend. (C)

_ I would work with my other-sex best friend to find a way to decide which concert to attend. (C)

_ I would avoid dealing with the decision as to which concert to attend. (AR)

I I would put the problem about which concert to attend out of my mind and refuse to think about it. (AR)

_ I would stand my ground and explain why I should get to decide which concert we attend. (AG)

_ I would step aside and let my other-sex best friend decide which concert we attend.

(AG)

\section{FORCED CHOICE DECISION:}

Ultimately, what decision would you make: (check one) I would go with my other-sex best friend to see the band I most want. (AG)

_ I would go with my other-sex best friend to see the band s/he most wants. (C) 
OFS-S3

You and your other-sex best friend have just completed a major accomplishment (e.g., graduation). In response to this event your family has decided to throw you a party and have set a time and date that will work for most of the important members of your family to attend. Your other-sex best friend's parents are also going to throw him/her a similar party. However, when you tell your best friend the date and time of your party, you both realize that each of your parents has picked the same day and time to hold each of the parties. You both hang out in the same group of friends. You both want all of your friends to be able to attend your party and also want to attend each other's parties. Thus, one of you will have to change the date of your party.

\section{STRATEGY ENDORSEMENT RATINGS:}

COMMUNAL (C)

I would talk with my other-sex best friend to decide who should change the date of their party.

\begin{tabular}{llll}
\hline Strongly disagree & & 3 & Strongly agree \\
1 & 2 & 3 & 4 \\
\hline
\end{tabular}

I would work with my other-sex best friend to find a way to decide who should change the date of their party.

Strongly disagree $\quad$ Strongly agree

$\begin{array}{llll}1 & 2 & 3 & 4\end{array}$

AFFECT REGULATION (AR)

I would avoid dealing with the decision as to who should change the date of their party.

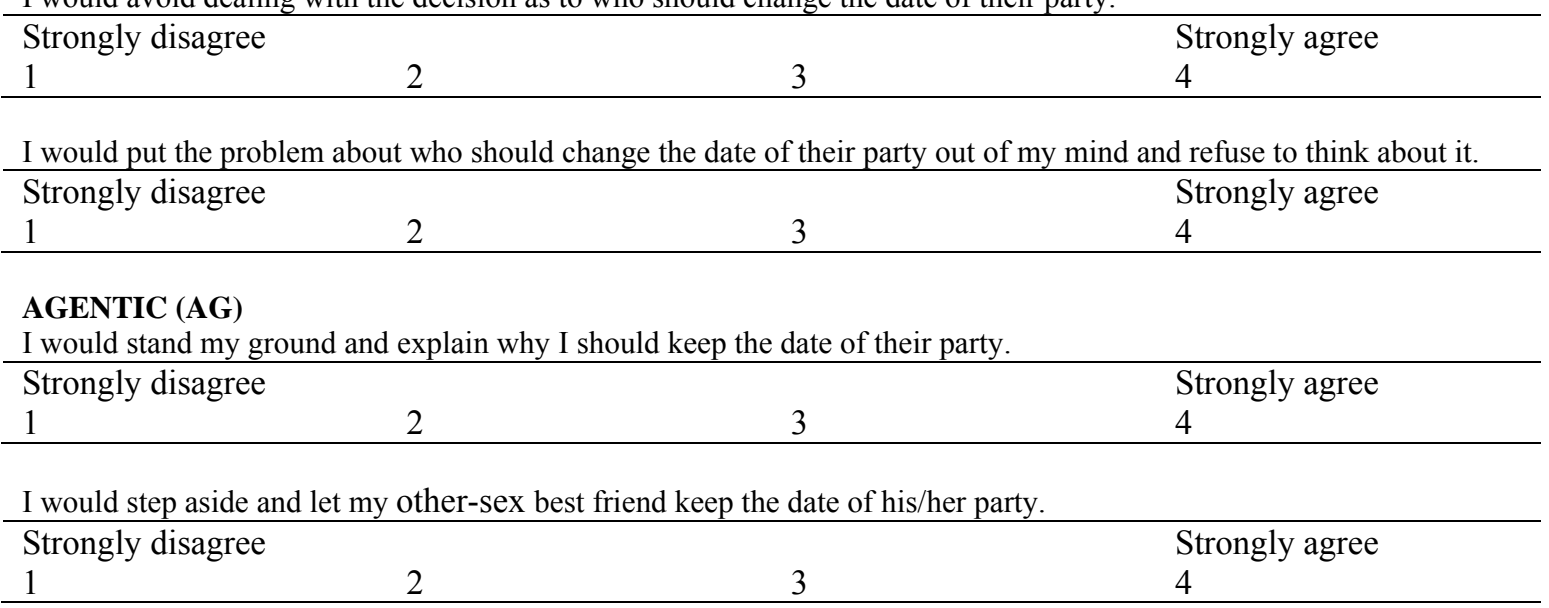

\section{OPEN-ENDED STRATEGIES}

In about a sentence, describe in your own words, what strategies you would use (or what you would do) in terms of managing this conflict.

\section{FORCED CHOICE STRATEGY}

Which of the above things would you be most likely to do? (choose one)

I would talk with my other-sex best friend to decide who should change the date of their party. (C)

_ I would work with my other-sex best friend to find a way to decide who should change the date of their party. (C)

I would avoid dealing other-sex with the decision as to who should change the date of their party. (AR)

I would put the problem about who should change the date of their party out of my mind and refuse to think about it. (AR)

- I would stand my ground and explain why I should keep the date of their party. (AG)

_ I would step aside and let my best friend keep the date of his/her party. (AG)

\section{FORCED CHOICE DECISION:}

Ultimately, what decision would you make: (check one)

I would change the date of my party and my best friend would not. (C)

_ I would not change the date of my party and my best friend would. (AG)

(Participants will now complete a distraction task from section 2, 3, or 7) 


\section{SAME-SEX FRIEND INSTRUCTIONS: STRATEGIES}

On the following screens, you will be asked what strategies you would use if you were in the described situations. Strategies refer to actions you would take to solve a problem or resolve an issue. For example, if the situation described involved buying a new cell phone, your strategy might be to talk to other people about their experiences with their cell phones. So, these are the steps you take to resolve the situation or solve the problem.

When you are imagining you and your same-sex best friend in the situations described, imagine that this other-sex best friend is very important to you and is about the same age as you. It is not important whether you have personally experienced the described situations. It is only important that you imagine yourself in the described situations.

Strategies refer to actions I would take to solve a problem or resolve a situation.

True False

I can answer the questions even if I have never personally experienced the described situations.

True False

When imagining a same-sex best friend, I should imagine someone who is important to me.

True False

\section{All of the answers to the above questions are True.}

Did you answer all of the questions correctly?

Yes NO

If you did not answer all of the questions correctly, did you go back and look at the instructions to be sure that you understand?

Yes No (I answered all questions correctly) No (I did not review my incorrect answers)

\section{MORE STRATEGY INSTRUCTIONS}

On the following screens, you will read about several hypothetical situations. PLEASE READ EACH HYPOTHETICAL SITUATION EACH TIME IT IS PRESENTED EVEN IF IT SEEMS SIMILAR OR IDENTICAL TO ONE THAT YOU HAVE ALREADY READ. Even if you have never been in the situation described, imagine what you would do if that situation occurred in your own life. There are no right or wrong answers; we are just interested in your opinion. Please answer honestly. 


\section{SAME-SEX FRIENDSHIP STRATEGIES}

Same-Sex Friendship-Strategies (SSF-S)1

You are at the library working on a term paper that is due tomorrow. You have worked hard all year and you need a good grade. Your same-sex best friend sends you a message telling you that his/her computer just crashed.

Despite trying everything your best friend has lost all of their work for an important project that is due tomorrow. Your same-sex best friend has worked hard all year, but still needs a good grade on this project to do well in the class and you are the only person who can help. Although you and your best friend often help each other, you will not have time to help your best friend and do your own work.

\section{STRATEGY ENDORSEMENT RATINGS:}

\section{COMMUNAL (C)}

I would talk with my same-sex best friend to decide which project I should work on. Strongly disagree 1 23 Strongly agree 4

I would work with my same-sex best friend to find a way to decide which project I should work on.

\begin{tabular}{llll}
\hline Strongly disagree & & Strongly agree \\
1 & 2 & 3 & 4 \\
\hline
\end{tabular}

AFFECT REGULATION (AR)

I would avoid dealing with the decision as to which project I should work on. Strongly disagree 1 $2 \quad 3$ Strongly agree 4

I would put the problem about which project I should work on out of my mind and refuse to think about it.

\begin{tabular}{llll} 
Strongly disagree & & Strongly agree \\
1 & 2 & 3 & 4 \\
\hline
\end{tabular}

AGENTIC (AG)

I would stand my ground and explain why I should only work on my own project. Strongly disagree 1 2 3 Strongly agree 4

I would put my project aside and work on my same-sex best friend's project.

\begin{tabular}{llll}
\hline Strongly disagree & & Strongly agree \\
1 & 2 & 3 & 4 \\
\hline
\end{tabular}

\section{OPEN-ENDED STRATEGIES}

In about a sentence, describe in your own words what strategies you would use (or what you would do) in terms of managing this conflict.

\section{FORCED CHOICE STRATEGY}

Which of the above things would you be most likely to do? (choose one)

I would talk with my same-sex best friend to decide which project I should work on. (C)

_ I would work with my same-sex best friend to find a way to decide which project I should work on. (C)

_ I would avoid dealing with the decision as to which project I should work on. (AR)

_ I would put the problem about which project I should work on out of my mind and refuse to think about it. (AR)

_ I would stand my ground and explain why I should only work on my own project. (AG)

_ I would put my project aside and work on my same-sex best friend's project. (AG)

\section{FORCED CHOICE DECISION:}

Ultimately, what decision would you make: (check one) I would work on my own project and not on my same-sex best friend's. (AG)

I w would work with my same-sex best friend on his/her project and put my project aside. (C) 
SSF-S2

You and your same-sex best friend want to do something together on Saturday and you both agree that it would be fun to go to a concert. There are two different bands playing on Saturday. One is your favorite; the other is your same-sex best friend's favorite. You cannot agree on which one to attend. You cannot go to both concerts, only one of you will get to see the band that they most want.

\section{STRATEGY ENDORSEMENT RATINGS:}

COMMUNAL (C)

I would talk with my same-sex best friend to decide which concert to attend.

\begin{tabular}{llll}
\hline Strongly disagree & & & Strongly agree \\
1 & 2 & 3 & 4 \\
\hline
\end{tabular}

I would work with my same-sex best friend to find a way to decide which concert to attend.

\begin{tabular}{llll}
\hline I would work with my same-sex best friend to find a way to decide which concert to attend. \\
\hline Strongly disagree & 2 & 3 & Strongly agree \\
1 & 2 & 4 \\
\hline
\end{tabular}

AFFECT REGULATION (AR)

I would avoid dealing with the decision as to which concert to attend.

\begin{tabular}{llll}
\hline Strongly disagree & & Strongly agree \\
1 & 2 & 3 & 4 \\
\hline
\end{tabular}

I would put the problem about which concert to attend out of my mind and refuse to think about it.

\begin{tabular}{llll}
\hline Strongly disagree & & Strongly agree \\
1 & 2 & 3 & 4 \\
\hline
\end{tabular}

AGENTIC (AG)

I would stand my ground and explain why I should get to decide which concert we attend.

$\begin{array}{llll}\text { Strongly disagree } & & \text { Strongly agree } \\ 1 & 2 & 3 & 4\end{array}$

I would step aside and let my best friend decide which concert we attend.

\begin{tabular}{|c|c|c|}
\hline Strongly disagree & & Strongly agree \\
\hline 1 & 3 & 4 \\
\hline
\end{tabular}

OPEN-ENDED STRATEGIES

In about a sentence, describe in your own words what strategies you would use (or what you would do) in terms of managing this conflict.

\section{FORCED CHOICE STRATEGY}

Which of the above things would you be most likely to do? (choose one)

I would talk with my same-sex best friend to decide which concert to attend. (C)

I would work with my same-sex best friend to find a way to decide which concert to attend. (C)

- I would avoid dealing with the decision as to which concert to attend. (AR)

_ I would put the problem about which concert to attend out of my mind and refuse to think about it. (AR)

_ I would stand my ground and explain why I should get to decide which concert we attend. (AG)

_ I would step aside and let my same-sex best friend decide which concert we attend. (AG)

\section{FORCED CHOICE DECISION:}

Ultimately, what decision would you make: (check one) I would go with my same-sex best friend to see the band I most want. (AG)

_ I would go with my same-sex best friend to see the band s/he most wants. (C) 
SSF-S3

You and your same-sex best friend have just completed a major accomplishment (e.g., graduation). In response to this event your family has decided to throw you a party and have set a time and date that will work for most of the important members of your family to attend. Your same-sex best friend's parents are also going to throw him/her a similar party. However, when you tell your best friend the date and time of your party, you both realize that each of your parents has picked the same day and time to hold each of the parties. You both hang out in the same group of friends. You both want all of your friends to be able to attend your party and also want to attend each other's parties. Thus, one of you will have to change the date of your party.

\section{STRATEGY ENDORSEMENT RATINGS:}

COMMUNAL (C)

I would talk with my same-sex best friend to decide who should change the date of their party.

\begin{tabular}{llll}
\hline Strongly disagree & & Strongly agree \\
1 & 2 & 3 & 4 \\
\hline
\end{tabular}

I would work with my same-sex best friend to find a way to decide who should change the date of their party.

Strongly disagree $\quad$ Strongly agree

$\begin{array}{llll}1 & 2 & 3 & 4\end{array}$

AFFECT REGULATION (AR)

I would avoid dealing with the decision as to who should change the date of their party.

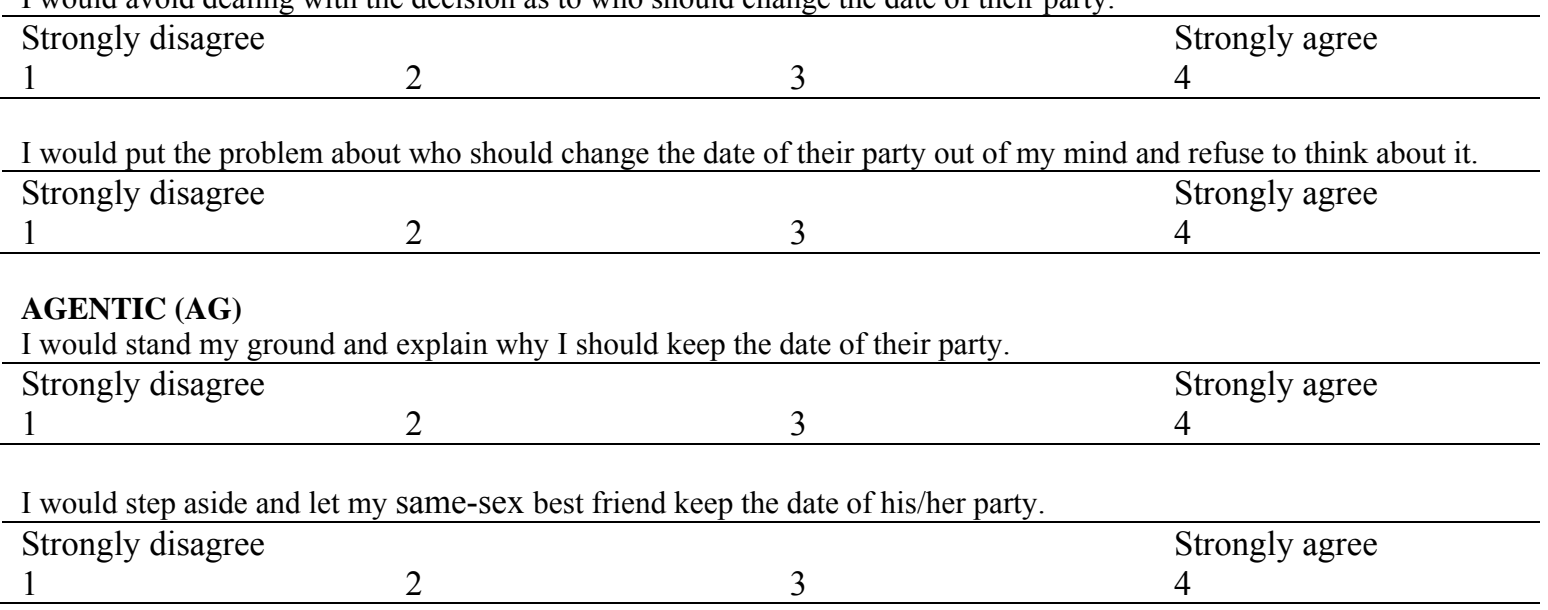

\section{OPEN-ENDED STRATEGIES}

In about a sentence, describe in your own words what strategies you would use (or what you would do) in terms of managing this conflict.

\section{FORCED CHOICE STRATEGY}

Which of the above things would you be most likely to do? (choose one)

I would talk with my same-sex best friend to decide who should change the date of their party. (C)

I would work with my same-sex best friend to find a way to decide who should change the date of their party. (C)

- I would avoid dealing with the decision as to who should change the date of their party. (AR)

_ I would put the problem about who should change the date of their party out of my mind and refuse to think about it. (AR)

_ I would stand my ground and explain why I should keep the date of their party. (AG)

_ I would step aside and let my same-sex best friend keep the date of his/her party. (AG)

\section{FORCED CHOICE DECISION:}

Ultimately, what decision would you make: (check one)

I would change the date of my party and my same-sex best friend would not. (C)

- I would not change the date of my party and my same-sex best friend would. (AG)

(Participants will now complete a distraction task from section 2, 3, or 7) 


\section{Section 2}

\section{Demographics}

(Demographics also used as a distraction Task)

\section{Same-Sex Friendship Demographics}

Listed below are questions for this section of the survey. Please provide a response for every question. If you are given the option to decline to answer a question, then declining to answer is considered a response.

1. Have you ever had a same-sex best friend?

Yes

- No

2. Do you currently have a best friend that is the same sex and about the same age as you?

- Yes

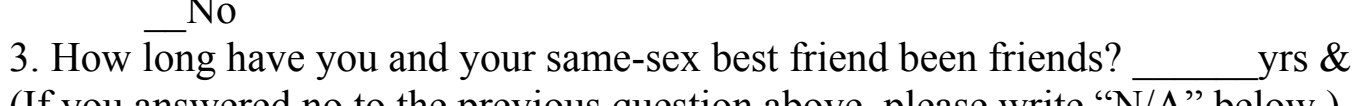

(If you answered no to the previous question above, please write "N/A" below.)

4. How much time do you spend together alone vs. hanging out in a group? (select one)

We spend all our time together alone

We spend the majority of our time together alone

We spend the majority of our time together hanging out in a group

— We spend all of our time together hanging out in a group

\section{Other-Sex Best Friendship Demographics}

Listed below are questions for this section of the survey. Please provide a response for every question. If you are given the option to decline to answer a question, then declining to answer is considered a response.

1. Have you ever had an other-sex best friend? (select one)

$-\mathrm{Yes}$

2. Do you currently have a best friend that is the other sex and about the same age as you?

- Yes

3. How long have you and your other-sex best friend been friends? yrs \& months (If you answered no to the previous question above, please write "N/A" below.)

4. How much time do you spend alone together vs. hanging out in a group? (select one)

We spend all our time together alone

— We spend the majority of our time together alone

— We spend the majority of our time together hanging out in a group

_ We spend all of our time together hanging out in a group 


\section{Romantic Relationship Demographics}

Listed below are questions for this section of the survey. Please provide a response for every question. If you are given the option to decline to answer a question, then declining to answer is considered a response.

1. What is your marital status? (select one)

Married

Not married, but living together

Widowed

Divorced

Never married

Other

2. Please specify number of years married (if apply). If you choose widowed or divorce for the previous question, specify number of years widowed or divorce.

3. Have you ever been in a committed romantic relationship? (select one)

$$
\begin{aligned}
& \text { Yes } \\
& -\mathrm{No}
\end{aligned}
$$

4. How old were you when you had your first long-term committed romantic (i.e., a relationship that lasted for at least 3 months) relationship? Answer N/A if the question does not apply.

5. How long was your longest committed romantic relationship? (Answer N/A if the question does not apply)

6. What is your current romantic relationship status? (select one)

I am not dating casually, nor am I in a committed relationship.

I am dating, but am not in a committed relationship.

I am in a fairly new committed relationship (less than 3 months).

I have been in a committed relationship for 3 to 6 months.

I have been in a committed relationship for 6 months to 1 year.

I have been in a committed relationship for 1 to 2 years.

I have been in a committed relationship for $2+$ years.

7. How old is your boyfriend/girlfriend? (answer N/A if you are not in a committed relationship) Age in years Birth Date

8. How much time do you spend alone together vs. hanging out in a group? (select one)

We spend all our time together alone

_ We spend the majority of our time together alone

_ We spend the majority of our time together hanging out in a group

_ We spend all of our time together hanging out in a group 


\section{Basic Demographics}

Listed below are questions for this section of the survey. Please provide a response for every question. If you are given the option to decline to answer a question, then declining to answer is considered a response.

1. Sex (select one)

Male

—Female

2. Age years

3. Date of Birth:

4. Today's Date:

5. Race (select all that apply):

African American

Asian

Caucasian

Hispanic

_other

6. Class (select one):

Freshman

_ Sophomore

Junior

_ Senior

7. Current overall g.p.a.:

8. Parent's combined yearly income (select one)

Less than $\$ 10,000$

$\$ 10,001-\$ 20,000$

$\$ 20,001-\$ 30,000$

$\$ 30,001-\$ 40,000$

$\$ 40,001-\$ 50,000$

$\$ 50,001-\$ 60,000$

More than $\$ 60,000$

Don't know

9. What is your father's occupation?
10. What is the highest level of education your father attained? (select one)

Less than High School

High School/GED

Some College

2-year college degree (Associates)

4-year college degree (BA,BS)

Master's Degree

Doctoral Degree

Professional Degree (MD, JD)

11. What is your Mother's occupation?

12. What is the highest level of education your mother attained? (select one)

Less than High School

High School/GED

Some College

2-year college degree (Associates) 4-year college degree (BA,BS)

Master's Degree

Doctoral Degree

Professional Degree (MD, JD)

13. How much financial difficulty do your parents have paying their bills? Would you say: (select one)

1 A great deal of difficulty

2 Some difficulty

3 A little difficulty

4 No difficulty

— 5 Does not apply

14. What city/town and state are you a permanent resident of? 


\section{Section 3}

\section{Spence \& Helmreich’s (1978) Personal Attributes Questionnaire}

\section{Personal Attributes Questionnaire (PAQ)}

Listed below are questions for this section of the survey. Please provide a response for every question. If you are given the option to decline to answer a question, then declining to answer is considered a response. The items below inquire about what kind of person you think are. Each item consists of a pair of characteristics. For example, 1 (Not Artistic at all) 2345 (Very Artistic)

Each pair describes contradictory characteristics-that is, you cannot be both at the same time, such as very artistic and not at all artistic. The numbers form a scale between the two extremes. You are to choose a number which describes where you fall on the scale. For example, if you think that you no artistic ability, you would choose 1 . If you think that you are pretty good, you might choose 4 . If you are only a medium, you might choose 3 , and so forth.

Masculine (M) = Instrumental

Feminine (F) = Expressive

Masculine - Feminine (MF) = Androgyny

\section{I am (MF)}

\begin{tabular}{lllll}
\hline Not at all aggressive & & & Very aggressive \\
1 & 2 & 3 & 4 & 5 \\
\hline
\end{tabular}

2. I am (M)

\begin{tabular}{lllll}
\hline Not at all independent & & & Very independent \\
1 & 2 & 3 & 4 & 5 \\
\hline
\end{tabular}

3. I am (F)

\begin{tabular}{lllll}
\hline Not at all emotional & & & Very Emotional \\
1 & 2 & 3 & 4 & 5 \\
\hline
\end{tabular}

4. I am (MF)

\begin{tabular}{lllll}
\hline Very Submissive & & & Very Dominant \\
1 & 2 & 3 & 4 & 5 \\
\hline
\end{tabular}

5. I am (MF) R

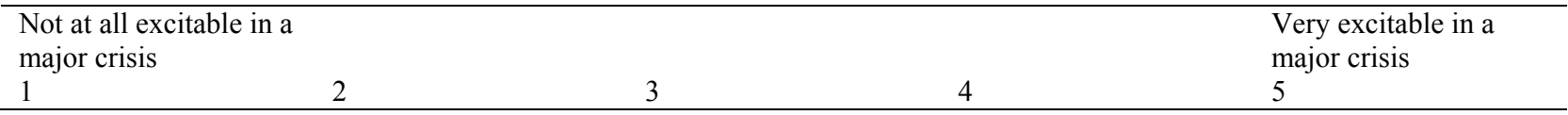

6. I am (M)

\begin{tabular}{lllll}
\hline Very Passive & & & Very Active \\
1 & 2 & 3 & 4 & 5 \\
\hline
\end{tabular}

7. I am (F)

Not at all able to devote myself completely to others 1
2

3

\author{
Able to devote \\ myself
}


8. I am (F)

\begin{tabular}{|c|c|c|c|c|}
\hline Very rough & & & & Very gentle \\
\hline 1 & 2 & 3 & 4 & 5 \\
\hline
\end{tabular}

9. I am (F)

\begin{tabular}{l}
$\begin{array}{l}\text { Not at all helpful to } \\
\text { others } \\
1\end{array}$ \\
\hline
\end{tabular}

10. I am (M)

Not at all competitive 1

2

$3 \quad 4$

Very Competitive 5

11. I am (MF)

\begin{tabular}{lllll}
\hline Very home oriented & & & Very worldly \\
1 & 2 & 3 & 4 & 5 \\
\hline
\end{tabular}

\section{I am (F)}

Not at all kind 1

1 .

2

3

$\begin{array}{ll}4 & 5 \\ \end{array}$

13. I am (MF) $\mathbf{R}$

Indifferent to other's

approval

1

2

3

4

High needful of others' approval

5

\section{My (MF) $\mathbf{R}$}

Feelings are not easily Hurt

1 2

3

4 Feelings are easily hurt

\section{I am (F)}

Not at all aware of the
feelings of others
1

16. I (M) R

Can make decisions easily 1

17. I (M)
2 3 4

Very aware of the feelings of others 5
Very Kind 5 
18. I (MF) R

\begin{tabular}{|c|c|c|c|c|}
\hline $\begin{array}{l}\text { Never cry } \\
1\end{array}$ & 2 & 3 & 4 & $\begin{array}{l}\text { Cry very easily } \\
5\end{array}$ \\
\hline
\end{tabular}

19. I am (M)

\begin{tabular}{|c|c|c|c|c|}
\hline $\begin{array}{l}\text { Not at all self- } \\
\text { confident }\end{array}$ & & & & Very self-confident \\
\hline 1 & 2 & 3 & 4 & 5 \\
\hline
\end{tabular}

20. I (M)

\begin{tabular}{llll}
\hline Feel very inferior & & & Feel very superior \\
1 & 2 & 3 & 4 \\
\hline
\end{tabular}

21. I am (F)

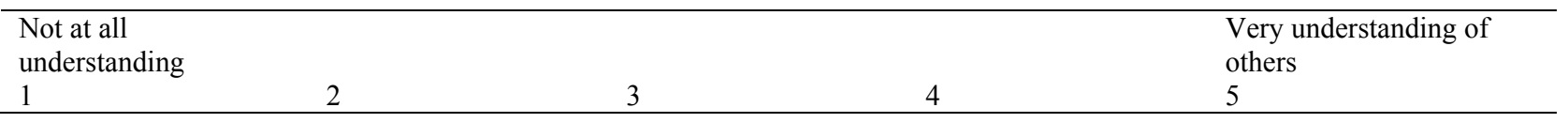

22. I am (F)

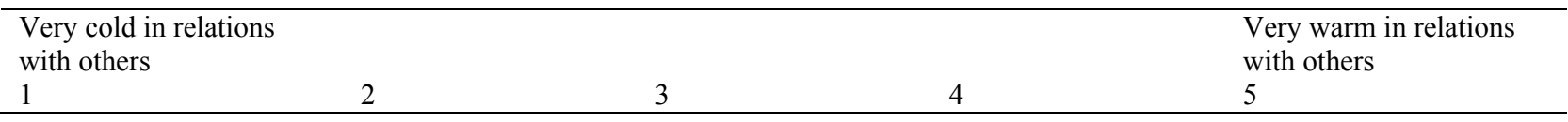

23. I have (MF) $\mathbf{R}$

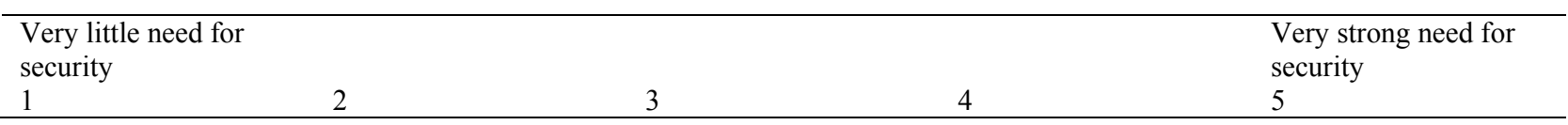

24. I (M)

\begin{tabular}{|c|c|c|c|c|}
\hline $\begin{array}{l}\text { Go to pieces under } \\
\text { pressure }\end{array}$ & & & & $\begin{array}{l}\text { Stand up well under } \\
\text { pressure }\end{array}$ \\
\hline 1 & 2 & 3 & 4 & 5 \\
\hline
\end{tabular}




\section{Section 4}

(Goals for use in future research)

ROMANTIC PARTNER GOAL INSTRUCTIONS:

On the following screens, you will be asked what your goals would be if you were in the described situations. Goals refer to what you would want to happen. For example, if the situation described involved buying a new cell phone, your goal might be to save money. So, the most important aspect of the decision to consider is the cost of the phone. In contrast, if you wanted to get the phone with the newest technology, then regardless of the cost, you would want the phone with the newest features.

When you are imagining you and your boyfriend/girlfriend in the situations described, imagine that this boyfriend/girlfriend is very important to you. It is not important whether you have personally experienced the described situations. It is only important that you imagine yourself in the described situations.

\section{MANIPULATION CHECK:}

Goals refer to what I would want to happen in a given situation.

True False

I can answer the questions even if I have never personally experienced the described situations.

True False

When imagining a boyfriend/girlfriend, I should imagine someone who is important to me.

True False

All of the answers to the above questions are TRUE. Did you answer all of the questions correctly?

Yes

NO

If you did not answer all of the questions correctly, did you go back and look at the instructions to be sure that you understand?

Yes No (I answered all questions correctly) No (I did not review my incorrect answers) 
BEFORE ALL GOAL SECTIONS INSTRUCTIONS: (Romantic Partner)

On the following screens, you will read several scenarios and will answer questions about your goals in the described situations. While some scenarios are presented more than once, others may appear to be repeated but are actually different. The scenario to which the questions correspond will appear at the top of each page. Please keep in mind the specific scenario when answering questions.

\section{MANIPULATION CHECK:}

The scenario to which the questions correspond will appear at the top of each page.

True $\quad$ False

The answer to the above question is TRUE. Did you answer the question correctly?

Yes NO

If you did not answer of the question correctly, did you go back and look at the instructions to be sure that you understand?

Yes No (I answered correctly) No (I did not review my incorrect answer)

\section{More Goal Instructions}

On the following screens, you will read about several hypothetical situations. PLEASE READ EACH HYPOTHETICAL SITUATION EACH TIME IT IS PRESENTED EVEN IF IT SEEMS SIMILAR OR IDENTICAL TO ONE THAT YOU HAVE ALREADY READ. Even if you have never been in the situation described, imagine what you would do if that situation occurred in your own life. There are no right or wrong answers; we are just interested in your opinion. Please answer honestly. 
ROMANTIC GOALS

ROMANTIC PARTNER-GOALS (RP-G) 1

You are at the library working on a term paper that is due tomorrow. You have worked hard all year and you need a good grade. Your boyfriend/girlfriend sends you a message telling you that his/her computer just crashed. Despite trying everything your boyfriend/girlfriend has lost all of their work for an important project that is due tomorrow. Your boyfriend/girlfriend has worked hard all year, but still needs a good grade on this project to do well in the class and you are the only person who can help. Although you and your boyfriend/girlfriend often help each other, you will not have time to help your boyfriend/girlfriend and do your own work.

\section{GOAL ENDORSEMENT RATINGS:}

COMMUNAL (C)

I would want both of us to decide which project I should work on in a way that satisfies both of us.

\begin{tabular}{llll}
\hline Strongly disagree & & Strongly agree \\
1 & 2 & 3 & 4 \\
\hline
\end{tabular}

I would want both of us to have a voice in deciding which project I should work on.

\begin{tabular}{llll}
\hline Strongly disagree & & Strongly agree \\
1 & 2 & 3 & 4 \\
\hline
\end{tabular}

AFFECT REGULATION (AR)

I would want to avoid getting upset when deciding which project I should work on.

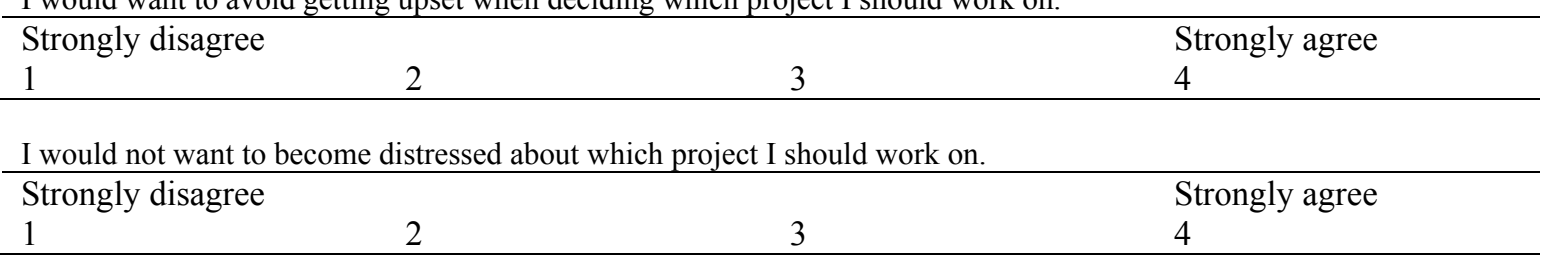

AGENTIC (AG)

I would want to convince my boyfriend/girlfriend that I should only work on my own project.

\begin{tabular}{llll}
\hline Strongly disagree & & Strongly agree \\
1 & 2 & 3 & 4 \\
\hline
\end{tabular}

I would want to do what was best for me and only work on my own project.

\begin{tabular}{llll}
\hline Strongly disagree & 3 & Strongly agree \\
1 & 2 & 3 & 4
\end{tabular}

OPEN-ENDED GOAL

In about a sentence, describe in your own words what your goal would be in terms of managing this conflict.

\section{FORCED CHOICE GOAL}

Which of the above goals would most likely be your goal (check one)

I would want both of us to decide which project I should work on in a way that satisfies both of us. (C)

- I would want both of us to have a voice in deciding which project I should work on. (C)

_ I would want to avoid getting upset when deciding which project I should work on. (AR)

I would not want to become distressed about which project I should work on. (AR)

I would want to convince my boyfriend/girlfriend that I should only work on my own project. (AG)

_ I would want to do what was best for me and only work on my own project. (AG)

\section{FORCED CHOICE DECISION:}

Ultimately, what decision would you make: (check one) I would work on my own project and not on my boyfriend/girlfriend's. (AG)

_ _ I would work with my boyfriend/girlfriend on his/her project and put my project aside. (C) 
RP-G2

You and your boyfriend/girlfriend want to do something together on Saturday and you both agree that it would be fun to go to a concert. There are two different bands playing on Saturday. One is your favorite; the other is your boyfriend/girlfriend's favorite. You cannot agree on which one to attend. You cannot go to both concerts, only one of you will get to see the band that they most want.

\section{GOAL ENDORSEMENT RATINGS:}

COMMUNAL (C)

I would want both of us to decide which concert to attend in a way that satisfies both of us. Strongly disagree

$\begin{array}{lll}1 & 2 & 3\end{array}$

Strongly agree 4

I would want both us to have a voice in deciding which concert to attend.

Strongly disagree $\quad$ Strongly agree

$\begin{array}{llll}1 & 2 & 3 & 4\end{array}$

AFFECT REGULATION (AR)

I would want to avoid getting upset when deciding which concert to attend. Strongly disagree

1
2 3 Strongly agree 4

I would not want to become distressed about which concert to attend. Strongly disagree 1 $2 \quad 3$ Strongly agree 4

AGENTIC (AG)

I would want to convince my boyfriend/girlfriend to go to the concert that I want. Strongly disagree 1 2 3 Strongly agree 4

I would want to do what is best for me and decide which concert we attend. Strongly disagree 1 2 3 Strongly agree 4

\section{OPEN-ENDED GOAL}

In about a sentence, describe in your own words, what your goal would be in terms of managing this conflict.

\section{FORCED CHOICE GOAL}

Which of the above goals would most likely be your goal (check one)

I would want both of us to decide which concert to attend in a way that satisfies both of us. (C)

- I would want both us to have a voice in deciding which concert to attend. (C)

I would want to avoid getting upset when deciding which concert to attend. (AR)

_ I would not want to become distressed about which concert to attend. (AR)

_ I would want to convince my boyfriend/girlfriend to go to the concert that I want. (AG)

I I would want to do what is best for me and decide which concert we attend. (AG)

\section{FORCED CHOICE DECISION:}

Ultimately, what decision would you make: (check one) I would go with my boyfriend/girlfriend to see the band I most want. (AG)

_ I would go with my boyfriend/girlfriend to see the band s/he most wants. (C) 
RP-G3

You and your boyfriend/girlfriend have just completed a major accomplishment (e.g., graduation). In response to this event your family has decided to throw you a party and have set a time and date that will work for most of the important members of your family to attend. Your boyfriend/girlfriend's parents are also going to throw him/her a similar party. However, when you tell your boyfriend/girlfriend the date and time of your party, you both realize that each of your parents has picked the same day and time to hold each of the parties. You both hang out in the same group of friends. You both want all of your friends to be able to attend your party and also want to attend each other's parties. Thus, one of you will have to change the date of your party.

\section{GOAL ENDORSEMENT RATINGS:}

COMMUNAL (C)

I would want both of us to decide who should change the date of their party in a way that satisfies both of us.

\begin{tabular}{llll}
\hline Strongly disagree & & Strongly agree \\
1 & 2 & 3 & 4
\end{tabular}

$1 \quad 2 \quad 3$

I would want both us to have a voice in deciding who should change the date of their party.

\begin{tabular}{llll}
\hline Strongly disagree & & Strongly agree \\
1 & 2 & 3 & 4 \\
\hline
\end{tabular}

AFFECT REGULATION (AR)

I would want to avoid getting upset when deciding who should change the date of their party.

\begin{tabular}{lcl}
\hline Strongly disagree & 3 & Strongly agree \\
1 & 2 & 4 \\
\hline I would not want to become distressed about who should change the date of their party. \\
\hline $\begin{array}{l}\text { Strongly disagree } \\
1\end{array}$ & 3 & Strongly agree \\
\hline
\end{tabular}

AGENTIC (AG)

I would want to convince my boyfriend/girlfriend to change the date of their party.

$\begin{array}{llll}\text { Strongly disagree } & & & \text { Strongly agree } \\ 1 & 2 & 3 & 4\end{array}$

\begin{tabular}{lcc} 
I would want to do what is best for me and not change the date of my party. \\
\hline Strongly disagree \\
1
\end{tabular}

\section{OPEN-ENDED GOAL}

In about a sentence, describe in your own words, what your goal would be in terms of managing this conflict.

\section{FORCED CHOICE GOAL}

Which of the above goals would most likely be your goal (choose one)

I would want both of us to decide who should change the date of their party in a way that satisfies both of us. (C)

I would want both us to have a voice in deciding who should change the date of their party. (C)

- I would want to avoid getting upset when deciding who should change the date of their party. (AR)

_ I would not want to become distressed about who should change the date of their party. (AR)

I would want to convince my boyfriend/girlfriend to change the date of their party. (AG)

_ I would want to do what is best for me and not change the date of my party. (AG)

\section{FORCED CHOICE DECISION:}

Ultimately, what decision would you make: (check one)

I would change the date of my party and my boyfriend/girlfriend would not. (C)

I would not change the date of my party and my boyfriend/girlfriend would. (AG)

(Participants will now complete a distraction task from section 2, 3, or 7) 


\section{BEFORE ALL GOAL SECTIONS INSTRUCTIONS: (Same-Sex Friend)}

On the following screens, you will read several scenarios and will answer questions about your goals in the described situations. While some scenarios are presented more than once, others may appear to be repeated but are actually different. The scenario to which the questions correspond will appear at the top of each page. Please keep in mind the specific scenario when answering questions.

The scenario to which the questions correspond will appear at the top of each page.

True $\quad$ False

The answer to the above question is TRUE. Did you answer the question correctly?

Yes NO

If you did not answer of the question correctly, did you go back and look at the instructions to be sure that you understand?

Yes No (I answered all questions correctly) No (I did not review my incorrect answers) 


\section{SAME-SEX FRIEND GOAL INSTRUCTIONS:}

On the following screens, you will be asked what your goals would be if you were in the described situations. Goals refer to what you would want to happen. For example, if the situation described involved buying a new cell phone, your goal might be to save money. So, the most important aspect of the decision to consider is the cost of the phone. In contrast, if you wanted to get the phone with the newest technology, then regardless of the cost, you would want the phone with the newest features.

When you are imagining you and your same-sex best friend in the situations described, imagine that this same-sex best friend is very important to you. It is not important whether you have personally experienced the described situations. It is only important that you imagine yourself in the described situations.

Goals refer to what I would want to happen in a given situation.

True False

I can answer the questions even if I have never personally experienced the described situations.

True False

When imagining a same-sex best friend, I should imagine someone who is important to me.

True False

All of the answers to the above questions are TRUE. Did you answer all of the questions correctly? Yes NO

If you did not answer all of the questions correctly, did you go back and look at the instructions to be sure that you understand?

Yes No (I answered all questions correctly) No (I did not review my incorrect answers)

\section{More Goal Instructions}

On the following screens, you will read about several hypothetical situations. PLEASE READ EACH HYPOTHETICAL SITUATION EACH TIME IT IS PRESENTED EVEN IF IT SEEMS SIMILAR OR IDENTICAL TO ONE THAT YOU HAVE ALREADY READ. Even if you have never been in the situation described, imagine what you would do if that situation occurred in your own life. There are no right or wrong answers; we are just interested in your opinion. Please answer honestly. 


\section{SAME-SEX FRIENDSHIP GOALS}

Same-Sex Friendship (SSF-G) 1

You are at the library working on a term paper that is due tomorrow. You have worked hard all year and you need a good grade. Your same-sex best friend sends you a message telling you that his/her computer just crashed.

Despite trying everything your best friend has lost all of their work for an important project that is due tomorrow.

Your same-sex best friend has worked hard all year, but still needs a good grade on this project to do well in the class and you are the only person who can help. Although you and your best friend often help each other, you will not have time to help your best friend and do your own work.

\section{GOAL ENDORSEMENT RATINGS: \\ COMMUNAL (C)}

I would want both of us to decide which project I should work on in a way that satisfies both of us.

\begin{tabular}{llll}
\hline Strongly disagree & & Strongly agree \\
1 & 2 & 3 & 4 \\
\hline
\end{tabular}

I would want both of us to have a voice in deciding which project I should work on.

\begin{tabular}{llll}
\hline Strongly disagree & & Strongly agree \\
1 & 2 & 3 & 4 \\
\hline
\end{tabular}

AFFECT REGULATION (AR)

I would want to avoid getting upset when deciding which project I should work on.

\begin{tabular}{lll}
\hline $\begin{array}{l}\text { Strongly disagree } \\
1\end{array}$ & 2 & Strongly agree \\
& 3 & 4 \\
I would not want to become distressed about which project I should work on. \\
\hline $\begin{array}{l}\text { Strongly disagree } \\
1\end{array}$ & 3 & Strongly agree \\
\hline
\end{tabular}

AGENTIC (AG)

I would want to convince my same-sex best friend that I should only work on my own project.

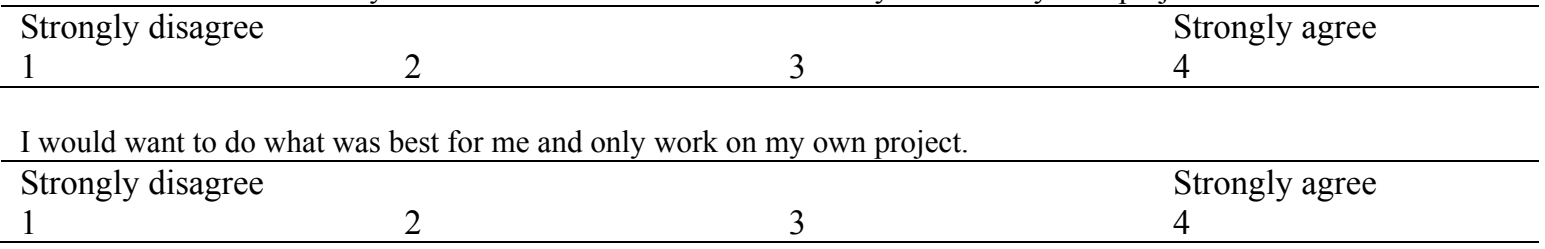

\section{OPEN-ENDED GOAL}

In about a sentence, describe in your own words what your goal would be in terms of managing this conflict.

\section{FORCED CHOICE GOAL}

Which of the above goals would most likely be your goal (check one)

I would want both of us to decide which project I should work on in a way that satisfies both of us. (C)

_ I would want both of us to have a voice in deciding which project I should work on. (C)

_ I would want to avoid getting upset when deciding which project I should work on.

_ I would not want to become distressed about which project I should work on. (AR)

I would want to convince my same-sex best friend that I should only work on my own project. (AG)

I would want to do what was best for me and only work on my own project. (AG)

\section{FORCED CHOICE DECISION:}

Ultimately, what decision would you make: (check one)

I would work on my own project and not on my same-sex best friend's. (AG)

_ I would work with my same-sex best friend on his/her project and put my project aside. (C) 
SSF-G2

You and your same-sex best friend want to do something together on Saturday and you both agree that it would be fun to go to a concert. There are two different bands playing on Saturday. One is your favorite; the other is your same-sex best friend's favorite. You cannot agree on which one to attend. You cannot go to both concerts, only one of you will get to see the band that they most want.

\section{GOAL ENDORSEMENT RATINGS:}

COMMUNAL (C)

I would want both of us to decide which concert to attend in a way that satisfies both of us. Strongly disagree

1
2 3 Strongly agree 4

I would want both us to have a voice in deciding which concert to attend.

\begin{tabular}{llll}
\hline Strongly disagree & & 3 & Strongly agree \\
1 & 2 & 3 & 4
\end{tabular}

\section{AFFECT REGULATION (AR)}

I would want to avoid getting upset when deciding which concert to attend. Strongly disagree 1 2 3 Strongly agree 4

I would not want to become distressed about which concert to attend. Strongly disagree 1

23
Strongly agree 4

AGENTIC (AG)

I would want to convince my same-sex best friend to go to the concert that I want. Strongly disagree 1 23 Strongly agree 4

I would want to do what is best for me and decide which concert we attend.

\begin{tabular}{llll}
\hline Strongly disagree & & Strongly agree \\
1 & 2 & 3 & 4 \\
\hline
\end{tabular}

\section{OPEN-ENDED GOAL}

In about a sentence, describe in your own words what your goal would be in terms of managing this conflict.

\section{FORCED CHOICE GOAL}

Which of the above goals would most likely be your goal (check one)

I would want both of us to decide which concert to attend in a way that satisfies both of us. (C)

_ I would want both us to have a voice in deciding which concert to attend. (C)

I I would want to avoid getting upset when deciding which concert to attend. (AR)

I would not want to become distressed about which concert to attend. (AR)

_ I would want to convince my same-sex best friend to go to the concert that I want. (AG)

_ I would want to do what is best for me and decide which concert we attend. (AG)

\section{FORCED CHOICE DECISION:}

Ultimately, what decision would you make: (check one)

I would go with my same-sex best friend to see the band I most want. (AG)

_ I would go with my same-sex best friend to see the band s/he most wants. (C) 
SSF-G3

You and your same-sex best friend have just completed a major accomplishment (e.g., graduation). In response to this event your family has decided to throw you a party and have set a time and date that will work for most of the important members of your family to attend. Your same-sex best friend's parents are also going to throw him/her a similar party. However, when you tell your best friend the date and time of your party, you both realize that each of your parents has picked the same day and time to hold each of the parties. You both hang out in the same group of friends. You both want all of your friends to be able to attend your party and also want to attend each other's parties. Thus, one of you will have to change the date of your party.

\section{GOAL ENDORSEMENT RATINGS:}

COMMUNAL (C)

I would want both of us to decide who should change the date of their party in a way that satisfies both of us.

\begin{tabular}{llll}
\hline Strongly disagree & & 3 & Strongly agree \\
1 & 2 & 3 & 4
\end{tabular}

I would want both us to have a voice in deciding who should change the date of their party.

\begin{tabular}{llll}
\hline Strongly disagree & & Strongly agree \\
1 & 2 & 3 & 4 \\
\hline
\end{tabular}

AFFECT REGULATION (AR)

I would want to avoid getting upset when deciding who should change the date of their party.

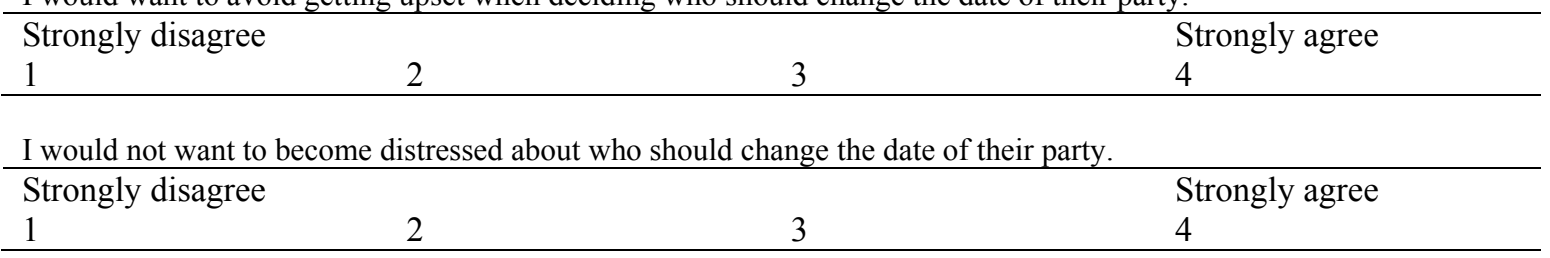

AGENTIC (AG)

I would want to convince my same-sex best friend to change the date of their party.

\begin{tabular}{llll} 
Strongly disagree & & Strongly agree \\
1 & 2 & 3 & 4 \\
\hline
\end{tabular}

I would want to do what is best for me and not change the date of my party.

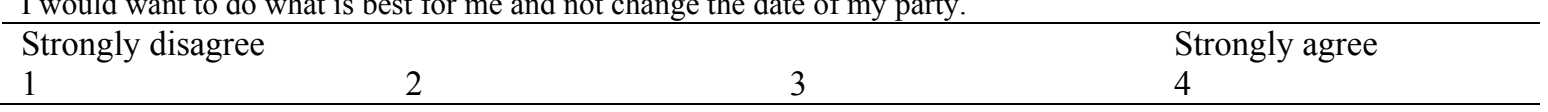

OPEN-ENDED GOAL

In about a sentence, describe in your own words what your goal would be in terms of managing this conflict.

\section{FORCED CHOICE GOAL}

Which of the above goals would most likely be your goal (choose one)

I would want both of us to decide who should change the date of their party in a way that satisfies both of us. (C)

_ I would want both us to have a voice in deciding who should change the date of their party. (C)

_ I would want to avoid getting upset when deciding who should change the date of their party. (AR)

- I would not want to become distressed about who should change the date of their party. (AR)

_ I would want to convince my same-sex best friend to change the date of their party. (AG)

_ I would want to do what is best for me and not change the date of my party. (AG)

\section{FORCED CHOICE DECISION:}

Ultimately, what decision would you make: (check one)

I would change the date of my party and my same-sex best friend would not. (C)

I would not change the date of my party and my same-sex best friend would. (AG)

(Participants will now complete a distraction task from section 2, 3, or 7) 


\section{OTHER-SEX FRIEND GOAL INSTRUCTIONS:}

On the following screens, you will be asked what your goals would be if you were in the described situations. Goals refer to what you would want to happen. For example, if the situation described involved buying a new cell phone, your goal might be to save money. So, the most important aspect of the decision to consider is the cost of the phone. In contrast, if you wanted to get the phone with the newest technology, then regardless of the cost, you would want the phone with the newest features.

When you are imagining you and your same-sex best friend in the situations described, imagine that this other-sex best friend is very important to you. It is not important whether you have personally experienced the described situations. It is only important that you imagine yourself in the described situations.

Goals refer to what I would want to happen in a given situation.

True False

I can answer the questions even if I have never personally experienced the described situations.

True False

When imagining an other-sex best friend, I should imagine someone who is important to me.

True False

All of the answers to the above questions are TRUE. Did you answer all of the questions correctly?

Yes

NO

If you did not answer all of the questions correctly, did you go back and look at the instructions to be sure that you understand?

Yes No (I answered all questions correctly) No (I did not review my incorrect answers)

\section{More Goal Instructions}

On the following screens, you will read about several hypothetical situations. PLEASE READ EACH HYPOTHETICAL SITUATION EACH TIME IT IS PRESENTED EVEN IF IT SEEMS SIMILAR OR IDENTICAL TO ONE THAT YOU HAVE ALREADY READ. Even if you have never been in the situation described, imagine what you would do if that situation occurred in your own life. There are no right or wrong answers; we are just interested in your opinion. Please answer honestly. 


\section{OTHER-SEX FRIENDSHIP GOALS}

Friendship Other-Sex-GOALS (FS-G) 1

You are at the library working on a term paper that is due tomorrow. You have worked hard all year and you need a good grade. Your other-sex best friend sends you a message telling you that his/her computer just crashed.

Despite trying everything your best friend has lost all of their work for an important project that is due tomorrow.

Your other-sex best friend has worked hard all year, but still needs a good grade on this project to do well in the class and you are the only person who can help. Although you and your best friend often help each other, you will not have time to help your best friend and do your own work.

\section{GOAL ENDORSEMENT RATINGS:}

COMMUNAL (C)

I would want both of us to decide which project I should work on in a way that satisfies both of us.

\begin{tabular}{llll}
\hline Strongly disagree & & Strongly agree \\
1 & 2 & 3 & 4 \\
\hline
\end{tabular}

I would want both of us to have a voice in deciding which project I should work on.

\begin{tabular}{llll}
\hline Strongly disagree & & Strongly agree \\
1 & 2 & 3 & 4 \\
\hline
\end{tabular}

AFFECT REGULATION (AR)

I would want to avoid getting upset when deciding which project I should work on.

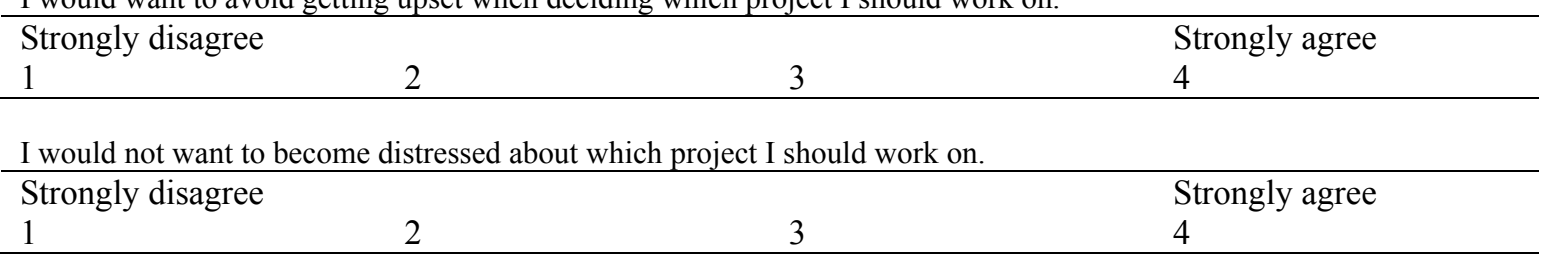

AGENTIC (AG)

I would want to convince my other-sex best friend that I should only work on my own project.

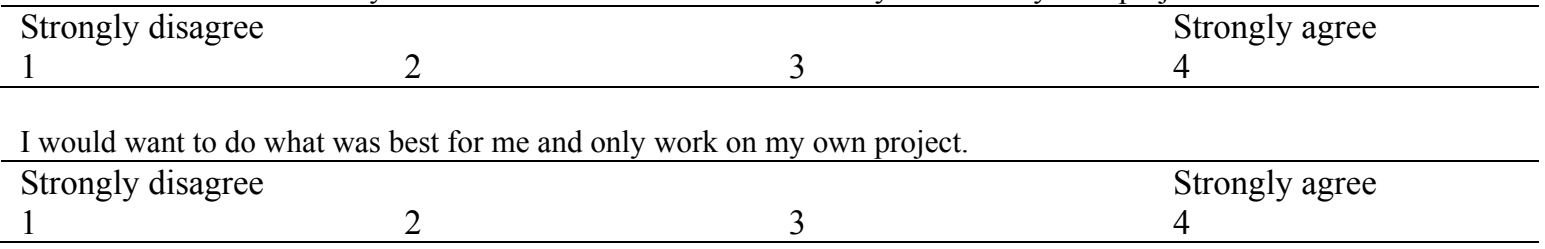

OPEN-ENDED GOAL

In about a sentence, describe in your own words what your goal would be in terms of managing this conflict.

\section{FORCED CHOICE GOAL}

Which of the above goals would most likely be your goal (check one)

I would want both of us to decide which project I should work on in a way that satisfies both of us. (C)

_ I would want both of us to have a voice in deciding which project I should work on. (C)

_I would want to avoid getting upset when deciding which project I should work on.

_ I would not want to become distressed about which project I should work on. (AR)

_ I would want to convince my other-sex best friend that I should only work on my own project. (AG)

_ I would want to do what was best for me and only work on my own project. (AG)

\section{FORCED CHOICE DECISION:}

Ultimately, what decision would you make: (check one)

I would work on my own project and not on my other-sex best friend's. (AG)

_ I would work with my other-sex best friend on his/her project and put my project aside. (C) 
FS-G2

You and your other-sex best friend want to do something together on Saturday and you both agree that it would be fun to go to a concert. There are two different bands playing on Saturday. One is your favorite; the other is your other-sex best friend's favorite. You cannot agree on which one to attend. You cannot go to both concerts, only one of you will get to see the band that they most want.

\section{GOAL ENDORSEMENT RATINGS:}

COMMUNAL (C)

I would want both of us to decide which concert to attend in a way that satisfies both of us.

\begin{tabular}{llll}
\hline Strongly disagree & & Strongly agree \\
1 & 2 & 3 & 4 \\
\hline
\end{tabular}

I would want both us to have a voice in deciding which concert to attend.

\begin{tabular}{llll}
\hline Strongly disagree & & Strongly agree \\
1 & 2 & 3 & 4 \\
\hline
\end{tabular}

AFFECT REGULATION (AR)

I would want to avoid getting upset when deciding which concert to attend.

\begin{tabular}{llll} 
Strongly disagree & & Strongly agree \\
1 & 2 & 3 & 4 \\
\hline
\end{tabular}

I would not want to become distressed about which concert to attend.
Strongly disagree
Strongly agree

1

2

4

AGENTIC (AG)

I would want to convince my other-sex best friend to go to the concert that I want.

\begin{tabular}{llll}
\hline Strongly disagree & & Strongly agree \\
1 & 2 & 3 & 4 \\
\hline
\end{tabular}

I would want to do what is best for me and decide which concert we attend.

\begin{tabular}{llll}
\hline Strongly disagree & & Strongly agree \\
1 & 2 & 3 & 4 \\
\hline
\end{tabular}

\section{OPEN-ENDED GOAL}

In about a sentence, describe in your own words what your goal would be in terms of managing this conflict.

\section{FORCED CHOICE GOAL}

Which of the above goals would most likely be your goal (check one)

I would want both of us to decide which concert to attend in a way that satisfies both of us. (C)

- I would want both us to have a voice in deciding which concert to attend. (C)

_ I would want to avoid getting upset when deciding which concert to attend. (AR)

_ I would not want to become distressed about which concert to attend. (AR)

- I would want to convince my other-sex best friend to go to the concert that I want. (AG)

_ I would want to do what is best for me and decide which concert we attend. (AG)

\section{FORCED CHOICE DECISION:}

Ultimately, what decision would you make: (check one)

I would go with my other-sex best friend to see the band I most want. (AG)

I would go with my other-sex best friend to see the band s/he most wants. (C) 


\section{FS-G3}

You and your other-sex best friend have just completed a major accomplishment (e.g., graduation). In response to this event your family has decided to throw you a party and have set a time and date that will work for most of the important members of your family to attend. Your other-sex best friend's parents are also going to throw him/her a similar party. However, when you tell your best friend the date and time of your party, you both realize that each of your parents has picked the same day and time to hold each of the parties. You both hang out in the same group of friends. You both want all of your friends to be able to attend your party and also want to attend each other's parties. Thus, one of you will have to change the date of your party.

\section{GOAL ENDORSEMENT RATINGS:}

COMMUNAL (C)

I would want both of us to decide who should change the date of their party in a way that satisfies both of us.
Strongly disagree

1 2

3

I would want both us to have a voice in deciding who should change the date of their party.

\begin{tabular}{llll}
\hline Strongly disagree & 3 & Strongly agree \\
1 & 2 & 3 & 4 \\
\hline
\end{tabular}

AFFECT REGULATION (AR)

I would want to avoid getting upset when deciding who should change the date of their party.

\begin{tabular}{llll}
\hline Strongly disagree & & Strongly agree \\
1 & 2 & 3 & 4 \\
\hline
\end{tabular}

I would not want to become distressed about who should change the date of their party.

$\begin{array}{llll}\text { Strongly disagree } & & \text { Strongly agree } \\ 1 & 2 & 3 & 4\end{array}$

AGENTIC (AG)

I would want to convince my other-sex best friend to change the date of their party.

\begin{tabular}{llll}
\hline Strongly disagree & & Strongly agree \\
1 & 2 & 3 & 4 \\
\hline
\end{tabular}

I would want to do what is best for me and not change the date of my party.

$\begin{array}{llll}\text { Strongly disagree } & & \text { Strongly agree } \\ 1 & 2 & 3 & 4\end{array}$

OPEN-ENDED GOAL

In about a sentence, describe in your own words what your goal would be in terms of managing this conflict.

\section{FORCED CHOICE GOAL}

Which of the above goals would most likely be your goal (choose one)

I would want both of us to decide who should change the date of their party in a way that satisfies both of us. (C)

_ I would want both us to have a voice in deciding who should change the date of their party. (C)

_ I would want to avoid getting upset when deciding who should change the date of their party. (AR)

- I would not want to become distressed about who should change the date of their party. (AR)

_ I would want to convince my other-sex best friend to change the date of their party. (AG)

_ I would want to do what is best for me and not change the date of my party. (AG)

\section{FORCED CHOICE DECISION:}

Ultimately, what decision would you make: (check one)

I would change the date of my party and my other-sex best friend would not. (C)

_ I would not change the date of my party and my other-sex best friend would. (AG)

(Participants will now complete a distraction task from section 2, 3, or 7) 


\section{Section 7}

(Distraction tasks also measures for future research)

\section{The Marlowe-Crowne Social Desirability Scale}

Listed below are a number of statements concerning personal attitudes and traits. Read each item and decide whether the statement is True or False as it pertains to you personally.

1. Have there been occasions when you took advantage of someone? Reverse (R)

True

False

2. Have you sometimes taken unfair advantage of another person? R

True

False

3. Are you always willing to admit when you make a mistake?

True

False

4. Are you quick to admit making a mistake?

True

False

5. Do you sometimes try to get even rather than forgive and forget? $\mathrm{R}$

True

False

6. Do you sometimes feel resentful when you don't get you own way? R

True

False

7. Are you always courteous, even to people who are disagreeable?

True

False

8. Are you always a good listener, no matter whom you are talking to?

True

False 


\section{Strough and Covatto’s Sex Segregation}

A.) Imagine that you must work with another student on a project in one of your classes at school. Think about five people you would most like to work with. Write their names in order of preference and circle whether they are male or female.

\section{First choice partner for working on a project at school:}

Male Female

Describe your relationship with this person:

\begin{tabular}{|lllll|}
\hline 1 & 2 & 3 & 4 & 5 \\
$\begin{array}{l}\text { We don't like each } \\
\text { other }\end{array}$ & We like each other & We are friends & We are good & We are best \\
& & & friends & friends \\
\hline
\end{tabular}

2. Second choice partner for working on a project at school:

Male Female

Describe your relationship with this person:

$\begin{array}{lllll}1 & 2 & 3 & 4 & 5 \\ \text { We don't like each } & \text { We like each other } & \text { We are friends } & \text { We are good } & \text { We are best } \\ \text { other } & & \text { friends } & \text { friends }\end{array}$

3. Third choice partner for working on a project at school:

Male Female

Describe your relationship with this person:

\begin{tabular}{|lllll|}
\hline 1 & 2 & 3 & 4 & 5 \\
We don't like each & We like each other & We are friends & We are good & We are best \\
other & & & friends & friends \\
\hline
\end{tabular}

\section{Fourth choice partner for working on a project at school:}

\section{Male Female}

Describe your relationship with this person:

\begin{tabular}{|lllll|}
\hline 1 & 2 & 3 & 4 & 5 \\
We don't like each & We like each other & We are friends & We are good & We are best \\
other & & & friends & friends \\
\hline
\end{tabular}




\section{Fifth choice partner for working on a project at school:}

$$
\text { Male Female }
$$

Describe your relationship with this person:

\begin{tabular}{|lllll|}
\hline 1 & 2 & 3 & 4 & 5 \\
$\begin{array}{l}\text { We don't like each } \\
\text { other }\end{array}$ & We like each other & We are friends & We are good & We are best \\
& & & friends & friends \\
\hline
\end{tabular}

B.) Now imagine that you are going to invite five friends over to your house to hang out. Think about whom you would invite over. Write their first name and last initial in order of preference, and circle whether they are male or female.

1. First choice for someone to invite over to your house to hang out:

Male Female

\begin{tabular}{|c|c|c|c|c|}
\hline 1 & 2 & 3 & 4 & 5 \\
\hline $\begin{array}{l}\text { We don't like each } \\
\text { other }\end{array}$ & We like each other & We are friends & $\begin{array}{l}\text { We are good } \\
\text { friends }\end{array}$ & $\begin{array}{l}\text { We are best } \\
\text { friends }\end{array}$ \\
\hline
\end{tabular}

2. Second choice for someone to invite over to your house to hang out:

\begin{tabular}{|lllll|}
\hline & & & \multicolumn{1}{c}{ Male } & Female \\
\hline $\begin{array}{l}1 \\
\begin{array}{l}\text { We don't like each } \\
\text { other }\end{array}\end{array}$ & $\begin{array}{l}\text { We like each other } \\
\text { Wthe }\end{array}$ & We are friends & $\begin{array}{l}4 \\
\text { We are good } \\
\text { friends }\end{array}$ & $\begin{array}{l}\text { We are best } \\
\text { friends }\end{array}$ \\
\hline
\end{tabular}

\section{Third choice for someone to invite over to your house to hang out:}

Male Female

\begin{tabular}{|lllll|}
\hline $\begin{array}{l}1 \\
\begin{array}{l}\text { We don't like each } \\
\text { other }\end{array}\end{array}$ & $\begin{array}{l}2 \\
\text { We like each other }\end{array}$ & We are friends & $\begin{array}{l}4 \\
\text { We are good } \\
\text { friends }\end{array}$ & $\begin{array}{l}5 \\
\text { We are best } \\
\text { friends }\end{array}$ \\
\hline
\end{tabular}

\section{Fourth choice for someone to invite over to your house to hang out:}

\begin{tabular}{|lllll|}
\hline & & & Male & Female \\
\hline $\begin{array}{l}1 \\
\begin{array}{l}\text { We don't like each } \\
\text { other }\end{array}\end{array}$ & $\begin{array}{l}2 \\
\text { We like each other }\end{array}$ & We are friends & $\begin{array}{l}4 \\
\text { We are good } \\
\text { friends }\end{array}$ & $\begin{array}{l}5 \\
\text { We are best } \\
\text { friends }\end{array}$ \\
\hline
\end{tabular}

\section{Fifth choice for someone to invite over to your house to hang out:}

Male Female

\begin{tabular}{|lllll|}
\hline $\begin{array}{l}1 \\
\begin{array}{l}\text { We don't like each } \\
\text { other }\end{array}\end{array}$ & 2 & 3 & 4 & 5 \\
We like each other & We are friends & $\begin{array}{l}\text { We are good } \\
\text { friends }\end{array}$ & $\begin{array}{l}\text { We are best } \\
\text { friends }\end{array}$ \\
\hline
\end{tabular}




\section{RELATIONSHIP QUALITY}

Furman's Network of Relationships Inventory

Everyone has a number of people who are important in his or her life. These questions ask about your relationships with each of the following people: romantic partner, a same-sex friend, and an opposite-sex friend.

1. We would like you to choose a boy/girl friend whom you are dating or dated. You may choose someone you are seeing now, or someone you went out with earlier in high school. If you choose a past boy/girl friend, please answer the questions as you would have when you were in the relationship.

\section{Boy/Girl Friend's First Name}

How long is/was the relationship? years months (please fill in numbers)
Are you seeing this person now?
A. Yes
B. No

2. Please choose the most important same-sex friend you have had in high school. You may select someone who is your most important same-sex friend now, or who was your most important same-sex friend earlier in high school. Do not choose a sibling. If you select a person with whom you are no longer friends, please answer the questions as you would have when you were in the relationship.

\section{Same-Sex Friend's First Name}

How long is/was the friendship? years months (please fill in numbers)

Are you close friends now?
A. Yes
B. Friends, but not as close as before
C. No

3. Please choose the most important other-sex friend you have had in high school. You may select someone who is your most important other-sex friend now, or who was your most important other-sex friend earlier in high school. Do not choose a sibling, relative, or boy/girl friend-even if she or he is or was your best friend. If you select a person with whom you are no longer friends, just answer the questions as you would have when you were in the relationship.

Other-Sex Friend's First Name

How long is/was the friendship? years months (please fill in numbers)

Are you close friends now?
A. Yes
B. Friends, but not as close as before
C. No 
Now we would like you to answer the following questions about the people you have selected above. Sometimes the answers for different people may be the same but sometimes they may be different.

4. How much free time do you spend with this person?

\begin{tabular}{llllll} 
Little or None & Somewhat & Very Much & Extremely Much & The Most & \\
1 & 2 & 3 & 4 & 5 & Boy/Girl Friend \\
1 & 2 & 3 & 4 & 5 & Same-Sex Friend \\
1 & 2 & 3 & 4 & 5 & Other-Sex Friend \\
\hline
\end{tabular}

5. How much do you and this person get upset with or mad at each other?

\begin{tabular}{llllll} 
Little or None & Somewhat & Very Much & Extremely Much & The Most & \\
1 & 2 & 3 & 4 & 5 & Boy/Girl Friend \\
1 & 2 & 3 & 4 & 5 & Same-Sex Friend \\
1 & 2 & 3 & 4 & 5 & Other-Sex Friend \\
\hline
\end{tabular}

6. How much does this person teach you how to do things that you don't know?

$\begin{array}{llllll}\text { Little or None } & \text { Somewhat } & \text { Very Much } & \text { Extremely Much } & \text { The Most } & \\ 1 & 2 & 3 & 4 & 5 & \text { Boy/Girl Friend } \\ 1 & 2 & 3 & 4 & 5 & \text { Same-Sex Friend } \\ 1 & 2 & 3 & 4 & 5 & \text { Other-Sex Friend }\end{array}$

7. How much do you and this person get on each other's nerves?

$\begin{array}{llllll}\text { Little or None } & \text { Somewhat } & \text { Very Much } & \text { Extremely Much } & \text { The Most } & \\ 1 & 2 & 3 & 4 & 5 & \text { Boy/Girl Friend } \\ 1 & 2 & 3 & 4 & 5 & \text { Same-Sex Friend } \\ 1 & 2 & 3 & 4 & 5 & \text { Other-Sex Friend }\end{array}$

8. How much do you talk about everything with this person?

$\begin{array}{llllll}\text { Little or None } & \text { Somewhat } & \text { Very Much } & \text { Extremely Much } & \text { The Most } & \\ 1 & 2 & 3 & 4 & 5 & \text { Boy/Girl Friend } \\ 1 & 2 & 3 & 4 & 5 & \text { Same-Sex Friend }\end{array}$


Other-Sex Friend

9. How much do you help this person with things she/he can't do by her/himself?

\begin{tabular}{llllll} 
Little or None & Somewhat & Very Much & Extremely Much & The Most & \\
1 & 2 & 3 & 4 & 5 & Boy/Girl Friend \\
1 & 2 & 3 & 4 & 5 & Same-Sex Friend \\
1 & 2 & 3 & 4 & 5 & Other-Sex Friend \\
\hline
\end{tabular}

10. How much does this person like or love you?

\begin{tabular}{llllll} 
Little or None & Somewhat & Very Much & Extremely Much & The Most & \\
1 & 2 & 3 & 4 & 5 & Boy/Girl Friend \\
1 & 2 & 3 & 4 & 5 & Same-Sex Friend \\
1 & 2 & 3 & 4 & 5 & Other-Sex Friend \\
\hline
\end{tabular}

11. How much does this person treat you like you're admired and respected?

$\begin{array}{llllll}\text { Little or None } & \text { Somewhat } & \text { Very Much } & \text { Extremely Much } & \text { The Most } & \\ 1 & 2 & 3 & 4 & 5 & \text { Boy/Girl Friend } \\ 1 & 2 & 3 & 4 & 5 & \text { Same-Sex Friend } \\ 1 & 2 & 3 & 4 & 5 & \text { Other-Sex Friend }\end{array}$

12. Who tells the other person what to do more often, you or this person?

$\begin{array}{llllll}\text { S/he always does } & \text { S/he often does } & \text { About the same } & \text { I often do } & \text { I always do } & \\ 1 & 2 & 3 & 4 & 5 & \text { Boy/Girl Friend } \\ 1 & 2 & 3 & 4 & 5 & \text { Same-Sex Friend } \\ 1 & 2 & 3 & 4 & 5 & \text { Other-Sex Friend }\end{array}$

13. How sure are you that this relationship will last no matter what?

$\begin{array}{llllll}\text { Little or None } & \text { Somewhat } & \text { Very Much } & \text { Extremely Much } & \text { The Most } & \\ 1 & 2 & 3 & 4 & 5 & \text { Boy/Girl Friend } \\ 1 & 2 & 3 & 4 & 5 & \text { Same-Sex Friend } \\ 1 & 2 & 3 & 4 & 5 & \text { Other-Sex Friend }\end{array}$


14. How much do you play around and have fun with this person?

\begin{tabular}{llllll} 
Little or None & Somewhat & Very Much & Extremely Much & The Most & \\
1 & 2 & 3 & 4 & 5 & Boy/Girl Friend \\
1 & 2 & 3 & 4 & 5 & Same-Sex Friend \\
1 & 2 & 3 & 4 & 5 & Other-Sex Friend \\
\hline
\end{tabular}

15. How much do you and this person disagree and quarrel?

\begin{tabular}{llllll} 
Little or None & Somewhat & Very Much & Extremely Much & The Most & \\
1 & 2 & 3 & 4 & 5 & Boy/Girl Friend \\
1 & 2 & 3 & 4 & 5 & Same-Sex Friend \\
1 & 2 & 3 & 4 & 5 & Other-Sex Friend \\
\hline
\end{tabular}

16. How much does this person help you figure out or fix things?

\begin{tabular}{llllll} 
Little or None & Somewhat & Very Much & Extremely Much & The Most & \\
1 & 2 & 3 & 4 & 5 & Boy/Girl Friend \\
1 & 2 & 3 & 4 & 5 & Same-Sex Friend \\
1 & 2 & 3 & 4 & 5 & Other-Sex Friend \\
\hline
\end{tabular}

17. How much do you and this person get annoyed with each other's behavior?

\begin{tabular}{llllll} 
Little or None & Somewhat & Very Much & Extremely Much & The Most & \\
1 & 2 & 3 & 4 & 5 & Boy/Girl Friend \\
1 & 2 & 3 & 4 & 5 & Same-Sex Friend \\
1 & 2 & 3 & 4 & 5 & Other-Sex Friend \\
\hline
\end{tabular}

18. How much do you share your secrets and private feelings with this person?

\begin{tabular}{llllll} 
Little or None & Somewhat & Very Much & Extremely Much & The Most & \\
1 & 2 & 3 & 4 & 5 & Boy/Girl Friend \\
1 & 2 & 3 & 4 & 5 & Same-Sex Friend \\
1 & 2 & 3 & 4 & 5 & Other-Sex Friend \\
\hline
\end{tabular}


19. How much do you protect and look out for this person?

\begin{tabular}{llllll} 
Little or None & Somewhat & Very Much & Extremely Much & The Most & \\
1 & 2 & 3 & 4 & 5 & Boy/Girl Friend \\
1 & 2 & 3 & 4 & 5 & Same-Sex Friend \\
1 & 2 & 3 & 4 & 5 & Other-Sex Friend \\
\hline
\end{tabular}

20. How much does this person really care about you?

$\begin{array}{llllll}\text { Little or None } & \text { Somewhat } & \text { Very Much } & \text { Extremely Much } & \text { The Most } & \\ 1 & 2 & 3 & 4 & 5 & \text { Boy/Girl Friend } \\ 1 & 2 & 3 & 4 & 5 & \text { Same-Sex Friend } \\ 1 & 2 & 3 & 4 & 5 & \text { Other-Sex Friend }\end{array}$

21. How much does this person treat you like you're good at many things?

$\begin{array}{llllll}\text { Little or None } & \text { Somewhat } & \text { Very Much } & \text { Extremely Much } & \text { The Most } & \\ 1 & 2 & 3 & 4 & 5 & \text { Boy/Girl Friend } \\ 1 & 2 & 3 & 4 & 5 & \text { Same-Sex Friend } \\ 1 & 2 & 3 & 4 & 5 & \text { Other-Sex Friend }\end{array}$

22. Between you and this person, who tends to be the BOSS in this relationship?

$\begin{array}{llllll}\text { S/he always does } & \text { S/he often does } & \text { About the same } & \text { I often do } & \text { I always do } & \\ 1 & 2 & 3 & 4 & 5 & \text { Boy/Girl Friend } \\ 1 & 2 & 3 & 4 & 5 & \text { Same-Sex Friend } \\ 1 & 2 & 3 & 4 & 5 & \text { Other-Sex Friend }\end{array}$

23. How sure are you that your relationship will last in spite of fights?

$\begin{array}{llllll}\text { Little or None } & \text { Somewhat } & \text { Very Much } & \text { Extremely Much } & \text { The Most } & \\ 1 & 2 & 3 & 4 & 5 & \text { Boy/Girl Friend } \\ 1 & 2 & 3 & 4 & 5 & \text { Same-Sex Friend } \\ 1 & 2 & 3 & 4 & 5 & \text { Other-Sex Friend }\end{array}$


24. How much do you go places and do enjoyable things with this person?

\begin{tabular}{llllll} 
Little or None & Somewhat & Very Much & Extremely Much & The Most & \\
1 & 2 & 3 & 4 & 5 & Boy/Girl Friend \\
1 & 2 & 3 & 4 & 5 & Same-Sex Friend \\
1 & 2 & 3 & 4 & 5 & Other-Sex Friend \\
\hline
\end{tabular}

25. How much do you and this person argue with each other?

$\begin{array}{llllll}\text { Little or None } & \text { Somewhat } & \text { Very Much } & \text { Extremely Much } & \text { The Most } & \\ 1 & 2 & 3 & 4 & 5 & \text { Boy/Girl Friend } \\ 1 & 2 & 3 & 4 & 5 & \text { Same-Sex Friend } \\ 1 & 2 & 3 & 4 & 5 & \text { Other-Sex Friend }\end{array}$

26. How much does this person help you when you need to get something done?

$\begin{array}{llllll}\text { Little or None } & \text { Somewhat } & \text { Very Much } & \text { Extremely Much } & \text { The Most } & \\ 1 & 2 & 3 & 4 & 5 & \text { Boy/Girl Friend } \\ 1 & 2 & 3 & 4 & 5 & \text { Same-Sex Friend } \\ 1 & 2 & 3 & 4 & 5 & \text { Other-Sex Friend }\end{array}$

27. How much do you and this person hassle or nag one another?

$\begin{array}{llllll}\text { Little or None } & \text { Somewhat } & \text { Very Much } & \text { Extremely Much } & \text { The Most } & \\ 1 & 2 & 3 & 4 & 5 & \text { Boy/Girl Friend } \\ 1 & 2 & 3 & 4 & 5 & \text { Same-Sex Friend } \\ 1 & 2 & 3 & 4 & 5 & \text { Other-Sex Friend }\end{array}$

28. How much do you talk to this person about things that you don't want others to know?

$\begin{array}{llllll}\text { Little or None } & \text { Somewhat } & \text { Very Much } & \text { Extremely Much } & \text { The Most } & \\ 1 & 2 & 3 & 4 & 5 & \text { Boy/Girl Friend } \\ 1 & 2 & 3 & 4 & 5 & \text { Same-Sex Friend } \\ 1 & 2 & 3 & 4 & 5 & \text { Other-Sex Friend }\end{array}$


29. How much do you take care of this person?

\begin{tabular}{llllll} 
Little or None & Somewhat & Very Much & Extremely Much & The Most & \\
1 & 2 & 3 & 4 & 5 & Boy/Girl Friend \\
1 & 2 & 3 & 4 & 5 & Same-Sex Friend \\
1 & 2 & 3 & 4 & 5 & Other-Sex Friend \\
\hline
\end{tabular}

30. How much does this person have a strong feeling of affection (loving or liking) toward you?

$\begin{array}{llllll}\text { Little or None } & \text { Somewhat } & \text { Very Much } & \text { Extremely Much } & \text { The Most } & \\ 1 & 2 & 3 & 4 & 5 & \text { Boy/Girl Friend } \\ 1 & 2 & 3 & 4 & 5 & \text { Same-Sex Friend } \\ 1 & 2 & 3 & 4 & 5 & \text { Other-Sex Friend }\end{array}$

31. How much does this person like or approve of the things you do?

\begin{tabular}{llllll} 
Little or None & Somewhat & Very Much & Extremely Much & The Most & \\
1 & 2 & 3 & 4 & 5 & Boy/Girl Friend \\
1 & 2 & 3 & 4 & 5 & Same-Sex Friend \\
1 & 2 & 3 & 4 & 5 & Other-Sex Friend \\
\hline
\end{tabular}

32. In your relationship with this person, who tends to take charge and decide what should be done?

$\begin{array}{llllll}\text { S/he always does } & \text { S/he often does } & \text { About the same } & \text { I often do } & \text { I always do } & \\ 1 & 2 & 3 & 4 & 5 & \text { Boy/Girl Friend } \\ 1 & 2 & 3 & 4 & 5 & \text { Same-Sex Friend } \\ 1 & 2 & 3 & 4 & 5 & \text { Other-Sex Friend }\end{array}$


33. How sure are you that your relationship will continue in the years to come?

\begin{tabular}{llllll} 
Little or None & Somewhat & Very Much & Extremely Much & The Most & \\
1 & 2 & 3 & 4 & 5 & Boy/Girl Friend \\
1 & 2 & 3 & 4 & 5 & Same-Sex Friend \\
1 & 2 & 3 & 4 & 5 & Other-Sex Friend \\
\hline
\end{tabular}

34. Earlier, when we asked you to choose your most important same- and other-sex friends, we said that they could not be a sibling or a relative. Now please tell us who, of all these people, is your best friend?
A. My boy/girl friend.
B. My same-sex friend.
C. My opposite-sex friend. 